Prepared for the U.S. Department of Energy

under Contract DE-AC05-76RL01830

\title{
Speciation and Oxidative Stability of Alkaline Soluble, Non-Pertechnetate Technetium
}

TG Levitskaia BM Rapko

A Anderson JM Peterson

SD Chatterjee ED Walter

HM Cho NM Washton

September 2014

Pacific Northwest

NATIONAL LABORATORY

Proudly Operated by Battelle Since 1965 


\title{
DISCLAIMER
}

This report was prepared as an account of work sponsored by an agency of the United States Government. Neither the United States Government nor any agency thereof, nor Battelle Memorial Institute, nor any of their employees, makes any warranty, express or implied, or assumes any legal liability or responsibility for the accuracy, completeness, or usefulness of any information, apparatus, product, or process disclosed, or represents that its use would not infringe privately owned rights. Reference herein to any specific commercial product, process, or service by trade name, trademark, manufacturer, or otherwise does not necessarily constitute or imply its endorsement, recommendation, or favoring by the United States Government or any agency thereof, or Battelle Memorial Institute. The views and opinions of authors expressed herein do not necessarily state or reflect those of the United States Government or any agency thereof.

\author{
PACIFIC NORTHWEST NATIONAL LABORATORY \\ operated by \\ BATTELLE \\ for the \\ UNITED STATES DEPARTMENT OF ENERGY \\ under Contract DE-AC05-76RL01830 \\ Printed in the United States of America
Available to DOE and DOE contractors from the Office of Scientific and Technical Information, P.O. Box 62, Oak Ridge, TN 37831-0062; ph: (865) 576-8401 fax: (865) 576-5728 email: reports@adonis.osti.gov \\ Available to the public from the National Technical Information Service \\ 5301 Shawnee Rd., Alexandria, VA 22312 \\ ph: (800) 553-NTIS (6847) \\ email: orders@ntis.gov <http://www.ntis.gov/about/form.aspx> \\ Online ordering: http://www.ntis.gov
}




\section{Speciation and Oxidative Stability of Alkaline Soluble, Non-Pertechnetate Technetium}

$\begin{array}{ll}\text { TG Levitskaia } & \text { BM Rapko } \\ \text { A Anderson } & \text { JM Peterson } \\ \text { SD Chatterjee } & \text { ED Walter } \\ \text { HM Cho } & \text { NM Washton }\end{array}$

September 2014

Prepared for

the U.S. Department of Energy

under Contract DE-AC05-76RL01830

Pacific Northwest National Laboratory

Richland, Washington 99352 



\section{Executive Summary}

The long half-life, complex chemical behavior in tank waste, limited incorporation in mid- to high-temperature immobilization processes, and high mobility in subsurface environments make technetium (Tc) one of the most difficult contaminants to dispose of and/or remediate. Technetium exists predominantly in the liquid tank waste phase as the relatively mobile form of pertechnetate, $\mathrm{TcO}_{4}{ }^{-}$. However, based on experimentation to-date, a significant fraction of the soluble Tc cannot be effectively separated from the wastes and may be present as a non- pertechnetate species. The presence of a non-pertechnetate species significantly complicates disposition of low-activity waste (LAW), and the development of methods to either convert them to pertechnetate or to separate directly is needed. The challenge is the uncertainty regarding the chemical form of the alkaline-soluble, low-valence, non-pertechnetate species in the liquid tank waste. This report summarizes work done in fiscal year (FY) 2014 exploring the chemistry of a low-valence technetium(I) species, $\left[(\mathrm{CO})_{3} \mathrm{Tc}\left(\mathrm{H}_{2} \mathrm{O}\right)_{3}\right]^{+}$, a compound of interest due to its implication in the speciation of alkaline-soluble technetium in several Hanford tank waste supernatants.

The key findings from this year's task are summarized below:

1. A synthetic procedure for preparation of $\mathrm{Tc}(\mathrm{I})\left[\mathrm{Tc}(\mathrm{CO})_{3}\right]^{+}$species was optimized. The preparation of $\left[\mathrm{Et}_{4} \mathrm{~N}\right]_{2}\left[(\mathrm{CO})_{3} \mathrm{TcCl}_{3}\right]$, an insoluble solid which in mildly acidic solution forms the target starting compound $\left[(\mathrm{CO})_{3} \mathrm{Tc}\left(\mathrm{H}_{2} \mathrm{O}\right)_{3}\right]^{+}$in an overall $75 \%$ yield, was achieved based on two-step reduction of ammonium pertechnetate. The reaction product was characterized by several techniques, including

${ }^{99} \mathrm{Tc}$ nuclear magnetic resonance (NMR), infrared (IR), ultraviolet-visible (UV-vis) spectroscopies, and electrospray ionization mass spectrometry (ESI-MS).

2. Oxidative stability and hydrolytic speciation of $\left[\mathrm{Tc}(\mathrm{CO})_{3}\left(\mathrm{H}_{2} \mathrm{O}\right)_{3}\right]^{+}$in a pseudo-Hanford tank supernatant simulant solution at variable nitrate and hydroxide concentrations was investigated. The method used for these studies was primarily ${ }^{99} \mathrm{Tc}$ NMR spectroscopy. It was demonstrated that in the solutions with the high hydroxide concentrations, the $\left[\mathrm{Tc}(\mathrm{CO})_{3}\right]^{+}$species undergo fast oxidative decomposition most likely due to the hydrolytic destruction of the Tc-CO backbone via $\mathrm{OH}^{-}$ nucleophilic attack at the carbonyl carbon. Presence of the high salt and relatively low $\mathrm{OH}^{-}$ concentrations in LAW (typical for the majority of tanks) increases the stability of non-pertechnetate species. Increasing hydroxide concentration promotes decomposition of the $\left[\mathrm{Tc}(\mathrm{CO})_{3}\right]^{+}$species. Interestingly, the oxidative stability of the hydrolyzed $\left[\mathrm{Tc}(\mathrm{CO})_{3}(\mathrm{OH})\left(\mathrm{H}_{2} \mathrm{O}\right)_{2}\right]$ species in the supernatant simulants containing $0.42,0.83$, or $1.47 \mathrm{M} \mathrm{OH}^{-}$was greater than that in the $5 \mathrm{M} \mathrm{NaNO}_{3}$ solutions containing corresponding $\mathrm{NaOH}$ concentrations. In this study, under optimum conditions $(0-0.01 \mathrm{M} \mathrm{NaOH}$ and $5 \mathrm{M}$ sodium nitrate), almost three months have gone by either without any detectable pertechnetate formation or only about $10 \%$ conversion to pertechnetate, a half-life for reoxidation under conditions compatible with those found in actual Hanford tank sludge. This observation implies that if the conditions required for formation of the Tc(I)-tricarbonyl compounds exist in the tank, the organic complexants are not required for the product to be stable in conditions associated with Hanford tank supernatants. Alternatively, instead of Tc(I)-tricarbonyl/complexant species being required, the Tc(I)-tricarbonyl hydrolysis products of general composition $\left[\mathrm{Tc}(\mathrm{CO})_{3}(\mathrm{OH})_{n}\left(\mathrm{H}_{2} \mathrm{O}\right)_{m}\right]^{1-n}$ that are anticipated to exist in the alkaline waste may be sufficient.

3. Formation and oxidative stability of $\left[\mathrm{Tc}(\mathrm{CO})_{3}\right]^{+} /$gluconate complex was tested in the pseudo-Hanford tank supernatant simulant solutions at variable hydroxide concentration. The oxidation rate of the 
$\left[\mathrm{Tc}(\mathrm{CO})_{3}\right]^{+} /$gluconate complex was considerably slower in the supernatant simulant than in the simple $5 \mathrm{M} \mathrm{NaNO}_{3} / 0.5 \mathrm{M} \mathrm{NaOH} / 0.5 \mathrm{M} \mathrm{NaGluconate} \mathrm{solution.}$

4. These results indicate that a carbonyl complex is a viable candidate for the source of non-pertechnetate in tank waste. As indicated, testing has identified a range of conditions under which a significant portion of the carbonyl complex is stable for extended periods of time.

Preliminary studies have shown a viable route for the formation of this complex under tank waste conditions. Also, since the range of concentration in tank waste varies from less than $0.1 \%$ to greater than $50 \%$, the rates of production and destruction under these varying conditions obviously vary dramatically, and as such, the balance of these two reactions will be highly dependent upon tank waste chemistry.

5. A proof-of-principle demonstration corroborating the mechanism and feasibility of $\left[\operatorname{Tc}(\mathrm{CO})_{3}\right]^{+}$ formation from pertechnetate using $\mathrm{CO} / \mathrm{H}_{2}$ reductant in the presence of an organic chelator and catalytic noble metals in the tank waste simulant was performed. The simulant used was based on the previously used Pretreatment Engineering Platform (PEP) simulant formulation, albeit with altered free hydroxide concentrations and with the addition of some noble metals (simulating fission products) to catalyze any needed reduction of $\mathrm{Tc}(\mathrm{VII})$ by hydrogen and gluconate as a reductant/complexant. Reaction conditions were approximately $1300 \mathrm{psi}$ atmosphere, at $80^{\circ} \mathrm{C}$ for about 12 days. The bulk of the pertechnetate was reduced following this treatment and the $\mathrm{Tc}(\mathrm{I})$-tricarbonyl/gluconate compound was observed by ${ }^{99} \mathrm{Tc}$ NMR spectroscopy. The same product can be prepared independently by the reaction of $\left[\mathrm{Tc}(\mathrm{CO})_{3}\right]^{+}$with gluconate in water, sodium nitrate, or supernatant simulant solutions. In short, this proof-of-principle test supports the concept of alkaline-soluble, low-valent Tc being formed by pertechnetate reduction under conditions consistent with those found in Hanford tank supernatants, albeit at intentionally high concentrations of carbon monoxide in this first proof-of-principle test.

6. To understand Tc speciation in the alkaline solutions, significant effort was placed on the expansion of the Tc characterization techniques and development of computational approaches to enhance interpretation of the experimental observations.

In this work, considerable achievements were made toward verifying that the Tc(I)-tricarbonyl species is a viable candidate for the source of alkaline-soluble, non-pertechnetate Tc in the Hanford tank supernatants. This work confirmed that the Tc species based on the $\left[\mathrm{Tc}(\mathrm{CO})_{3}\right]^{+}$center can be obtained by the laboratory synthetic route and that a potential route exists for their production in the alkaline tank wastes. These non-pertechnetate species are sufficiently stable under the conditions associated with Hanford tank supernatants. However, considerable work remains, specifically to achieve control over Tc redox behavior in the alkaline media, and to develop methods for the separation of non-pertechnetate species from LAW by either their conversion to pertechnetate or direct removal. 


\section{Acronyms and Abbreviations}

ATR

DI

DOE

DOE-EM

EMSL

EPR

ESI

ESI-MS

FEP

FTIR

FY

IDF

IR

LAW

NMR

PEP

PNNL

PTFE

RPL

RPP

SRNL

UV-vis attenuated total reflectance

deionized (water)

U.S. Department of Energy

U.S. Department of Energy Office of Environmental Management

Environmental Molecular Sciences Laboratory

electron paramagnetic resonance

electrospray ionization

electrospray ionization mass spectrometry

fluorinated ethylene propylene

Fourier Transform Infrared

fiscal year

Integrated Disposal Facility

infrared

low-activity waste

nuclear magnetic resonance

Pretreatment Engineering Platform

Pacific Northwest National Laboratory

polytetrafluoroethylene

Radiochemical Processing Laboratory

River Protection Project

Savannah River National Laboratory

ultraviolet-visible spectroscopy 



\section{Contents}

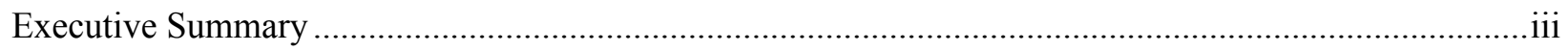

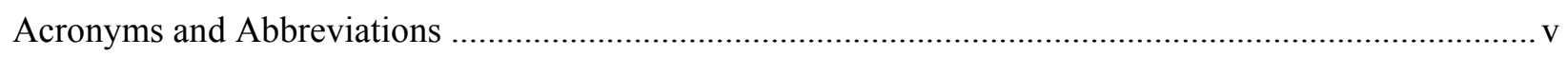

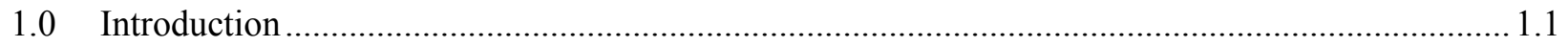

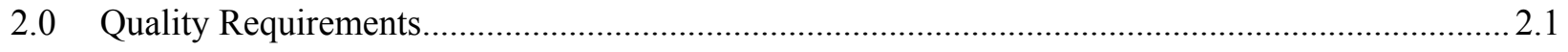

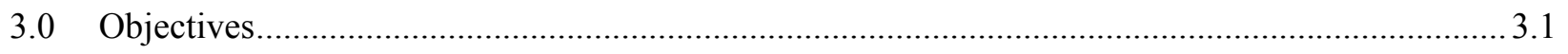

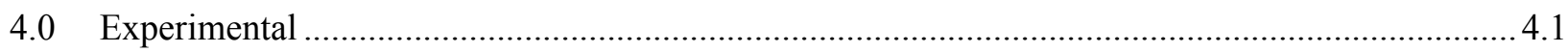

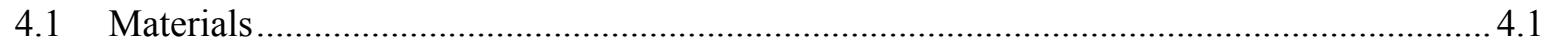

4.2 Simulated Hanford Tank Waste Supernatant ............................................................... 4.1

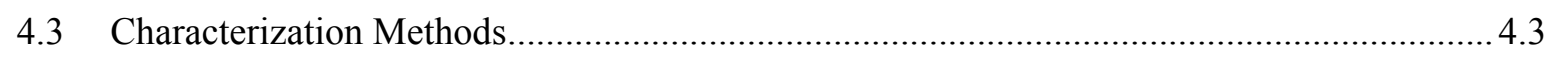

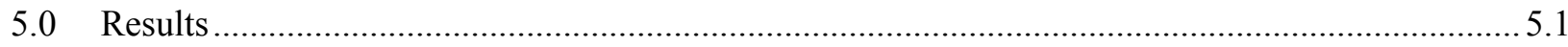

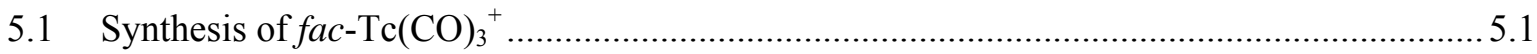

5.1.1 Synthesis of $\mathrm{fac}-\mathrm{Tc}(\mathrm{CO})_{3}{ }^{+}$by two-step $\mathrm{TcO}_{4}{ }^{-}$reduction in the diglyme solvent ....... 5.1

5.1.2 Characterization of the $\left[\mathrm{Tc}(\mathrm{CO})_{3}\right]^{+}$species ......................................................... 5.3

5.1.2.1 Characterization of the $\left[\mathrm{Tc}(\mathrm{CO})_{3} \mathrm{Cl}_{3}\right]^{2-}$ reaction product.........................5.3

5.1.2.2 Characterization of the aqueous $\left[\mathrm{Tc}(\mathrm{CO})_{3}\right]^{+}$species..............................5.6

5.1.3 Preparation and characterization of the aqueous $\left[\mathrm{Tc}(\mathrm{CO})_{3}\right]^{+}$gluconate complex .....5.9

5.1.4 COSMO prediction of the ${ }^{99} \mathrm{Tc}$ NMR spectra for $f a c-\mathrm{Tc}(\mathrm{CO})_{3}{ }^{+} \ldots \ldots \ldots \ldots \ldots \ldots \ldots \ldots \ldots . . .5 .10$

5.1.5 Development of ${ }^{99} \mathrm{Tc}$ EPR characterization technique .......................................... 5.11

5.2 Stability of the $\left[\mathrm{Tc}(\mathrm{CO})_{3}\right]^{+}$Species at High Nitrate Concentrations ................................... 5.14

5.2.1 Stability of $\left[\mathrm{Tc}(\mathrm{CO})_{3}\right]^{+}$species in $\mathrm{NaNO}_{3}$ solutions.............................................. 5.15

5.2.2 Stability of $\left[\mathrm{Tc}(\mathrm{CO})_{3}\right]^{+}$species in $5 \mathrm{M} \mathrm{NaNO}_{3} / 0.01-2 \mathrm{M} \mathrm{NaOH}$ solutions ...........5.19

5.2.3 Stability of $\left[\mathrm{Tc}(\mathrm{CO})_{3}\right]^{+}$species in $5 \mathrm{M} \mathrm{NaNO}_{3} / 0.01-0.5 \mathrm{M} \mathrm{NaOH} / 0.5 \mathrm{M}$ sodium

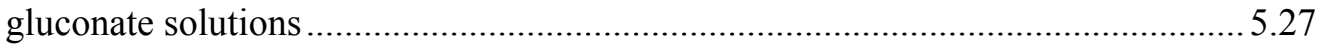

5.2.4 Stability of $\left[\mathrm{Tc}(\mathrm{CO})_{3}\right]^{+}$species in a pseudo-Hanford tank supernatant simulant ....5.30 5.3 Reduction of $\mathrm{TcO}_{4}{ }^{-}$in a Pseudo-Hanford Tank Supernatant Simulant ............................. 5.34

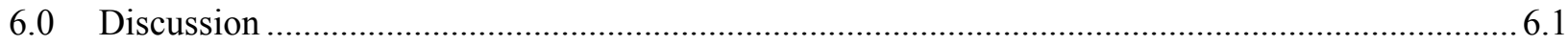

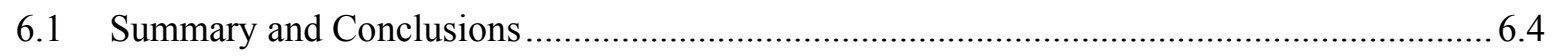

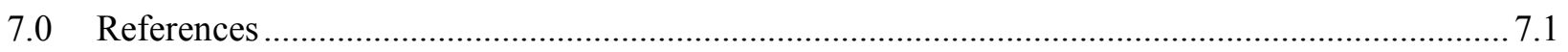




\section{Figures}

1.1. Structures of pertechnetate anion; tri-carbonyl-tris-aqua-technetium(I) cation;

tri-carbonyl-gluconate-technetium(I) anion; and tri-carbonyl-gluconate-technetium(I)

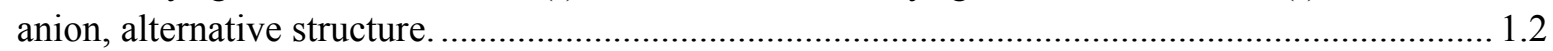

5.1. FTIR Spectrum of the Solid $\left[\mathrm{Et}_{4} \mathrm{~N}\right]_{2}\left[\mathrm{Tc}(\mathrm{CO})_{3} \mathrm{Cl}_{3}\right]$ Product...................................................... 5.3

5.2. FTIR Spectrum of the Solution of $\left[\mathrm{Et}_{4} \mathrm{~N}_{2}\left[\mathrm{Tc}(\mathrm{CO})_{3} \mathrm{Cl}_{3}\right]\right.$ in Acetonitrile ...................................... 5.4

5.3. Technetium-99 NMR Spectrum of the $\left[\mathrm{Et}_{4} \mathrm{~N}\right]_{2}\left[\mathrm{Tc}(\mathrm{CO})_{3} \mathrm{Cl}_{3}\right]$ Solution in Acetonitrile ................... 5.5

5.4. UV-vis Spectrum of the $\left[\mathrm{Et}_{4} \mathrm{~N}\right]_{2}\left[\mathrm{Tc}(\mathrm{CO})_{3} \mathrm{Cl}_{3}\right]$ Solution in Acetonitrile ........................................ 5.5

5.5. ESI-MS Spectrum Normalized to the $\mathrm{Bu}_{4} \mathrm{~N}^{+}$Band with $\mathrm{m} / \mathrm{z}=241.8$, Positive Ionization Mode, of the $\left[\mathrm{Et}_{4} \mathrm{~N}\right]_{2}\left[\mathrm{Tc}(\mathrm{CO})_{3} \mathrm{Cl}_{3}\right]$ Solution in Acetonitrile.................................................. 5.6

5.6. $\quad$ FTIR Spectra of the Aqueous $\left[\mathrm{Tc}(\mathrm{CO})_{3}\right]^{+}$Solutions $\quad 5.8$

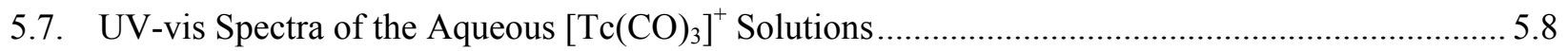

5.8. Time Dependent UV-vis Spectra of the $\left[\mathrm{Tc}(\mathrm{CO})_{3}\right]^{+}$Gluconate Complex ................................... 5.9

5.9. Room Temperature EPR Spectrum of the $\left[\mathrm{TcOCl}_{4}\right]^{-/}\left[\mathrm{TcOCl}_{5}\right]^{2-}$ Sample in Methylene

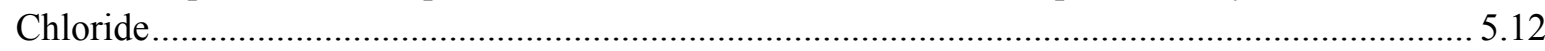

5.10. EPR Spectrum of the $\left[\mathrm{TcOCl}_{4}\right]^{-/} /\left[\mathrm{TcOCl}_{5}\right]^{2-}$ Sample in Methylene Chloride Obtained at

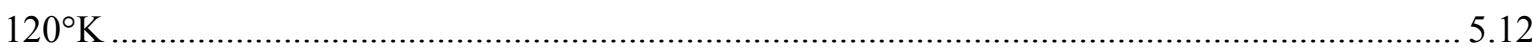

5.11. Wide Field Sweep EPR Spectrum the $\left[\mathrm{TcOCl}_{4}\right]^{-} /\left[\mathrm{TcOCl}_{5}\right]^{2-}$ Sample at $5 \mathrm{~K} \ldots \ldots \ldots \ldots \ldots \ldots \ldots \ldots \ldots . . . . . . . . . . . . . . . . . .13$

5.12. Monitoring the Stability of $\left[\mathrm{Tc}(\mathrm{CO})_{3}\right]^{+}$Species in $2 \mathrm{M} \mathrm{NaNO}_{3}$ with Time ................................ 5.15

5.13. Monitoring the Stability of $\left[\mathrm{Tc}(\mathrm{CO})_{3}\right]^{+}$Species in $5 \mathrm{M} \mathrm{NaNO}_{3}$ with Time ............................... 5.16

5.14. Monitoring the Stability of $\left[\mathrm{Tc}(\mathrm{CO})_{3}\right]^{+}$Species in $5.7 \mathrm{M} \mathrm{NaNO}_{3}$ with Time ............................. 5.17

5.15. Monitoring the Stability of $\left[\mathrm{Tc}(\mathrm{CO})_{3}\right]^{+}$Species in $5 \mathrm{M} \mathrm{NaNO}_{3} / 0.01 \mathrm{M} \mathrm{NaOH}$ with Time ........... 5.20

5.16. Monitoring the Stability of $\left[\mathrm{Tc}(\mathrm{CO})_{3}\right]^{+}$Species in $5 \mathrm{M} \mathrm{NaNO}_{3} / 0.1 \mathrm{M} \mathrm{NaOH}$ with Time ............ 5.21

5.17. Monitoring the Stability of $\left[\mathrm{Tc}(\mathrm{CO})_{3}\right]^{+}$Species in $5 \mathrm{M} \mathrm{NaNO}_{3} / 0.5 \mathrm{M} \mathrm{NaOH}$ with Time ............ 5.22

5.18. Monitoring the Stability of $\left[\mathrm{Tc}(\mathrm{CO})_{3}\right]^{+}$Species in $5 \mathrm{M} \mathrm{NaNO}_{3} / 1 \mathrm{M} \mathrm{NaOH}$ with Time ............... 5.23

5.19. Monitoring the Stability of $\left[\mathrm{Tc}(\mathrm{CO})_{3}\right]^{+}$Species in $5 \mathrm{M} \mathrm{NaNO}_{3} / 2 \mathrm{M} \mathrm{NaOH}$ with Time ............... 5.23

5.20. Technetium-99 Time Speciation in $5 \mathrm{M} \mathrm{NaNO}_{3} /$ Variable Hydroxide Solutions Containing

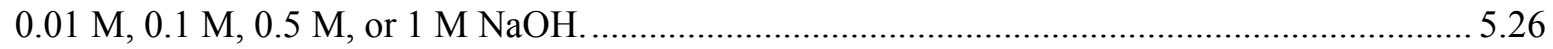

5.21. Dependence of the Kinetics of Tc(I) Oxidation to $\mathrm{TcO}_{4}{ }^{-}$on the $\mathrm{OH}^{-}$Concentration in $5 \mathrm{M}$

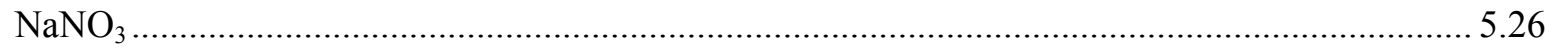

5.22. Selected Spectral Regions of Representative Spectra from Monitoring the Stability of $\left[\mathrm{Tc}(\mathrm{CO})_{3}\right]^{+}$Species in $5 \mathrm{M} \mathrm{NaNO}_{3} / 0.1 \mathrm{M} \mathrm{NaOH} / 0.5 \mathrm{M}$ Sodium Gluconate with Time............... 5.27

5.23. Technetium-99 Time Speciation in $5 \mathrm{M} \mathrm{NaNO}_{3} / 0.5 \mathrm{M}$ Sodium Gluconate Solutions Containing $0.01 \mathrm{M}, 0.1 \mathrm{M}$, or $0.5 \mathrm{M} \mathrm{NaOH}$.

5.24. Dependence of the Kinetics of $\mathrm{Tc}(\mathrm{I})$ Oxidation to $\mathrm{TcO}_{4}{ }^{-}$on the $\mathrm{OH}^{-}$Concentration in the

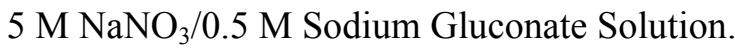

5.25. Effect of Variable Hydroxide Solutions and Presence of Noble Metals/0.05 M NaGluconate on Tc Time Speciation in PEP Simulant....... 
5.26. Dependence of the Kinetics of $\mathrm{Tc}(\mathrm{I})$ Oxidation to $\mathrm{TcO}_{4}{ }^{-}$on the $\mathrm{OH}^{-}$Concentration in the PEP Simulant

5.27. Comparison of the Pertechnetate Resonances in the ${ }^{99} \mathrm{Tc}$ NMR Spectra of the Pseudo-Hanford Tank Supernatant Simulant Containing Noble Metals and Gluconate Before and After the $\mathrm{TcO}_{4}{ }^{-}$Reduction by $\mathrm{CO} / \mathrm{H}_{2}$

5.28. Comparison of the ${ }^{99} \mathrm{Tc}$ NMR Spectra of the $\left[\mathrm{Tc}(\mathrm{CO})_{3}\right]^{+}$Gluconate Complex Generated by the Reduction of $\mathrm{TcO}_{4}{ }^{-}$in the $\mathrm{CO} / \mathrm{H}_{2}$-reacted Pseudo-Hanford Tank Supernatant Simulant Solutions Containing Noble Metals and $0.05 \mathrm{M}$ Gluconate $/ 5 \mathrm{mM}$ Tc or $0.1 \mathrm{M}$ Gluconate/10 mM Tc with the Spectra of Tc(I) Solutions Obtained by the Dissolution of the $\left[\mathrm{Et}_{4} \mathrm{~N}\right]_{2}\left[\mathrm{Tc}(\mathrm{CO})_{3} \mathrm{Cl}_{3}\right]$ Compound in the $5 \mathrm{M} \mathrm{NaNO}_{3} / 0.5 \mathrm{M} \mathrm{NaOH} / 0.5 \mathrm{M}$ Sodium Gluconate, and in the Pseudo-Hanford Tank Supernatant Simulant Containing Noble Metals and $0.05 \mathrm{M}$ Gluconate 


\section{Tables}

4.1. Specific Supernatant Composition for PEP Simulant 4.1

4.2. Target PEP Supernatant Simulant Composition

4.3. Actual PEP Supernatant Simulant Composition Determined by ICP-OES or Raman Spectroscopy

5.1. Techetium-99-NMR Characterization of the Aqueous Reaction Products

5.2. Comparison of the Calculated and Experimental ${ }^{99} \mathrm{Tc}$ NMR Chemical Shifts for the $\left[\mathrm{Tc}(\mathrm{CO})_{3}\right]^{+}$Species in Water

5.3. Comparison of the Experimental, Calculated, and Literature Magnetic Parameters for $\left[\mathrm{TcOCl}_{\mathrm{x}}\right]^{\mathrm{y}-}$ Species

5.4. Time Stability of $\left[\mathrm{Tc}(\mathrm{CO})_{3}\right]^{+}$Species in $\mathrm{NaNO}_{3} / \mathrm{NaOH}$ Solutions Monitored by ${ }^{99} \mathrm{Tc} \mathrm{NMR}$ Spectroscopy

5.5. Time Stability of $\left[\mathrm{Tc}(\mathrm{CO})_{3}\right]^{+}$Species in $\mathrm{NaNO}_{3} / \mathrm{NaOH}$ Solutions Monitored by ${ }^{99} \mathrm{Tc} \mathrm{NMR}$ Spectroscopy

5.6. Time Stability of $\left[\mathrm{Tc}(\mathrm{CO})_{3}\right]^{+}$Species in $5 \mathrm{M} \mathrm{NaNO}_{3} / 0.01-0.5 \mathrm{M} \mathrm{NaOH} / 0.5 \mathrm{M}$ Sodium Gluconate Solutions as Monitored by ${ }^{99} \mathrm{Tc}$ NMR Spectroscopy

5.7. Stability of $\left[\mathrm{Tc}(\mathrm{CO})_{3}\right]^{+}$Species in a Pseudo-Hanford Tank Supernatant Simulant Monitored by ${ }^{99}$ Tc NMR Spectroscopy as a Function of Time

5.8. Time Monitoring of the Observed ${ }^{99} \mathrm{Tc}$ NMR Resonances in the $\mathrm{CO} / \mathrm{H}_{2}$-reacted Pseudo-Hanford Tank Supernatant Simulant.

6.1. $\left[\mathrm{Tc}(\mathrm{CO})_{3}\right]^{+}$Speciation in Water and $5 \mathrm{M} \mathrm{NaNO}_{3}$ by ${ }^{99} \mathrm{Tc}-\mathrm{NMR}$ Spectroscopy 


\subsection{Introduction}

The fate of technetium-99 (Tc), a Hanford Nuclear Reservation tank waste constituent, is a major River Protection Project (RPP) flowsheet uncertainty. The key driver to this flowsheet uncertainty is associated with the Integrated Disposal Facility (IDF) Performance Assessment Tc risk determinations. Previous attempts to remove Tc from the Hanford tank waste using an ion-exchange process specific to pertechnetate $\left(\mathrm{TcO}_{4}{ }^{-}\right.$; Figure 1.1a) were only somewhat successful due to the presence of other Tc-containing species in the waste supernatant.

The majority of Tc at the Hanford Site is soluble in the supernatant fraction of both single- and double-shell tanks. In strongly alkaline environments, Tc exists as pertechnetate $\left(\mathrm{TcO}_{4}{ }^{-}\right)$(oxidation state VII) and in the reduced forms (oxidation state $<$ VII) collectively known as non-pertechnetate (non- $\mathrm{TcO}_{4}{ }^{-}$) species. Pertechnetate is a well-characterized, anionic Tc species that can be removed from LAW by anion exchange or solvent extraction methods. There is no definitive information on the origin and comprehensive description of the non- $\mathrm{TcO}_{4}{ }^{-}$species. This project is focused on characterization of the composition of non- $\mathrm{TcO}_{4}{ }^{-}$species to gain better understanding and control over their redox behavior. The objective of this work is to investigate interconversion among soluble $\mathrm{TcO}_{4}{ }^{-}$and non- $\mathrm{TcO}_{4}{ }^{-}$species and to elucidate the mechanistic pathways for the oxidation of non- $\mathrm{TcO}_{4}{ }^{-}$species to separate them from LAW as $\mathrm{TcO}_{4}{ }^{-}$.

In fiscal year 2012 (FY 2012), a study reviewed prior work on the nature and extent of this non-pertechnetate, alkaline-soluble technetium in the Hanford waste tanks (Rapko et al. 2013a). As noted in that report, prior work has identified a Tc(I) carbonyl type compound as a non-pertechnetate species present in tank waste.

In FY 2013, laboratory research began to investigate the chemistry of the Tc-tricarbonyl compound noted above. Multiple synthetic approaches described in the literature to prepare compounds with this structural feature were explored. A method was selected which, albeit time-consuming, was shown to provide a Tc-tricarbonyl compound pure with respect to Tc. Characterization of this product by a variety of methods was also explored and a report summarizing the FY 2013 work was issued (Rapko et al. 2013b).

Later in FY 2013, a joint report by Pacific Northwest National Laboratory (PNNL) and Savannah River National Laboratory (SRNL) (Brown et al. 2013) summarized technical issues associated with the development of low-temperature waste forms for the immobilization of U.S. Department of Energy (DOE) aqueous waste streams, along with technetium removal, as an implementing technology. In response to this report, the U.S. Department of Energy's Office of Environmental Management (DOE-EM) sponsored work on low-valence technetium as summarized in PNNL Test Plan TP-EMSP-0016, Rev. 0.0.

In FY 2014, a literature review report "Technetium Inventory, Distribution, and Speciation in Hanford Tanks" (Serne and Rapko 2014) was prepared. It states that "based on all investigations and detailed measurements, $\mathrm{n}$-Tc species in the Hanford DST (double shell tank) supernates are tentatively identified as $\mathrm{Tc}(\mathrm{I})$ carbonyl complexes derived from either $\mathrm{Tc}(\mathrm{CO})_{3}{ }^{+}$or $\mathrm{Tc}(\mathrm{CO})_{2}(\mathrm{NO})^{2+}$ precursor molecules that may lead to final species such as $\mathrm{Tc}(\mathrm{CO})_{3}{ }^{+}$-gluconate as a result of the radiolytic 
decomposition of organics and nitrite in the DSTs." To date, there is no literature evidence supporting the presence of the $\mathrm{Tc}(\mathrm{CO})_{2}(\mathrm{NO})^{2+}$ in the alkaline waste. However, formation of the $\left[\mathrm{Tc}(\mathrm{CO})_{2}(\mathrm{NO}) \mathrm{X}\right]$ compounds (where $\mathrm{X}$ is organic ligand) in the aqueous and organic media was demonstrated in the few radiopharmaceutical studies (Rattat et al. 2001; Rattat et al. 2004; Yang et al. 2007). It was achieved by the reaction of the $\left[\mathrm{Tc}(\mathrm{CO})_{3} \mathrm{X}\right]$ parent material with $[\mathrm{NO}]\left[\mathrm{BH}_{4}\right]$ complex. It was speculated that $[\mathrm{NO}]\left[\mathrm{BH}_{4}\right]$ complex hydrolyzes in water to produce nitrous acid, $\mathrm{HNO}_{2}$, which in acidic, oxygen-free solution dissociates to provide $\mathrm{NO}^{+}$. In order to get enough $\mathrm{NO}^{+}$from $[\mathrm{NO}]\left[\mathrm{BH}_{4}\right]$ complex, excess acid, e.g., $\mathrm{HCl}$, should be added to the reaction mixture (Yang et al. 2007). The $\left[\mathrm{Tc}(\mathrm{CO})_{3} \mathrm{X}\right]$ converted to $\left[\mathrm{Tc}(\mathrm{CO})_{2}(\mathrm{NO}) \mathrm{X}\right]$ in $>99 \%$ yield. Kurz et al. (2005) demonstrated the unusual $\mathrm{pH}$ behavior of the $\left[\mathrm{Tc}(\mathrm{CO})_{2}(\mathrm{NO})\left(\mathrm{H}_{2} \mathrm{O}\right)_{3}\right]^{2+}$ complex with the formation of stable water-insoluble $\left[\operatorname{Re}\left(\mu_{3}-\mathrm{O}\right)(\mathrm{CO})_{2}(\mathrm{NO})\right]_{4}$ cluster at $\mathrm{pH} 2-6$ when solution $\mathrm{pH}$ was increased slowly. Fast $\mathrm{pH}$ increase resulted in the $\left[\mathrm{Tc}(\mathrm{CO})_{2}(\mathrm{NO})(\mathrm{OH})\left(\mathrm{H}_{2} \mathrm{O}\right)_{2}\right]^{+}$complex up to $\mathrm{pH}$ of 10 . Further $\mathrm{pH}$ increased generated $\left.\mathrm{ReC}(\mathrm{O}) \mathrm{O}(\mathrm{NO})\right]$ species. The investigation of the $\left[\mathrm{Tc}(\mathrm{CO})_{2}(\mathrm{NO})\left(\mathrm{H}_{2} \mathrm{O}\right)_{3}\right]^{2+}$ compounds in the alkaline solutions was outside the scope of the current project but should certainly be considered in the future as candidate non-pertechnetate species.

In FY 2014, experimental work continued on understanding various aspect of the stability of various Tc-tricarbonyl species under simple alkaline conditions, alkaline conditions in the presence of the complexing agent sodium gluconate, high-ionic-strength alkaline conditions in the presence and absence of gluconate, and in the presence of alkaline Hanford tank solution simulants. The proof-of-principle tests were conducted to evaluate the concept of reductive conversion of pertechnetate to Tc-tricarbonyl in the simulant solutions. Efforts have also continued to optimize the synthesis of the Tc-tricarbonyl starting precursor and to search for alternatives more readily applicable to the preparation of up to gram quantities of this starting compound.

This report describes FY 2014 research activities and fulfills the milestone of a PNNL formal report describing said FY 2014 research activities.

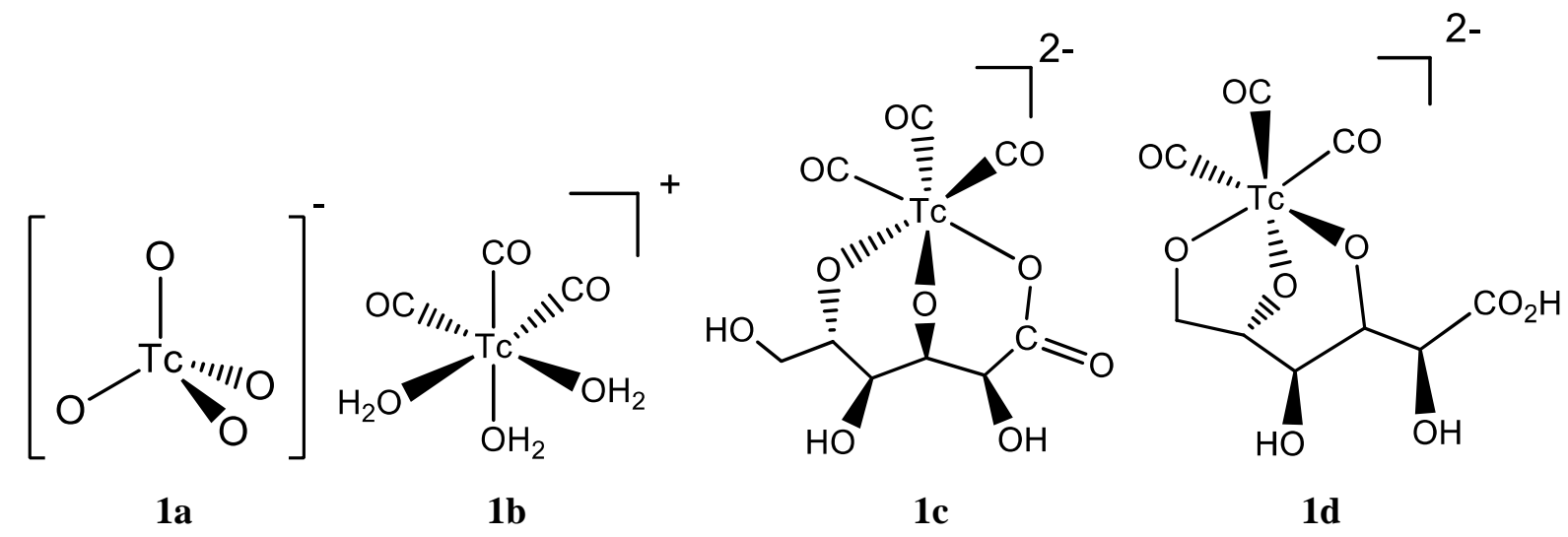

Figure 1.1. Structures of 1a: pertechnetate anion; 1b: tri-carbonyl-tris-aqua-technetium(I) cation;

1c: tri-carbonyl-gluconate-technetium(I) anion, structure proposed by Lukens et al. (2004);

1d: tri-carbonyl-gluconate-technetium(I) anion, alternative structure. 


\subsection{Quality Requirements}

All research and development (R\&D) work at PNNL is performed in accordance with PNNL's Laboratory-level Quality Management Program, which is based on a graded application of NQA-1-2000, Quality Assurance Requirements for Nuclear Facility Applications, to R\&D activities. To ensure that all client quality assurance (QA) expectations were addressed, the QA controls of the Environmental Management Support Program (EMSP) QA program were also implemented for this work. The EMSP QA program consists of the EMSP Quality Assurance Plan (QA-EMSP-001) and associated QA-EMSP-numbered procedures that provide detailed instructions for implementing NQA-1-2000 for R\&D work.

The work described in this report was assigned the technology level "Applied Research" and, except as noted below and in Appendix A, was planned, performed, documented, and reported in accordance with Procedure QA-EMSP-1102, Scientific Investigation for Applied Research. All staff members contributing to the work received proper technical and quality assurance training prior to performing quality-affecting work.

The work presented in this report combines results obtained under Tasks 1 and 3 as described in Test Plan TP-EMSP-0016, currently Rev. 1.0, Technetium Management - Hanford Site. Experimental work for Task 3 was performed in accordance with Test Instruction TI-EMSP-0016, EMSP Task 3: Investigations Into the Nature of Alkaline Soluble, Non-Pertechnetate Tc.

Experimental work for Task 1 was to have been performed in accordance with Test Instruction TI-EMSP-0015, EMSP Task 1: Investigations Into the Nature of Alkaline Soluble, Non-Pertechnetate Tc. However, Task 1 work was performed before the Test Instruction was issued and approved for use. Consequently, the experimental work for Task 1 does not meet the requirements of the EMSP QA program and the results (presented in Appendix A at the end of this document) do not have the NQA-1 pedigree of results produced under the EMSP QA program. They must be considered For Information Only. 



\subsection{Objectives}

FY 2014 investigations continued FY 2013 research that was focused on an assessment and selection of technically viable and practical options for the treatment and/or removal of the various Tc species from the Hanford waste streams and to gain better understanding and control over the redox behavior of Tc as described in Test Plan TP-EMSP-0016, Rev. 0.0, Technetium Management - Hanford Site. The objective of the Task 1 and 3 investigations described in this report is to better understand the nature of any soluble non-pertechnetate species, the stability of said species in alkaline media, and the feasibility of their oxidation to $\mathrm{TcO}_{4}^{-}$. Goals for the FY 2014 research covered in this report were to:

1. Continue to investigate and optimize methods to obtain stock quantities of Tc-tricarbonyl moiety.

This includes continued investigation of the various literature methods to obtain this material, as well as optimizing the synthetic route described by Rapko et al. (2013b).

2. Obtain and characterize solid $\left[\mathrm{Et}_{4} \mathrm{~N}\right]_{2}\left[\mathrm{Tc}(\mathrm{CO})_{3} \mathrm{Cl}_{3}\right]$. This stable compound, readily soluble in water, serves as the source of the $\mathrm{Tc}(\mathrm{I})$-tricarbonyl species investigated in this report.

3. Investigate the composition and stability of Tc(I)-tricarbonyl species as a function of nitrate and hydroxide concentration.

4. Investigate the formation and stability of Tc(I)-tricarbonyl species in complex aqueous matrices. This work involves testing of Hanford supernatant simulants with and without catalytically active metals such as $\mathrm{Ru}, \mathrm{Rh}, \mathrm{Pd}$, and Pt.

5. Conduct experiments to evaluate the feasibility of $\mathrm{Tc}(\mathrm{VII})$ reduction and generation of $\mathrm{Tc}(\mathrm{I})$ non-pertechnetate species in the Hanford supernatant simulant solutions in the $\mathrm{CO} / \mathrm{H}_{2}$ atmosphere with and without potentially catalytically active metals such as $\mathrm{Ru}, \mathrm{Rh}, \mathrm{Pd}$, and $\mathrm{Pt}$. 



\subsection{Experimental}

\subsection{Materials}

In-house $\mathrm{NH}_{4} \mathrm{TcO}_{4}$ stock available at the Radiochemical Processing Laboratory (RPL) at PNNL was used. Diglyme, acetonitrile, diethyl ether, dichloromethane, and borane-tetrahydrofuran $\mathrm{BH}_{3} / \mathrm{THF}$ complex were obtained from Sigma-Aldrich and used without further purification. Gaseous CO used in the diglyme synthesis of the $\left[\mathrm{Et}_{4} \mathrm{~N}\right]_{2}\left[\mathrm{Tc}(\mathrm{CO})_{3} \mathrm{Cl}_{3}\right]$ was obtained from Matheson Tri-Gas. Argon gas also was obtained from Matheson. Carbon monoxide (CO) gas with approximately $75 \mathrm{ppb}_{2}$, used to test the feasibility of $\mathrm{TcO}_{4}{ }^{-}$reduction to the $\mathrm{Tc}(\mathrm{I})$-tricarbonyl complex in the simulated Hanford tank waste supernatant, was obtained from OXARC Inc. All inorganic sodium salts (including carbonate, oxalate, nitrate, nitrite, hydroxide, and sulfate) and aluminum nitrate were obtained from Sigma-Aldrich and were of reagent grade. All aqueous solutions were prepared from distilled water deionized to $\geq 15{\mathrm{M} \Omega \mathrm{cm}^{-1}}^{-1}$ with a Barnstead Nanopure water purification system.

\subsection{Simulated Hanford Tank Waste Supernatant}

A major objective of these tasks were to investigate speciation and time stability of the Tc(I)-tricarbonyl species in the complex caustic aqueous solutions of simulated Hanford tank waste supernatants. For this test, the average supernatant simulant composition previously developed for the Pretreatment Engineering Platform (PEP) testing (Scheele et al. 2009) was used, albeit with a reduced $\mathrm{NaOH}$ concentration. The composition of the simulant is given in Table 4.1, and the reagents needed for the simulant preparation are listed in Table 4.2.

Table 4.1. Specific Supernatant Composition for PEP Simulant (Scheele et al. 2009)

\begin{tabular}{|c|r|c|}
\hline \multirow{2}{*}{ Constituent } & \multicolumn{2}{|c|}{ Target Concentration } \\
\cline { 2 - 3 } & $\boldsymbol{\mu g} / \mathbf{m L}$ & $\mathbf{M}$ \\
\hline $\mathrm{Al}$ & 3,370 & 0.125 \\
\hline $\mathrm{Na}$ & 115,000 & 5.00 \\
\hline $\mathrm{C}_{2} \mathrm{O}_{4}$ & 1,250 & 0.014 \\
\hline $\mathrm{NO}_{2}$ & 23,300 & 0.507 \\
\hline $\mathrm{NO}_{3}$ & 99,100 & 1.60 \\
\hline $\mathrm{PO}_{4}$ & 6,250 & 0.066 \\
\hline $\mathrm{SO}_{4}$ & 16,900 & 0.176 \\
\hline $\mathrm{CO}_{3}$ & 6,640 & 0.553 \\
\hline $\mathrm{OH}$ & 18,500 & 1.09 \\
\hline
\end{tabular}


Table 4.2. Target PEP Supernatant Simulant Composition

\begin{tabular}{|l|c|c|}
\hline \multicolumn{1}{|c|}{ Component } & Chemical Formula & Concentration (g/L) \\
\hline Sodium oxalate & $\mathrm{Na}_{2} \mathrm{C}_{2} \mathrm{O}_{4}$ & 1.9 \\
\hline Aluminum nitrate & $\mathrm{Al}_{\left(\mathrm{NO}_{3}\right)_{3} \cdot 9 \mathrm{H}_{2} \mathrm{O}}$ & $78\left(60 \%\right.$ solution of $\left.\mathrm{Al}\left(\mathrm{NO}_{3}\right)_{3} \cdot 9 \mathrm{H}_{2} \mathrm{O}\right)$ \\
\hline Sodium phosphate & $\mathrm{Na}_{3} \mathrm{PO}_{4} \cdot 12 \mathrm{H}_{2} \mathrm{O}$ & 25 \\
\hline Sodium sulfate (anhydrous) & $\mathrm{Na}_{2} \mathrm{SO}_{4}$ & 25 \\
\hline Sodium nitrate & $\mathrm{NaNO}_{3}$ & 104 \\
\hline $\begin{array}{l}\text { Sodium hydroxide }(50 \% \\
\text { solution) }\end{array}$ & $\mathrm{NaOH}$ & $104(50 \%$ solution of $\mathrm{NaOH})$ \\
\hline Sodium nitrite & $\mathrm{NaNO}_{2}$ & 35 \\
\hline Sodium carbonate (anhydrous) & $\mathrm{Na}_{2} \mathrm{CO}_{3}$ & 58.57 \\
\hline
\end{tabular}

The procedure for the simulant preparation is as follows:

- Mix sodium oxalate in water (suggested water quantity is $10-20 \%$ of the final volume).

- Add aluminum nitrate solution and mix thoroughly until all dissolved. Heating should not be necessary to obtain dissolution; if it is, do not exceed $50{ }^{\circ} \mathrm{C}$.

- Add sodium phosphate while mixing, allow to dissolve (may be slow).

- Add sodium sulfate while mixing, allow to dissolve.

- Add sodium nitrate while mixing, allow to dissolve.

- Add sodium hydroxide while mixing, allow to dissolve.

- Add sodium nitrite while mixing, allow to dissolve.

- Add sodium carbonate while mixing, allow to dissolve.

- Dilute with deionized (DI) water to the final 1-L volume. Mix well.

- Remove undissolved solids by filtration.

The final concentrations of metallic elements in the simulant were determined by inductively-coupled plasma optical emission spectroscopy (ICP-OES) and oxy anions were determined by Raman analysis; the results are listed in Table 4.3. In selected cases, noble metal salts, including $\mathrm{K}_{4} \mathrm{PtCl}_{6}$ (Sigma-Aldrich), $\mathrm{Pd}(\mathrm{II})$ acetate, $\mathrm{Rh}$ (II) acetylacetonate, and $\left(\mathrm{NH}_{4}\right)_{4} \mathrm{Ru}(\mathrm{CN})_{6}$ (Strem Chemicals) were added at target $1 \mathrm{mM}$ concentrations and $0.05 \mathrm{M}$ potassium gluconate (Sigma-Aldrich) was added to the simulant. Metals analysis by ICP-OES was used to determine the actual concentrations of the noble metals and was found to be: $0.13 \mathrm{mM}$ for Pt, $0.57 \mathrm{mM}$ for Pd, $0.014 \mathrm{mM}$ for $\mathrm{Rh}$, and $1.04 \mathrm{mM}$ for $\mathrm{Ru}$. 
Table 4.3. Actual PEP Supernatant Simulant Composition Determined by ICP-OES or Raman Spectroscopy

\begin{tabular}{|c|c|c|}
\hline \multirow{2}{*}{ Constituent } & \multicolumn{2}{|c|}{ Target Concentration } \\
\cline { 2 - 3 } & $\boldsymbol{\mu g} / \mathbf{m L}$ & $\mathbf{M}$ \\
\hline $\mathrm{Al}^{\mathrm{a}}$ & 5,900 & 0.217 \\
\hline $\mathrm{Na}^{\mathrm{a}}$ & 108,700 & 4.73 \\
\hline $\mathrm{C}_{2} \mathrm{O}_{4}{ }^{\mathrm{b}, \mathrm{c}}$ & $<450$ & $<0.005$ \\
\hline $\mathrm{NO}_{2}{ }^{\mathrm{b}}$ & 25,300 & $0.55 \pm 0.03$ \\
\hline $\mathrm{NO}_{3}{ }^{\mathrm{b}}$ & 104,800 & $1.69 \pm 0.03$ \\
\hline $\mathrm{PO}_{4}{ }^{\mathrm{a}, \mathrm{d}}$ & 15,100 & 0.158 \\
\hline $\mathrm{SO}_{4}{ }^{\mathrm{a}}{ }^{\mathrm{d}}$ & 19,200 & 0.200 \\
\hline $\mathrm{CO}_{3}{ }^{\mathrm{b}}$ & 7,360 & $0.613 \pm 0.006$ \\
\hline $\mathrm{OH}^{\mathrm{b}}$ & 18,800 & 0.47 \\
\hline
\end{tabular}

a. Determined by ICP-OES

b. Determined by Raman spectroscopy

c. Based on Raman detection limit for oxalate

d. Based on total $\mathrm{P}$ and $\mathrm{S}$ and assuming all $\mathrm{P}$ and $\mathrm{S}$ is present as phosphate and sulfate, respectively.

\subsection{Characterization Methods}

Technetium-99 nuclear magnetic resonance (NMR) spectroscopy. The NMR solutions were placed in capped polytetrafluoroethylene (PTFE)/fluorinated ethylene propylene (FEP) copolymer sleeves (Wilmad), which were then inserted into 5- or 10-mm glass NMR tubes to provide secondary containment for the radioactive liquid. Technetium-99 NMR data were routinely collected at $67.565 \mathrm{MHz}$ on a Tecmag Discovery spectrometer equipped with a $10-\mathrm{mm}$ broadband Nalorac probe as described in Cho et al. (2004) at the RPL at PNNL. A solution containing $10 \mathrm{mM} \mathrm{TcO}_{4}{ }^{-}$was used as a ${ }^{99} \mathrm{Tc}$ chemical shift reference using the replacement method, and all chemical shift data are quoted relative to $\mathrm{TcO}_{4}{ }^{-}(\mathrm{Franklin}$ et al. 1982). The Tc(I) oxidative stability testing was conducted in part using alternative NMR instrumentation available at PNNL's Environmental Molecular Sciences Laboratory (EMSL) RadAnnex. These technetium-99 direct polarization (DP) experiments were conducted on a 17.6 Tesla wide-bore Bruker Avance III spectrometer, utilizing a 5.0-mm double resonance HX probe and tuned to a resonance frequency of $168.713257 \mathrm{MHz}$ for ${ }^{99} \mathrm{Tc}$ with the temperature held constant at $20{ }^{\circ} \mathrm{C}$. Spectra were acquired by collecting $4000-80000$ transients using calibrated ${ }^{99} \mathrm{Tc} \pi / 5$ pulses of $5.25 \mu \mathrm{s}$, a $400 \mathrm{kHz}$ sweep width, and a recycle delay of $2.5 \mathrm{~s}$. Time domain free induction decays were apodized with exponential functions corresponding to $50 \mathrm{~Hz}$ of Lorentzian broadening prior to Fourier transformation. ${ }^{99} \mathrm{Tc}$ resonances were referenced to aqueous pertechnetate ion, $\mathrm{TcO}_{4}{ }^{-}$, in the absence of added salt.

Technetium-99 electron paramagnetic resonance (EPR) spectroscopy. EPR spectra were acquired on a Bruker EMX Spectrometer equipped with an ER4102ST resonator (spectra at room temperature and $120 \mathrm{~K}$ ) or an ER4116DM Dual Mode resonator (spectra at $5 \mathrm{~K}$ ) and an Oxford ESR910 cryostat. Samples were doubly contained by employing unbreakable FEP tube liners (Wilmad) inside traditional quartz EPR tubes. Liquid samples employed $1.5 \mathrm{~mm}$ inner diameter (ID) liners and $4 \mathrm{~mm}$ outer diameter 
(OD) quartz tubes while frozen solution and powder samples used $3.15 \mathrm{~mm}$ ID liners and $5 \mathrm{~mm}$ OD tubes. EasySpin, a program for fitting and simulating EPR spectra, was used to find best-fit spin Hamiltonian parameters for the data.

Fourier Transform Infrared (FTIR) spectroscopy. FTIR measurements were conducted using a spectrometer (ALPHA model, Bruker Optics) operated with OPUS software (Version 6.5 Build 6.5.92). Samples were run directly on a diamond attenuated total reflectance (ATR) cell. For each sample, 24 scans with a resolution of 4 wavenumbers $\left(\mathrm{cm}^{-1}\right)$ were averaged to give the final spectrum. A background of ambient air was used for all samples. A sample volume of approximately $10 \mu \mathrm{L}$ was used for each analysis; this was adequate to cover the collection region of the ATR cell.

Ultraviolet-visible (UV-vis) spectroscopy. UV spectrophotometric measurements were performed using a deuterium light source DH2000 MIKROPACK UV-VIS-NIR, grating No 1 with $100 \mu \mathrm{m}$ slit width and a USB-2000 spectrophotometer $200-950 \mathrm{~nm}$. Visible spectrophotometric measurements were acquired using an HL-2000 Tungsten Halogen Light Source and the same spectrometer. Three replicate measurements were collected for each location. Spectral data were processed using a SpectraSuite Spectroscopy Platform Software version 2.0.140 (Ocean Optics, Inc.).

Electrospray ionization mass spectrometry (ESI-MS) measurements were conducted with a Finnigan MAT TSQ-7000 (Finnigan) triple-sector quadrupole mass spectrometer equipped with an electrospray source. Ultra-pure nitrogen was applied as a nebulizing gas at a manifold pressure of 3.0 to $3.5 \times 10^{-6}$ Torr. The standard sample introduction conditions were a spray voltage of $4.0 \mathrm{kV}$, a heated capillary temperature of $250{ }^{\circ} \mathrm{C}$, and a sample rate of $10 \mu \mathrm{L} \mathrm{min}{ }^{-1}$. During the set of measurements, the distance between the capillary and the cone was kept constant. A syringe pump (Harvard Apparatus) was used for the sample introduction into the electrospray ionization (ESI) source. Scanning was acquired using the parent quadrupole in the 20- to 2000-mass range over $2 \mathrm{~s}$. Each sample was introduced for 3 minutes, and the corresponding spectrum was obtained as an average of 90 scans. Acetonitrile was used as the sample solvent; organic samples were diluted in acetonitrile or acetonitrile/water, typically using 1:2000 dilution factor.

Measurements of solution $\mathrm{pH}$ were conducted with an Orion ROSS Ultra Semi-micro $\mathrm{pH}$ electrode. The $\mathrm{pH}$ probe was calibrated before use using $\mathrm{pH} 4$ and 10 buffer solutions from Fisher Scientific. 


\subsection{Results}

\subsection{Synthesis of $\mathrm{fac}-\mathrm{Tc}(\mathrm{CO})_{3}{ }^{+}$}

\subsubsection{Synthesis of fac-Tc $(\mathrm{CO})_{3}{ }^{+}$by two-step $\mathrm{TcO}_{4}{ }_{4}^{-}$reduction in the diglyme solvent}

To prepare $\mathrm{Tc}(\mathrm{I})$ compounds containing a fac- $\left[\mathrm{Tc}(\mathrm{CO})_{3}\right]^{+}$(in the following text, the abbreviated notation $\left[\mathrm{Tc}(\mathrm{CO})_{3}\right]^{+}$is used) center, $\mathrm{TcO}_{4}{ }^{-}$was reduced by a two-step reaction using the modified procedure that was originally reported elsewhere (Alberto et al. 1995) to obtain the targeted $\left[\mathrm{Et}_{4} \mathrm{~N}_{2}\left[\mathrm{Tc}(\mathrm{CO})_{3} \mathrm{Cl}_{3}\right]\right.$ product. When dissolved in water, the $\mathrm{Cl}^{-}$ligands in this compound are exchanged with $\mathrm{H}_{2} \mathrm{O}, \mathrm{OH}^{-}$, and/or organic ligands present in the aqueous solution so that $\left[\mathrm{Et}_{4} \mathrm{~N}\right]_{2}\left[\mathrm{Tc}(\mathrm{CO})_{3} \mathrm{Cl}_{3}\right]$ serves as a convenient source of an active, Tc(I)-tricarbonyl species.

The two-step reduction utilized in this work was selected based on our previous experimental assessment of several synthetic preparations of the $\left[\mathrm{Tc}(\mathrm{CO})_{3}\right]^{+}$compounds reported in the literature as described in Rapko et al. (2013b). The superior traits of this synthetic route include elimination of the need to generate any typically unstable $\mathrm{Tc}(\mathrm{V})$ intermediates in situ; this approach utilizes a stable external source of $\mathrm{Tc}(\mathrm{V})$. In the second reaction step, diglyme, with the boiling point of $162^{\circ} \mathrm{C}$, is used as a solvent. With diglyme as the solvent, the reaction mixture can be conveniently heated to higher temperatures (typically $110-120^{\circ} \mathrm{C}$ ) compared to alternative preparations, which results in an improved overall reaction yield. Finally and of key importance, the final product can be separated cleanly from the reaction mixture by simple precipitation.

The overall procedure was optimized in FY 2014 during repetitive syntheses of $\left[\mathrm{Et}_{4} \mathrm{~N}_{2}\left[\mathrm{Tc}(\mathrm{CO})_{3} \mathrm{Cl}_{3}\right]\right.$ and is described below:

Step 1. In the first step $\mathrm{TcO}_{4}{ }^{-}$is reduced to $\mathrm{Tc}(\mathrm{V})$ in the form of the stable compound $\left[\mathrm{Bu}_{4} \mathrm{~N}\right]\left[\mathrm{TcOCl}_{4}\right]$ as described by reaction 1 .

$$
\mathrm{TcO}_{4}^{-}+\left[\mathrm{Bu}_{4} \mathrm{~N}\right] \mathrm{Cl} \stackrel{12 \mathrm{~N} \mathrm{HCl}}{\longrightarrow} \quad\left[\mathrm{Bu}_{4} \mathrm{~N}\right]\left[\mathrm{TcOCl}_{4}\right]+\mathrm{Cl}+3 \mathrm{H}_{2} \mathrm{O}+\mathrm{Cl}_{2}
$$

In brief, this synthetic step is achieved by dissolving solid $\left[\mathrm{Bu}_{4} \mathrm{~N}\right] \mathrm{Cl}$ in the $\mathrm{TcO}_{4}{ }^{-} /$concentrated $\mathrm{HCl}$ solution, which results in the precipitation of the $\left[\mathrm{Bu}_{4} \mathrm{~N}\right]\left[\mathrm{TcOCl}_{4}\right]$ product. The precipitate is isolated by filtration and purified by crystallization. The detailed synthetic procedure for step 1 can be under normal atmospheric conditions and is outlined below.

1. Weigh a predetermined amount $(100-150 \mathrm{mg})$ of solid $\mathrm{NH}_{4} \mathrm{TcO}_{4}$ and dissolve in $2-3 \mathrm{~mL}$ water.

2. Aliquot $20-25 \mathrm{~mL}$ of concentrated $(12 \mathrm{M}) \mathrm{HCl}$ into a glass beaker, add a magnetic stir bar, and then add the $\mathrm{NH}_{4} \mathrm{TcO}_{4} / \mathrm{H}_{2} \mathrm{O}$ solution to the well-stirred $\mathrm{HCl}$ solution. Stir for 10 minutes. 
3. Prepare a saturated solution of $\mathrm{Bu}_{4} \mathrm{NCl}$ in water and add $3 \mathrm{~mL}$ drop-wise to the $\mathrm{NH}_{4} \mathrm{TcO}_{4} / \mathrm{HCl}$ solution. A light green precipitate forms. Stir for an additional 5 minutes. Stop stirring and let precipitate settle for about 10 minutes. Without stirring, add 1 additional drop of the saturated solution of $\mathrm{Bu}_{4} \mathrm{NCl}$ in water and observe if any additional green precipitate forms. If so, continue a drop-wise addition of the $\mathrm{Bu}_{4} \mathrm{NCl}$ solution until no more green precipitate is generated.

4. Filter the precipitate using a medium or finer sintered glass frit and wash the precipitate with diethyl ether 3 times. Allow the precipitate to air dry for at least 3 hours.

5. Dissolve the precipitate in $10 \mathrm{~mL} \mathrm{CH}_{2} \mathrm{Cl}_{2}$ and place the resulting solution in a $10{ }^{\circ} \mathrm{C}$ refrigerator. Observe daily. When green crystalline blocks of $\left[\mathrm{Bu}_{4} \mathrm{~N}\right]\left[\mathrm{TcOCl}_{4}\right]$ are formed, decant the mother liquor and air-dry the crystalline product.

Step 2. The second reaction step is described by reaction 2 .

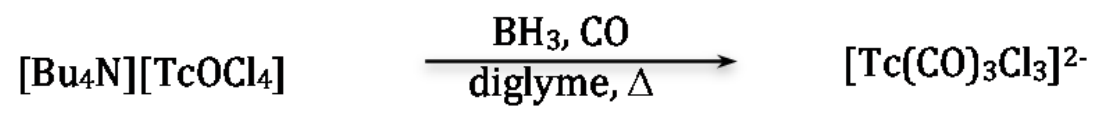

The detailed synthetic procedure for step 2 is described below. It was found that an Ar atmosphere is important to maximize the product yield. Under aerated conditions, the yellow intermediate Tc(IV) species $\left[\mathrm{TcCl}_{6}\right]^{2-}$ are stabilized and further reduction to $\mathrm{Tc}(\mathrm{I})$ is incomplete.

1. Under the Ar atmosphere, place $10 \mathrm{~mL}$ of anhydrous diglyme into a round-bottom Schlenk reaction flask. Add $5 \mathrm{~mL}$ of $1 \mathrm{M} \mathrm{BH}_{3} / \mathrm{THF}$ solution. If there is evolution of $\mathrm{H}_{2}$, add more $\mathrm{BH}_{3} / \mathrm{THF}$ until no further gas evolution is observed. Following completion of the borane-THF solution, bubble Ar first and then $\mathrm{CO}$ through the solution for 30 minutes each.

2. Weigh about $100 \mathrm{mg}$ of dried $\left[\mathrm{Bu}_{4} \mathrm{~N}\right]\left[\mathrm{TcOCl}_{4}\right]$ solid and dissolve the solid into $5 \mathrm{~mL}$ anhydrous diglyme under Ar.

3. Add the $\left[\mathrm{Bu}_{4} \mathrm{~N}\right]\left[\mathrm{TcOCl}_{4}\right] /$ diglyme solution drop-wise to the diglyme $/ \mathrm{BH}_{3} / \mathrm{THF}$ solution while stirring under a $\mathrm{CO}$ atmosphere. The resulting solution should turn yellow. If there is generation of $\mathrm{H}_{2}$ from the solution, add additional $\mathrm{BH}_{3}$ /THF until no further bubbling is observed. Next, increase the reaction solution temperature to about $110{ }^{\circ} \mathrm{C}$.

(Experimental note: to closely monitor the $\mathrm{CO}$ flux during the reaction and prevent pressure build-up in the reaction flask, the gas outlet line should be connected with a gas bubbler filled with water.)

4. Monitor the color of the reaction mixture. When the yellow color is gone and reaction mixture becomes colorless, cool the solution to room temperature. Reduce the volume of the reaction mixture by passing Ar over the solution in the absence of active heating.

5. Weigh out $200 \mathrm{mg}$ of solid $\mathrm{Et}_{4} \mathrm{NCl}$ and add the solid to the reaction solution. Heat the solution to $90{ }^{\circ} \mathrm{C}$ while stirring under an Ar atmosphere. A white $\left[\mathrm{Et}_{4} \mathrm{~N}\right]_{2}\left[\mathrm{Tc}(\mathrm{CO})_{3} \mathrm{Cl}_{3}\right]$ precipitate should form.

6. Filter the obtained product, wash it with excess diethyl ether, and dry.

The overall yield for this two-step reaction was calculated to be $75 \%$ based on ammonium pertechnetate. 
The obtained $\left[\mathrm{Tc}(\mathrm{CO})_{3} \mathrm{Cl}_{3}\right]^{2-}$ precursor can then be easily converted to the aqua complex $\left[\mathrm{Tc}(\mathrm{CO})_{3}\left(\mathrm{H}_{2} \mathrm{O}\right)_{3}\right]^{+}$by the exchange reaction 3 .

$$
\left[\mathrm{Tc}(\mathrm{CO})_{3} \mathrm{Cl}_{3}\right]^{2-}+3 \mathrm{H}_{2} \mathrm{O} \quad \stackrel{\mathrm{H}_{2} \mathrm{O}}{\Delta} \quad\left[\mathrm{Tc}(\mathrm{CO})_{3}\left(\mathrm{H}_{2} \mathrm{O}\right)_{3}\right]^{+}+3 \mathrm{Cl}^{-}
$$

\subsubsection{Characterization of the $\left[\mathrm{Tc}(\mathrm{CO})_{3}\right]^{+}$species}

\subsubsection{Characterization of the $\left[\mathrm{Tc}(\mathrm{CO})_{3} \mathrm{Cl}_{3}\right]^{2-}$ reaction product}

The $\left[\mathrm{Et}_{4} \mathrm{~N}\right]_{2}\left[\mathrm{Tc}(\mathrm{CO})_{3} \mathrm{Cl}_{3}\right]$ product was characterized by several spectroscopic techniques. The FTIR spectrum of the isolated solid $\left[\mathrm{Et}_{4} \mathrm{~N}\right]_{2}\left[\mathrm{Tc}(\mathrm{CO})_{3} \mathrm{Cl}_{3}\right]$ (Figure 5.1) showed the presence of the product compound's characteristic CO vibration bands at 2018, 1914 (shoulder), and $1892 \mathrm{~cm}^{-1}$. These bands have been attributed to the compound's symmetric in-plane, symmetric out-of-plane, and asymmetric stretches (Alberto et al. 1995; Dattelbaum et al. 2002). The positions of the observed characteristic bands are in agreement with the ones reported by Alberto et al. (1995) (shown in the parentheses): including 2018 (2028), 1892 (1902), 1463 (1458), 1186 (1184), 798 (798), 667 (668), 635 (638), and 503 (500) $\mathrm{cm}^{-1}$.

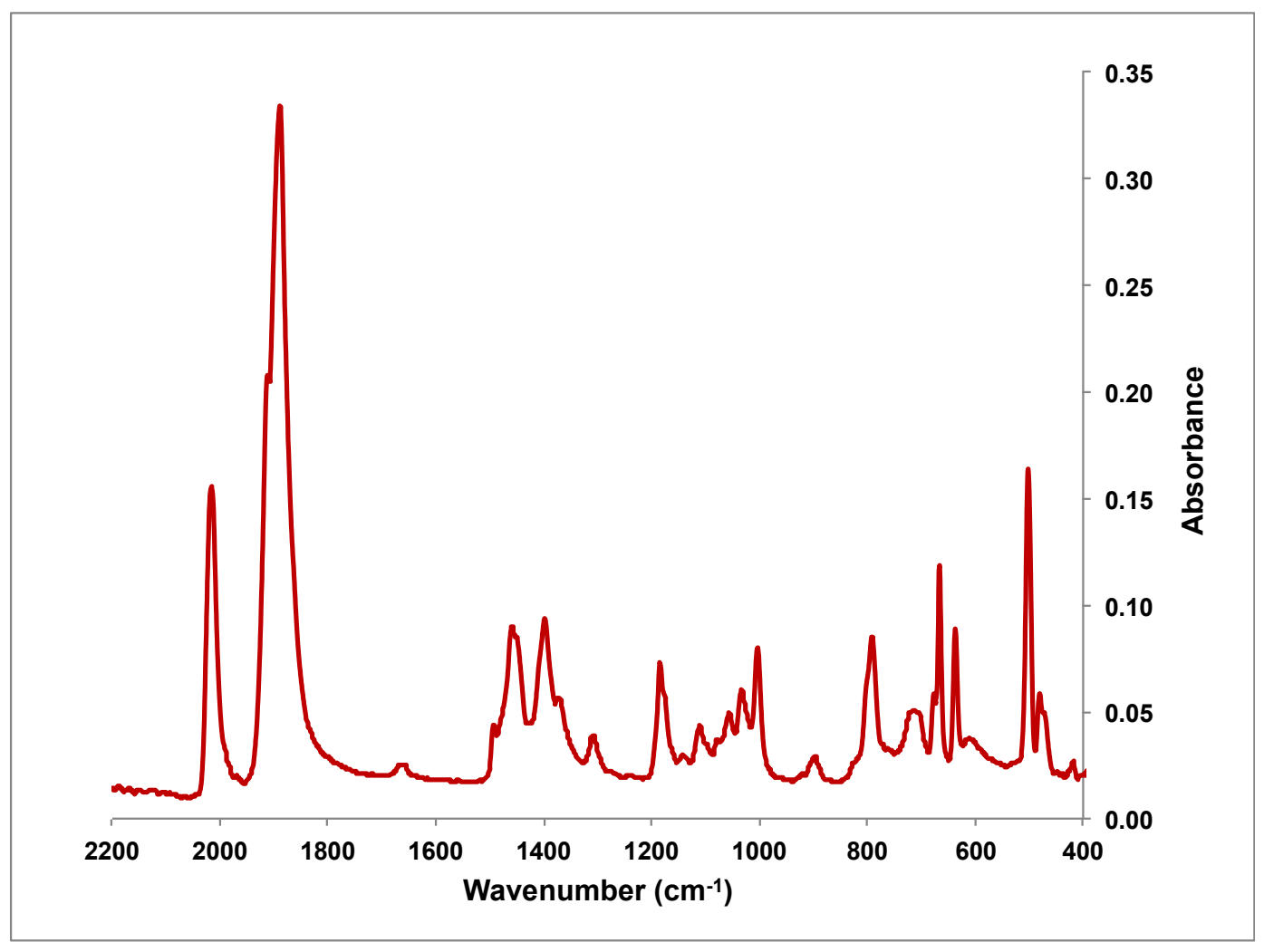

Figure 5.1. FTIR Spectrum of the Solid $\left[\mathrm{Et}_{4} \mathrm{~N}\right]_{2}\left[\mathrm{Tc}(\mathrm{CO})_{3} \mathrm{Cl}_{3}\right]$ Product

Solid $\left[\mathrm{Et}_{4} \mathrm{~N}\right]_{2}\left[\mathrm{Tc}(\mathrm{CO})_{3} \mathrm{Cl}_{3}\right]$ was dissolved in acetonitrile and FTIR, ${ }^{99} \mathrm{Tc}$ NMR, UV-vis, and ESI-MS spectra (Figures 5.2, 5.3, 5.4, and 5.5, respectively) were collected. 
The FTIR spectrum of the solution of the $\left[\mathrm{Tc}(\mathrm{CO})_{3} \mathrm{Cl}_{3}\right]^{2-}$ in acetonitrile (Figure 5.2) was found to be very similar to that of solid material. The characteristic $\mathrm{CO}$ vibrations at 2025, 1932 (shoulder), and $1897 \mathrm{~cm}^{-1}$ were observed.

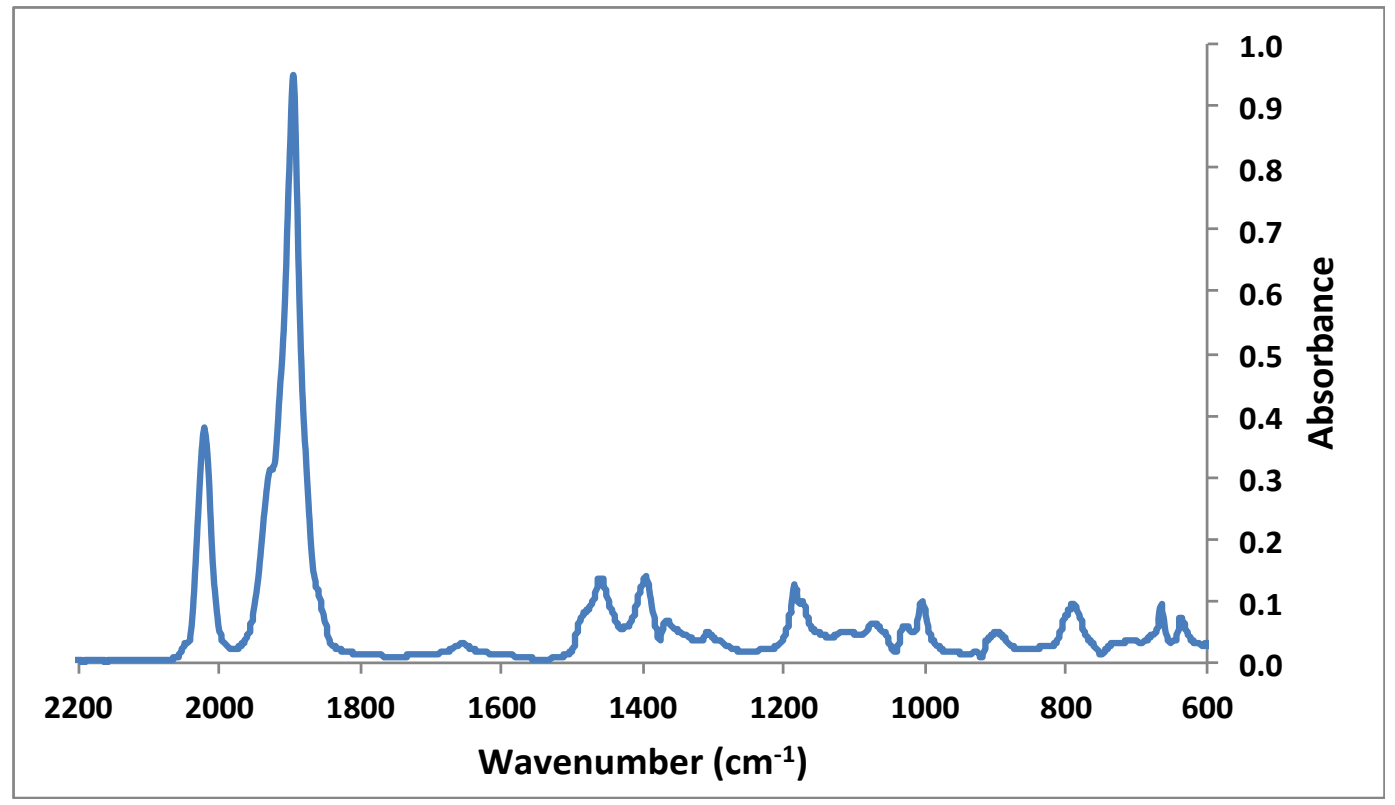

Figure 5.2. FTIR Spectrum of the Solution of $\left[\mathrm{Et}_{4} \mathrm{~N}_{2}\left[\mathrm{Tc}(\mathrm{CO})_{3} \mathrm{Cl}_{3}\right]\right.$ in Acetonitrile

The ${ }^{99} \mathrm{Tc}$ NMR spectrum showed two sharp resonances at -1128 and $-1136 \mathrm{ppm}$ (Figure 5.3B). The NMR resonance of the $\left[\mathrm{Tc}(\mathrm{CO})_{3} \mathrm{Cl}_{3}\right]^{2-}$ in aqueous chloride solution was previously reported at $-1008 \mathrm{ppm}$ (Gorshkov et al. 2003). It has been shown that conversion of the $\left[\mathrm{Tc}(\mathrm{CO})_{3} \mathrm{Cl}_{3}\right]^{2-}$ complex to $\left[\mathrm{Tc}(\mathrm{CO})_{3}(\mathrm{MeCN})_{3}\right]^{+}$is facile (Alberto et al. 1995). The ${ }^{99} \mathrm{Tc}$ NMR resonance of the $\left[\mathrm{Tc}(\mathrm{CO})_{3}(\mathrm{MeCN})_{3}\right]^{+}$ complex was reported at $-2853 \mathrm{ppm}$ (Mikhalev 2005). Based on this information the observed -1128 and $-1136 \mathrm{ppm}$ resonances were speculatively assigned to the mixed $\left[\mathrm{Tc}(\mathrm{CO})_{3} \mathrm{Cl}_{\mathrm{n}}(\mathrm{MeCN})_{3-\mathrm{n}}\right]^{1-\mathrm{n}}$ species. No resonance is observed around $0 \mathrm{ppm}$; the absence of the pertechnetate resonance denotes the completion of the reduction process so that the $\mathrm{Tc}(\mathrm{I})$ product is the only $\mathrm{Tc}$ species in the reaction mixture (Figure 5.3A). 


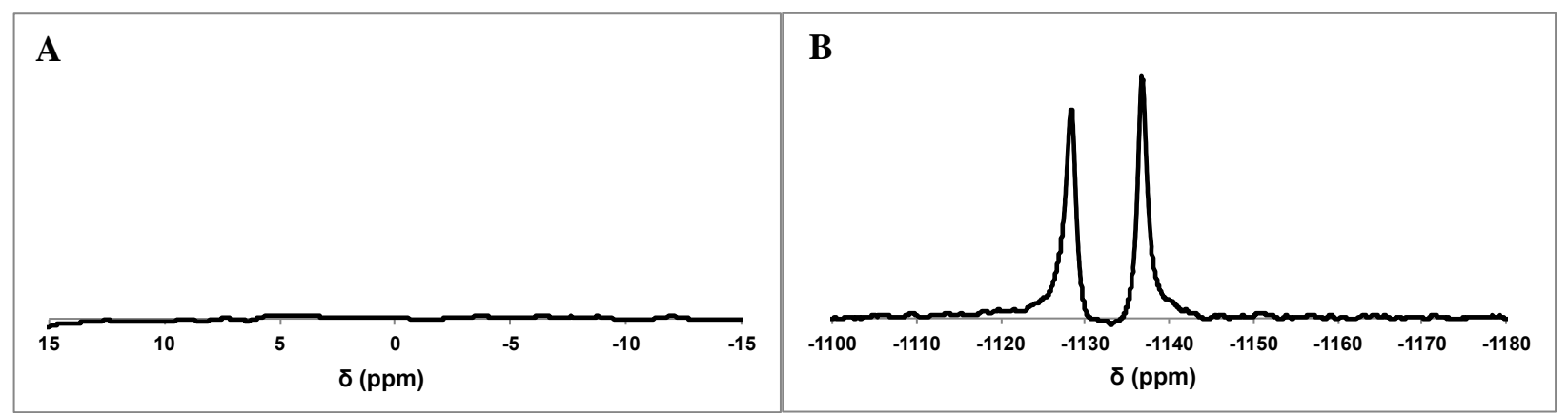

Figure 5.3. Technetium-99 NMR Spectrum of the $\left[\mathrm{Et}_{4} \mathrm{~N}\right]_{2}\left[\mathrm{Tc}(\mathrm{CO})_{3} \mathrm{Cl}_{3}\right]$ Solution in Acetonitrile:

(A) $\mathrm{Tc}$ (VII) pertechnetate spectral region around $0 \mathrm{ppm}$ showing the absence of the $\mathrm{TcO}_{4}{ }^{-}$ signal, and (B) Tc(I)-tricarbonyl region showing two resonances at -1128 and $-1136 \mathrm{ppm}$ assigned to the $\left[\mathrm{Tc}(\mathrm{CO})_{3} \mathrm{Cl}_{\mathrm{n}}(\mathrm{MeCN})_{3-\mathrm{n}}\right]^{1-\mathrm{n}}$ species.

The UV-vis spectrum of the $\left[\mathrm{Et}_{4} \mathrm{~N}\right]_{2}\left[\mathrm{Tc}(\mathrm{CO})_{3} \mathrm{Cl}_{3}\right]$ solution in acetonitrile exhibited one strong band at $276 \mathrm{~nm}$ (Figure 5.4, left pane) and a weak band at $342 \mathrm{~nm}$ (Figure 5.4, right pane).

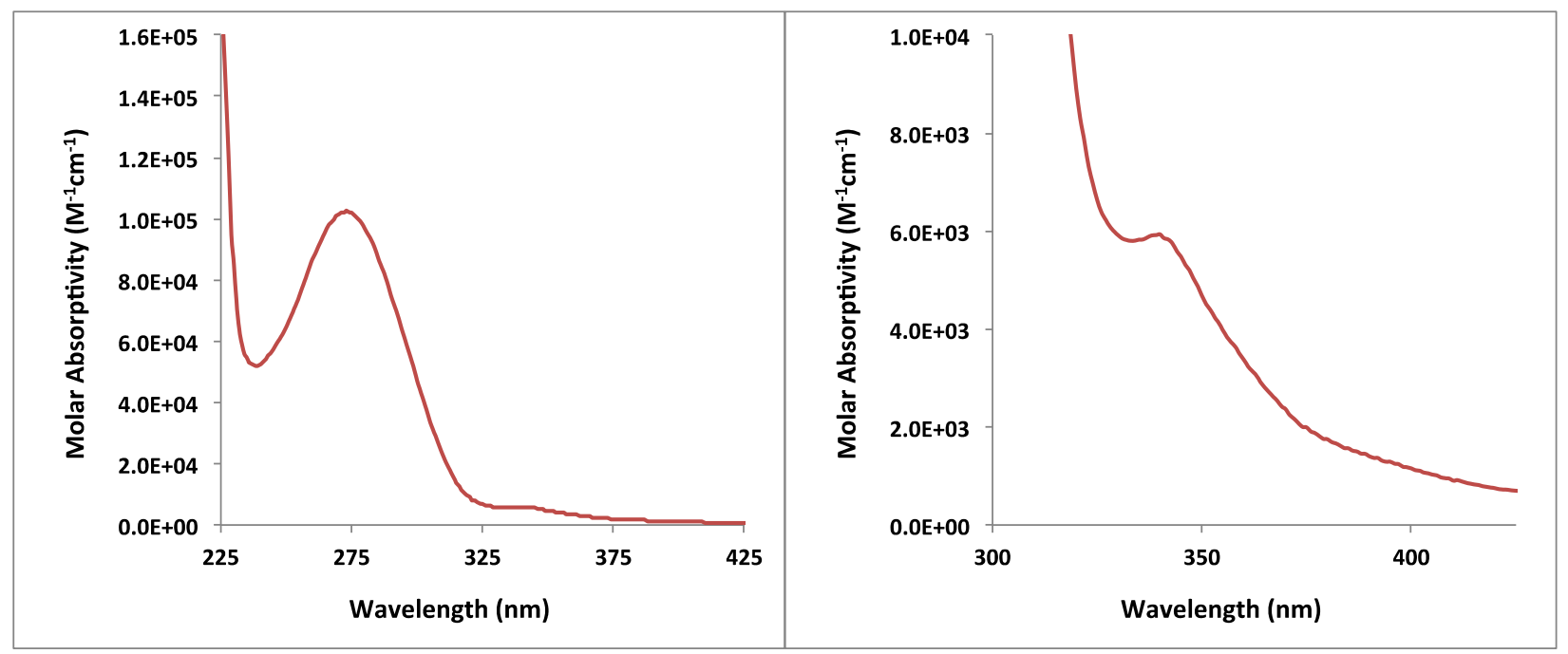

Figure 5.4. UV-vis Spectrum of the $\left[\mathrm{Et}_{4} \mathrm{~N}\right]_{2}\left[\mathrm{Tc}(\mathrm{CO})_{3} \mathrm{Cl}_{3}\right]$ Solution in Acetonitrile 


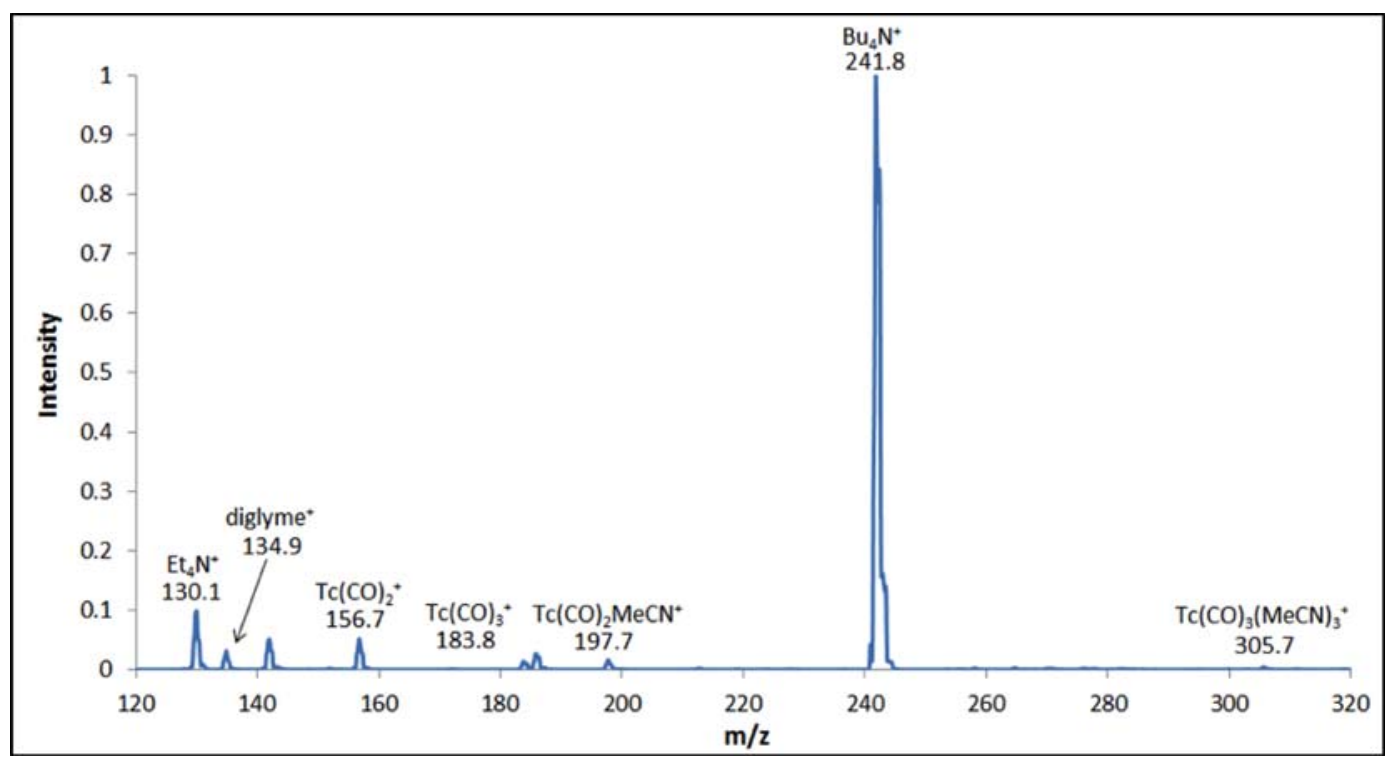

Figure 5.5. ESI-MS Spectrum Normalized to the $\mathrm{Bu}_{4} \mathrm{~N}^{+}$Band with $\mathrm{m} / \mathrm{z}=241.8$, Positive Ionization Mode, of the $\left[\mathrm{Et}_{4} \mathrm{~N}\right]_{2}\left[\mathrm{Tc}(\mathrm{CO})_{3} \mathrm{Cl}_{3}\right]$ Solution in Acetonitrile

The ESI-MS spectrum collected in the positive ionization mode exhibited the peak at $\mathrm{m} / \mathrm{z}$ ratio of 183 characteristic for the $\left[\mathrm{Tc}(\mathrm{CO})_{3}\right]^{+}$moiety (Figure 5.5). No peaks due to the $\left[\mathrm{Tc}(\mathrm{CO})_{3} \mathrm{Cl}_{3}\right]^{2-}$ complex were found in either the negative or positive ESI-MS modes. Instead, the $\left[\mathrm{Tc}(\mathrm{CO})_{3}(\mathrm{MeCN})_{3}\right]^{+}$species at $\mathrm{m} / \mathrm{z}$ of 305 were identified in the spectrum. The largest peak in the spectrum corresponds to the terabutylammonium cation, so it is likely that a mixed $\left[\mathrm{Et}_{4} \mathrm{~N} / \mathrm{Bu}_{4} \mathrm{~N}\right]_{2}\left[\mathrm{Tc}(\mathrm{CO})_{3} \mathrm{Cl}_{3}\right]$ salt is the reaction product. Some co-precipitation of the $\left[\mathrm{Bu}_{4} \mathrm{~N}\right] \mathrm{Cl}$ salt along with the reaction product also is possible.

\subsubsection{Characterization of the aqueous $\left[\mathrm{Tc}(\mathrm{CO})_{3}\right]^{+}$species}

Aqueous $\left[\mathrm{Tc}(\mathrm{CO})_{3}\right]^{+}$species were obtained by dissolving the $\left[\mathrm{Tc}(\mathrm{CO})_{3} \mathrm{Cl}_{3}\right]^{2-}$ precursor in either water or $5 \mathrm{M} \mathrm{NaNO}_{3}$ at a $\mathrm{pH}$ of 3,7 , or 14 and then were characterized by ${ }^{99} \mathrm{Tc} \mathrm{NMR}$. The $\mathrm{pH}$ adjustment was achieved by adding either $\mathrm{HNO}_{3}$ or $\mathrm{NaOH}$ to the test solution. In aqueous solution the chloride ligands coordinated to the $\mathrm{Tc}(\mathrm{I})$-tricarbonyl center are readily exchanged by $\mathrm{H}_{2} \mathrm{O}$ (Equation 3), and could likely be exchanged by $\mathrm{OH}^{-}$as well; the specific products formed depend on the solution composition. The observed ${ }^{99} \mathrm{Tc}$ resonances and corresponding assigned $\left[\mathrm{Tc}(\mathrm{CO})_{3}\right]^{+}$species are listed in Table 5.1. The ${ }^{99} \mathrm{Tc}$ resonances assignments were done based on comparison to previously reported chemical shifts and band half-widths (Gorshkov et al. 2000; Alberto et al. 1998). The same aqueous Tc(I) complexes were formed in water and $5 \mathrm{M} \mathrm{NaNO}_{3}$ solutions at the tested $\mathrm{pH}$ as evident from the nearly identical positions of the ${ }^{99} \mathrm{Tc}$ NMR resonances. In the acidic and near-neutral solutions, the reaction product was $\left[\mathrm{Tc}(\mathrm{CO})_{3}\left(\mathrm{H}_{2} \mathrm{O}\right)_{3}\right]^{+}$, identified by its characteristic resonance at about $-866 \mathrm{ppm}$. In the alkaline solutions examined, the only product observed was the hydrolyzed $\left[\mathrm{Tc}(\mathrm{CO})_{3}(\mathrm{OH})\left(\mathrm{H}_{2} \mathrm{O}\right)_{2}\right]$ species, identified by its characteristic resonance at $-1062 \mathrm{ppm}$. 
Table 5.1. Techetium-99-NMR Characterization of the Aqueous Reaction Products

\begin{tabular}{|c|c|c|c|c|}
\hline Solution & $\begin{array}{l}\text { Solution } \\
\text { Acidity }\end{array}$ & $\begin{array}{c}\text { Chemical Shift of } \\
{ }^{99} \text { Tc Resonance, ppm }\end{array}$ & $\begin{array}{l}\text { Half-width of }{ }^{99} \mathrm{Tc} \\
\text { Resonance, } \mathrm{Hz}\end{array}$ & $\begin{array}{l}\text { Assignment of }{ }^{99} \mathrm{Tc} \\
\text { Resonance }\end{array}$ \\
\hline \multirow{3}{*}{ Water } & $\mathrm{pH}=3$ & -867 & 100 & {$\left[\mathrm{Tc}(\mathrm{CO})_{3}\left(\mathrm{H}_{2} \mathrm{O}\right)_{3}\right]^{+\mathrm{a}, \mathrm{b}}$} \\
\hline & $\mathrm{pH}=6-7$ & -870 & 100 & {$\left[\mathrm{Tc}(\mathrm{CO})_{3}\left(\mathrm{H}_{2} \mathrm{O}\right)_{3}\right]^{+\mathrm{a}, \mathrm{b}}$} \\
\hline & $\mathrm{pH}=14$ & -1062 & 90 & {$\left[\mathrm{Tc}(\mathrm{CO})_{3}(\mathrm{OH})\left(\mathrm{H}_{2} \mathrm{O}\right)_{2}\right]^{\mathrm{a}, \mathrm{b}}$} \\
\hline \multirow{3}{*}{$5 \mathrm{M} \mathrm{NaNO}_{3}$} & $\mathrm{pH}=3$ & $\begin{array}{c}-869 \\
-902 \text { (very weak) }\end{array}$ & 120 & $\begin{array}{l}{\left[\mathrm{Tc}(\mathrm{CO})_{3}\left(\mathrm{H}_{2} \mathrm{O}\right)_{3}\right]^{+\mathrm{a}, \mathrm{b}}} \\
{\left[\mathrm{Tc}(\mathrm{CO})_{4}\left(\mathrm{H}_{2} \mathrm{O}\right)_{2}\right]^{+\mathrm{a}}}\end{array}$ \\
\hline & $\mathrm{pH}=6-7$ & $\begin{array}{c}-867 \\
-902 \text { (very weak) }\end{array}$ & 100 & $\begin{array}{l}{\left[\mathrm{Tc}(\mathrm{CO})_{3}(\mathrm{OH})\left(\mathrm{H}_{2} \mathrm{O}\right)_{2}\right]^{\mathrm{a}, \mathrm{b}}} \\
\quad\left[\mathrm{Tc}(\mathrm{CO})_{4}\left(\mathrm{H}_{2} \mathrm{O}\right)_{2}\right]^{+\mathrm{a}}\end{array}$ \\
\hline & $\mathrm{pH}=14$ & -1062 & 100 & {$\left[\mathrm{Tc}(\mathrm{CO})_{3}(\mathrm{OH})\left(\mathrm{H}_{2} \mathrm{O}\right)_{2}\right]^{\mathrm{a}, \mathrm{b}}$} \\
\hline
\end{tabular}

a. Assignment is based on the report by Gorshkov et al. (2000).

b. Assignment is based on the report by Alberto et al. (1998).

FTIR spectra of the aqueous $\left[\mathrm{Tc}(\mathrm{CO})_{3}\right]^{+}$system were acquired both in water at $\mathrm{pH}$ of 7 and in $1 \mathrm{M}$ $\mathrm{NaOH}$ solutions (Figure 5.6) and were found to be very similar to that of solid $\left(\mathrm{NEt}_{4}\right)_{2}\left[\mathrm{Tc}(\mathrm{CO})_{3} \mathrm{Cl}_{3}\right]$. The FTIR spectra possess the characteristic $\mathrm{CO}$ vibration pattern found in acetonitrile solutions of

$\left[\mathrm{Tc}(\mathrm{CO})_{3} \mathrm{Cl}_{3}\right]^{2-}$ (Figure 5.2), but with the peak's maxima significantly shifted to lower energy. This shift to lower energy is suggestive of an exchange of the starting material's chloride ligands with water or hydroxide. The bands' positions are at 2037, 1941, and $1912 \mathrm{~cm}^{-1}$ in water and at 2037, 1994, and $1915 \mathrm{~cm}^{-1}$ in $1 \mathrm{M} \mathrm{NaOH}$. The FTIR spectra of the $\left[\mathrm{Tc}(\mathrm{CO})_{3}\right]^{+}$in $5 \mathrm{M} \mathrm{NaNO}_{3}$ were found to be very similar to that observed in water. 


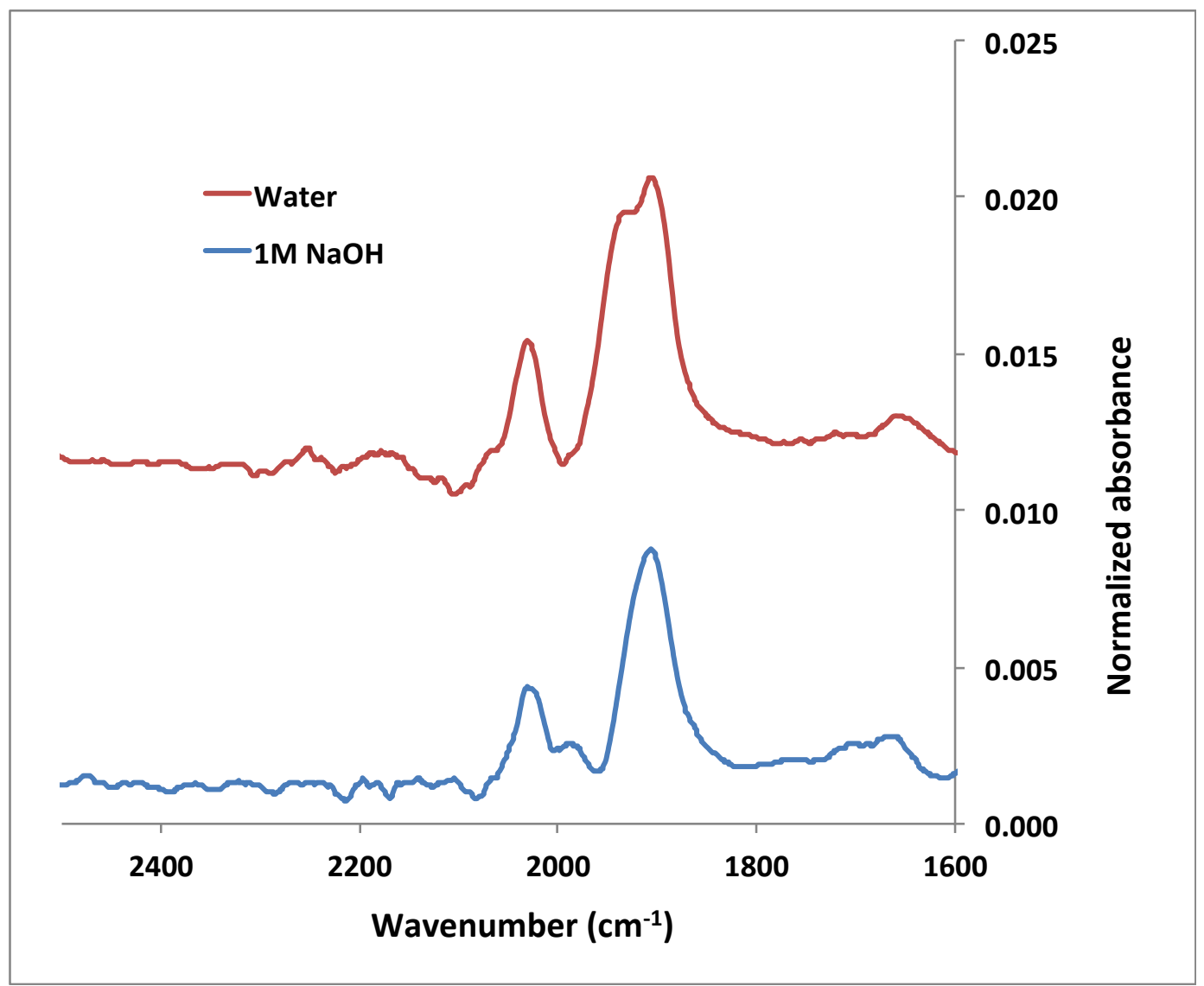

Figure 5.6. FTIR Spectra of the Aqueous $\left[\mathrm{Tc}(\mathrm{CO})_{3}\right]^{+}$Solutions

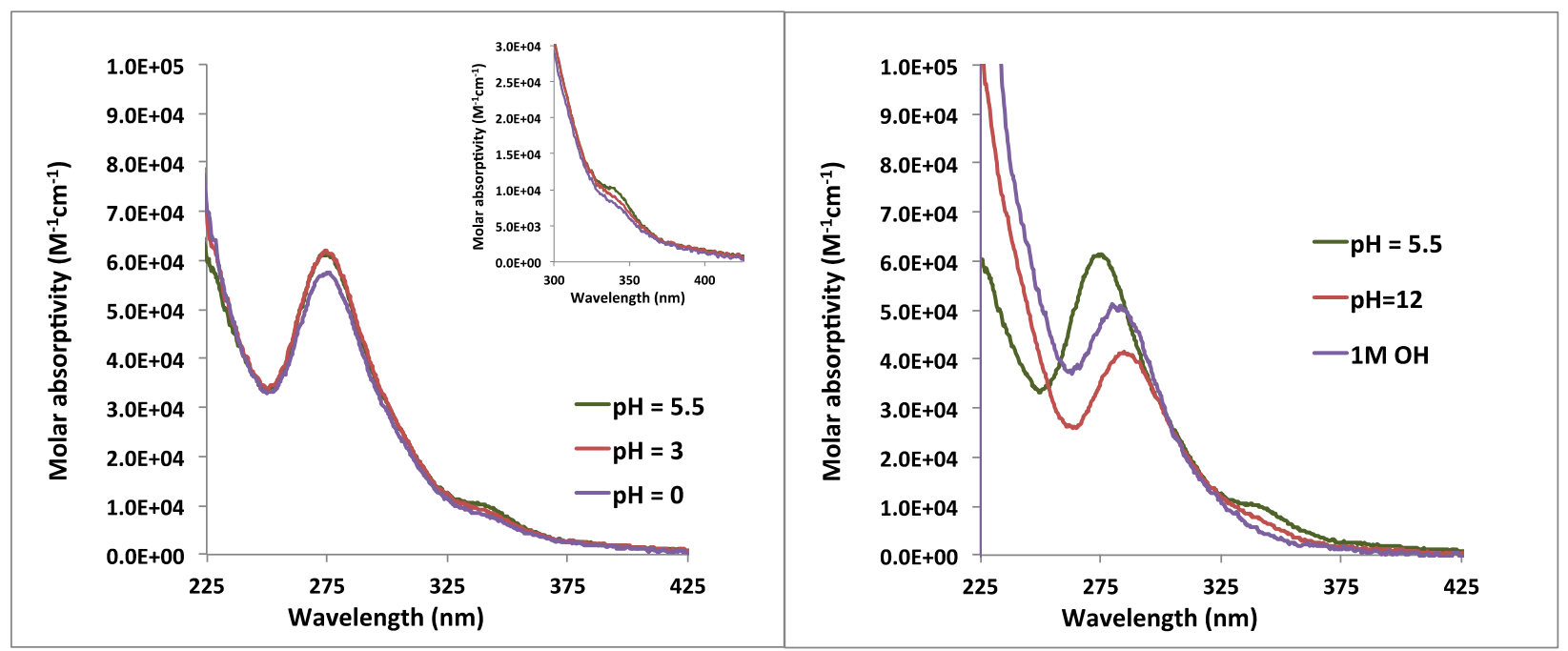

Figure 5.7. UV-vis Spectra of the Aqueous $\left[\mathrm{Tc}(\mathrm{CO})_{3}\right]^{+}$Solutions

$\mathrm{UV}$-vis spectra of the aqueous $\left[\mathrm{Tc}(\mathrm{CO})_{3}\right]^{+}$solutions were collected in water, with the $\mathrm{pH}$ adjusted using either $\mathrm{HCl}$ or $\mathrm{NaOH}$. It is not possible to obtain any analogous spectra in the nitrate solutions 
because $\mathrm{NO}_{3}{ }^{-}$strongly absorbs light in the UV region. The resulting spectra are shown in Figure 5.7. In acidic solution, the $\left[\mathrm{Tc}(\mathrm{CO})_{3}\left(\mathrm{H}_{2} \mathrm{O}\right)_{3}\right]^{+}$species dominates, and near identical spectra were obtained over the $\mathrm{pH}$ range $0-5.5$ (Figure 5.7, left pane). An intense UV band is apparent at $271 \mathrm{~nm}$, and a weaker band is observed at $337 \mathrm{~nm}$. In alkaline solution, the UV band undergoes a slight red shift and decrease in intensity (Figure 5.7, right pane) upon the formation of the hydrolyzed $\left[\mathrm{Tc}(\mathrm{CO})_{3}(\mathrm{OH})_{\mathrm{x}}\left(\mathrm{H}_{2} \mathrm{O}\right)_{3-\mathrm{x}}\right]$ species. The spectral profiles suggest that the weak, lower-energy band disappears with increasing $\mathrm{pH}$.

\subsubsection{Preparation and characterization of the aqueous $\left[\mathrm{Tc}(\mathrm{CO})_{3}\right]^{+}$gluconate complex}

The $\left[\mathrm{Tc}(\mathrm{CO})_{3}\right]^{+}$gluconate complex was obtained by the dissolution of the $\left[\mathrm{Tc}(\mathrm{CO})_{3} \mathrm{Cl}_{3}\right]^{2-}$ precursor into $5 \mathrm{M} \mathrm{NaNO}_{3}$ and then adding the resulting solution to a $5 \mathrm{M} \mathrm{NaNO}_{3} / 1 \mathrm{M} \mathrm{NaOH} / 0.5 \mathrm{M}$ sodium gluconate mixture in a 1:1 ratio. The ${ }^{99} \mathrm{Tc}$ NMR spectrum of the resulting solution showed two bands at -1233 and $-1253 \mathrm{ppm}$ with the half-widths of about $300 \mathrm{~Hz}$. The positions and profiles of these resonances were observed to be very similar for the $\left[\mathrm{Tc}(\mathrm{CO})_{3}\right]^{+}$gluconate samples previously observed in water (Rapko et al. 2013b).

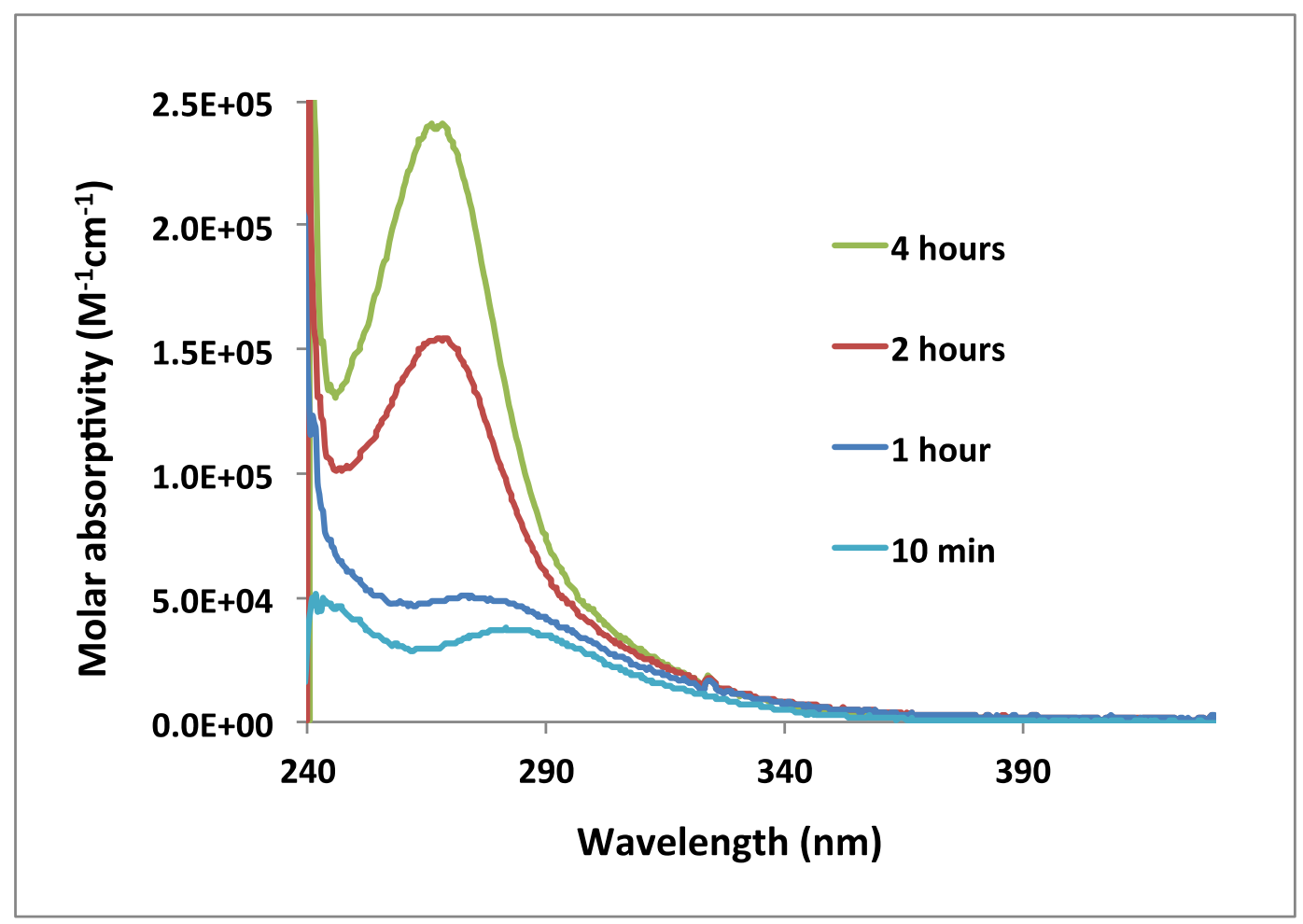

Figure 5.8. Time Dependent UV-vis Spectra of the $\left[\mathrm{Tc}(\mathrm{CO})_{3}\right]^{+}$Gluconate Complex

To characterize the $\left[\mathrm{Tc}(\mathrm{CO})_{3}\right]^{+}$gluconate complex by UV-vis spectroscopy, the test sample was prepared by the dissolution of the solid $\left[\mathrm{Tc}(\mathrm{CO})_{3} \mathrm{Cl}_{3}\right]^{2-}$ precursor into a $1 \mathrm{M} \mathrm{NaOH} / 0.5 \mathrm{M}$ sodium gluconate solution in the absence of nitrate. The resulting time-dependent spectra are shown in Figure 5.8. The initial spectrum, collected about 10 minutes after solution preparation, exhibited a band at about $282 \mathrm{~nm}$. The frequency and molar absorptivity of this band are nearly identical to those observed 
for the $\left[\mathrm{Tc}(\mathrm{CO})_{3}(\mathrm{OH})\left(\mathrm{H}_{2} \mathrm{O}\right)_{2}\right]$ species in $1 \mathrm{M} \mathrm{NaOH}$ solution containing no gluconate (Figure 5.7). With time, the in-growth of a new band at $264 \mathrm{~nm}$ was observed. This band is assigned to the $\left[\mathrm{Tc}(\mathrm{CO})_{3}\right]^{+}$ gluconate complex. The intensity of this band reached maximum at about 4 hours post-solution preparation and exhibits significantly greater molar absorptivity than the UV bands corresponding to the other aqueous $\left[\mathrm{Tc}(\mathrm{CO})_{3}\right]^{+}$species. Such slow kinetic formation of the $\left[\mathrm{Tc}(\mathrm{CO})_{3}\right]^{+}$gluconate complex formation in solution was previously observed in earlier studies (Rapko et al. 2013b).

\subsubsection{COSMO prediction of the ${ }^{99} \mathrm{Tc}$ NMR spectra for fac-Tc $(\mathrm{CO})_{3}{ }^{+}$}

Chemical shifts of technetium-99 for the investigated $\mathrm{fac}-\mathrm{Tc}(\mathrm{CO})_{3}{ }^{+}$compounds in water were calculated using the screening continuum solvation model COSMO. All calculations, geometry optimization, and magnetic response properties were performed at the B3LYP-DFT level of theory with the Def-TZVPP basis set. Spin-orbit coupling and relativistic effects were included with the zeroth order regular approximation (ZORA). Solvent effects of an aqueous solution were included with the implicit solvation model Conductor-like Screening Model (COSMO). The dielectric constant of water, 80.4 at $20{ }^{\circ} \mathrm{C}$, was used for the COSMO model. The gauge-including atomic orbital (GIAO) approach was used to calculate the NMR-related magnetic response properties. All chemical shifts are referenced to $\mathrm{TcO}_{4}{ }^{-}$: $\mathrm{d}=$ sref $-\mathrm{s}$ where $\mathrm{d}$ is the chemical shift of the compound of interest, sref is the reference compound's calculated magnetic shielding, and $\mathrm{s}$ is the calculated magnetic shielding of the compound of interest. The predicted and experimental ${ }^{99} \mathrm{Tc}$ NMR chemical shifts are in excellent agreement for all species except the gluconate complex as is evident from Table 5.2.

Table 5.2. Comparison of the Calculated and Experimental ${ }^{99}$ Tc NMR Chemical Shifts for the $\left[\mathrm{Tc}(\mathrm{CO})_{3}\right]^{+}$Species in Water

\begin{tabular}{|c|c|c|}
\hline Species & $\begin{array}{c}\text { Calculated Chemical } \\
\text { Shift (ppm) }\end{array}$ & $\begin{array}{c}\text { Experimental Chemical } \\
\text { Shift (ppm) }\end{array}$ \\
\hline$\left[\mathrm{Tc}(\mathrm{CO})_{3}\left(\mathrm{H}_{2} \mathrm{O}\right)_{3}\right]^{+}$ & -834 & -868 \\
\hline$\left[\mathrm{Tc}(\mathrm{CO})_{3}(\mathrm{OH})\left(\mathrm{H}_{2} \mathrm{O}\right)_{2}\right]$ & -1053 & -1062 \\
\hline$\left[\mathrm{Tc}(\mathrm{CO})_{3}(\mathrm{OH})_{2}\left(\mathrm{H}_{2} \mathrm{O}\right)\right]^{-}$ & -1129 & -1139 \\
\hline$\left[\mathrm{Tc}(\mathrm{CO})_{3}(\mathrm{OH})_{3}\right]^{-}$ & -1308 & Not measured \\
\hline$\left[\mathrm{Tc}(\mathrm{CO})_{3}(\mathrm{OH})_{4}\right.$ & -621 & -585 \\
\hline$\left[\mathrm{Tc}(\mathrm{CO})_{4}\left(\mathrm{H}_{2} \mathrm{O}\right)_{2}\right]^{+}$ & -983 & -902 \\
\hline$\left[\mathrm{Tc}(\mathrm{CO})_{3}(\mathrm{gluconate})\right]^{2-}$ & -958 & $-1232 /-1254$ \\
\hline
\end{tabular}

In the COSMO calculations, the structure of the Tc(I)-tricarbonyl gluconate complex was assumed to be $\left[\mathrm{Tc}(\mathrm{CO})_{3} \text { (gluconate) }\right]^{2-}$ where gluconate is bound to $\mathrm{Tc}(\mathrm{I})$ via two hydroxyl and one carboxyl oxygen atoms (Figure 1.1c) based on the structure proposed by Lukens et al. (2004). Poor agreement between the calculated and experimental chemical shift suggests the presence of a molecule with a different structure, e.g., where gluconate is bound through three hydroxyl oxygen atoms (Figure 1.1d). Note that NMR shows two equal intensity signals, which could indicate a gluconate bridging two $\left[\mathrm{Tc}(\mathrm{CO})_{3}\right]^{+}$groups. Another possible explanation is formation of the mixed hydroxo-gluconate $\left[\mathrm{Tc}(\mathrm{CO})_{3}(\mathrm{OH})_{\mathrm{n}}(\text { gluconate })\right]^{\mathrm{n}-2}$ complexes. In this mixed hydroxo-gluconate, the hydroxide ion is expected to increase the electron density and shielding of the ${ }^{99} \mathrm{Tc}$ nucleus, causing moving chemical shift of the $\left[\mathrm{Tc}(\mathrm{CO})_{3}(\mathrm{OH})_{\mathrm{n}}(\text { gluconate })\right]^{\mathrm{n}-2}$ species up-field in comparison with the $\left[\mathrm{Tc}(\mathrm{CO})_{3}\right.$ (gluconate $\left.)\right]^{2-}$ complex. This trend is evident for the successive substitution of $\mathrm{H}_{2} \mathrm{O}$ of the species $\left[\mathrm{Tc}(\mathrm{CO})_{3}\left(\mathrm{H}_{2} \mathrm{O}\right)_{3}\right]^{+}$by hydroxide 
upon hydrolysis and formation of $\left[\mathrm{Tc}(\mathrm{CO})_{3}(\mathrm{OH})\left(\mathrm{H}_{2} \mathrm{O}\right)_{2}\right]$ and $\left[\mathrm{Tc}(\mathrm{CO})_{3}(\mathrm{OH})_{2}\left(\mathrm{H}_{2} \mathrm{O}\right)\right]^{-}$, causing the respective chemical shifts to move up-field from $-868 \mathrm{ppm}$ to -1062 and $-1139 \mathrm{ppm}$.

\subsubsection{Development of ${ }^{99} \mathrm{Tc}$ EPR characterization technique}

While ${ }^{99} \mathrm{Tc}$ NMR has proven a sensitive technique for the characterization of the chemical species possessing Tc in odd, low-spin oxidation states, identification of the even oxidation states of Tc remains problematic. This difficulty in identification of Tc in even oxidation states affects understanding of the mechanisms of the redox and complexation processes. Technetium in oxidation states of II, IV, and VI has outer electron configuration of $4 \mathrm{~d}^{5}, 4 \mathrm{~d}^{3}$, and $4 \mathrm{~d}^{1}$, respectively, and is therefore paramagnetic. If developed, the EPR method can provide useful information about oxidation state, symmetry, and bonding properties of the Tc compounds in the even oxidation states. To date, the Tc EPR method has been largely applied for the investigation of radiopharmaceutical and nuclear medicine agents (Kirmse and Abram 1990).

Development of the Tc EPR method was initiated using the methylene chloride mother liquor solution produced in the synthesis of the $\left[\mathrm{TcOCl}_{4}\right]^{-}$compound as described in Section 5.1.1. The reduction of pertechnetate with $\mathrm{HCl}$ generates two equilibrium forms of $\mathrm{Tc}(\mathrm{V})$, namely $\left[\mathrm{TcOCl}_{4}\right]^{-}$and

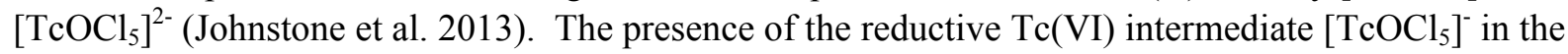
reaction mixture has been suggested, and its EPR spectrum and corresponding magnetic parameters reported (Kirmse et al. 1985). But the possibility remains that the triplet state of $\mathrm{Tc}(\mathrm{V})\left[\mathrm{TcOCl}_{5}\right]^{2-}$ might exist; if so, it should generate its own EPR response. Additionally, the pertechnetate reduction in concentrated $\mathrm{HCl}$ does not stop when $\mathrm{Tc}(\mathrm{V})$ is formed, it proceeds further to the thermodynamically stable $\left[\mathrm{TcCl}_{6}\right]^{2-}$, which has an EPR-active Tc(IV) center (Baldas et al. 1996). So this complex system is especially suited to develop the EPR method for Tc characterization and to understand Tc fundamental chemistry. With this in mind, EPR investigations relevant to the pertechnetate to $\mathrm{Tc}(\mathrm{I})$ reduction were examined.

The EPR spectrum of a liquid $\left[\mathrm{TcOCl}_{4}\right]^{-/}\left[\mathrm{TcOCl}_{5}\right]^{2-}$ sample in methylene chloride was acquired at room temperature and is shown in Figure 5.9. It displays splitting from the coupling of the unpaired electron's spin to the ${ }^{99} \mathrm{Tc}$ nucleus $(\mathrm{I}=9 / 2)$ and shows the characteristic ten-line pattern with $\mathrm{g}_{\text {iso }}=1.95$ and $\mathrm{A}_{\text {iso }}=443 \mathrm{MHz}$, which are typical for a Tc(VI) compound. Upon freezing $(120 \mathrm{~K})$, this species presented a spectrum with rhombic magnetic parameters (Figure 5.10). In addition, a very broad overlapping spectrum from a second species is also evident. To fit the low-temperature spectrum, it first was isolated from the broad spectrum by subtraction. The spin Hamiltonian parameters were then fit using the EasySpin plugin for Matlab. The best-fit spectrum is shown in dashed red (Figure 5.10), and contains all the features of the spectrum except for those that result from insufficient baseline subtraction. The parameters were then used as starting values for the fit of the room temperature spectrum, with the addition of a rotational correlation time (which parameterizes averaging of the anisotropic values by molecular tumbling in solution). When the temperature of the sample was further decreased to $5 \mathrm{~K}$, the $\mathrm{g}=1.95$ spectrum decreased in relative intensity and the very broad spectrum became more evident, Figure 5.11. 


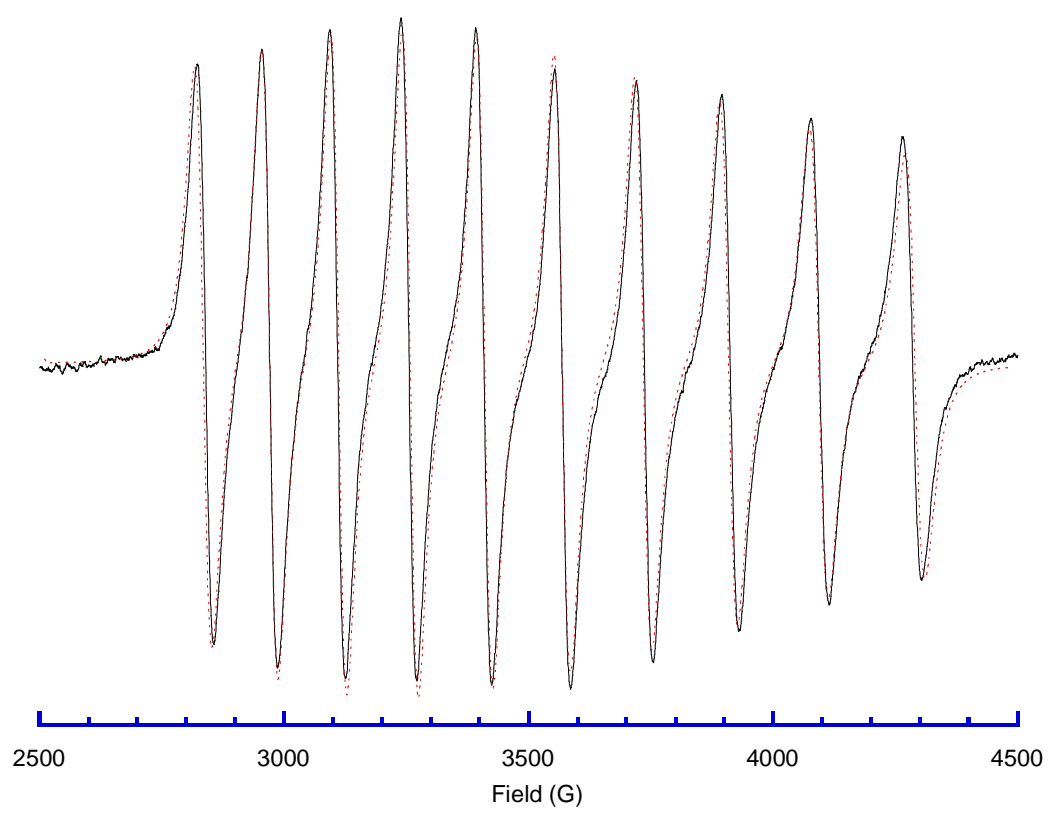

Figure 5.9. Room Temperature EPR Spectrum of the $\left[\mathrm{TcOCl}_{4}\right]^{-/}\left[\mathrm{TcOCl}_{5}\right]^{2-}$ Sample in Methylene Chloride (solid black trace). Microwave frequency was $9.785 \mathrm{GHz}$ at a power of $20 \mathrm{~mW}$. The field was swept over $2000 \mathrm{G}$ in $83 \mathrm{~s}$ with a $5 \mathrm{G}$ modulation and recorded with a $163 \mathrm{~ms}$ time constant. The EasySpin fit is shown by the dotted red trace.

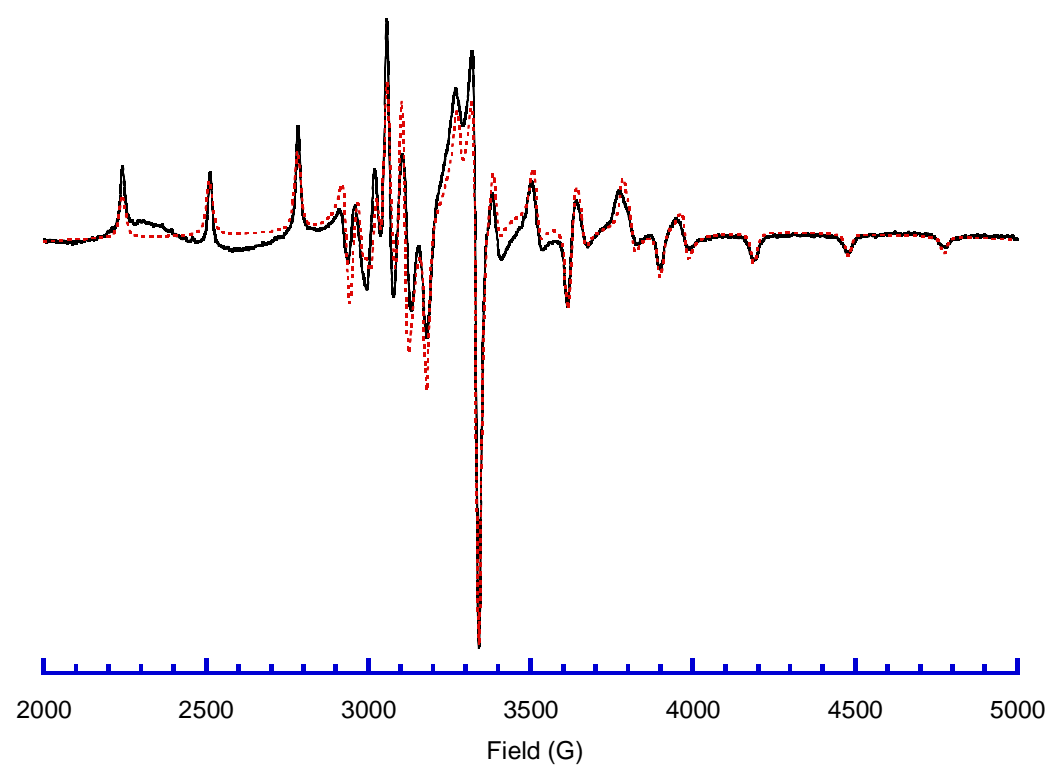

Figure 5.10. EPR Spectrum of the $\left[\mathrm{TcOCl}_{4}\right]^{-/}\left[\mathrm{TcOCl}_{5}\right]^{2-}$ Sample in Methylene Chloride Obtained at $120 \mathrm{~K}$ (solid black trace). Microwave frequency was $9.453 \mathrm{GHz}$ at a power of $20 \mathrm{~mW}$. The field was swept over $2000 \mathrm{G}$ in $83 \mathrm{~s}$ with a $5 \mathrm{G}$ modulation and recorded with a $163 \mathrm{~ms}$ time constant. EasySpin fit is shown by the dotted red trace. 


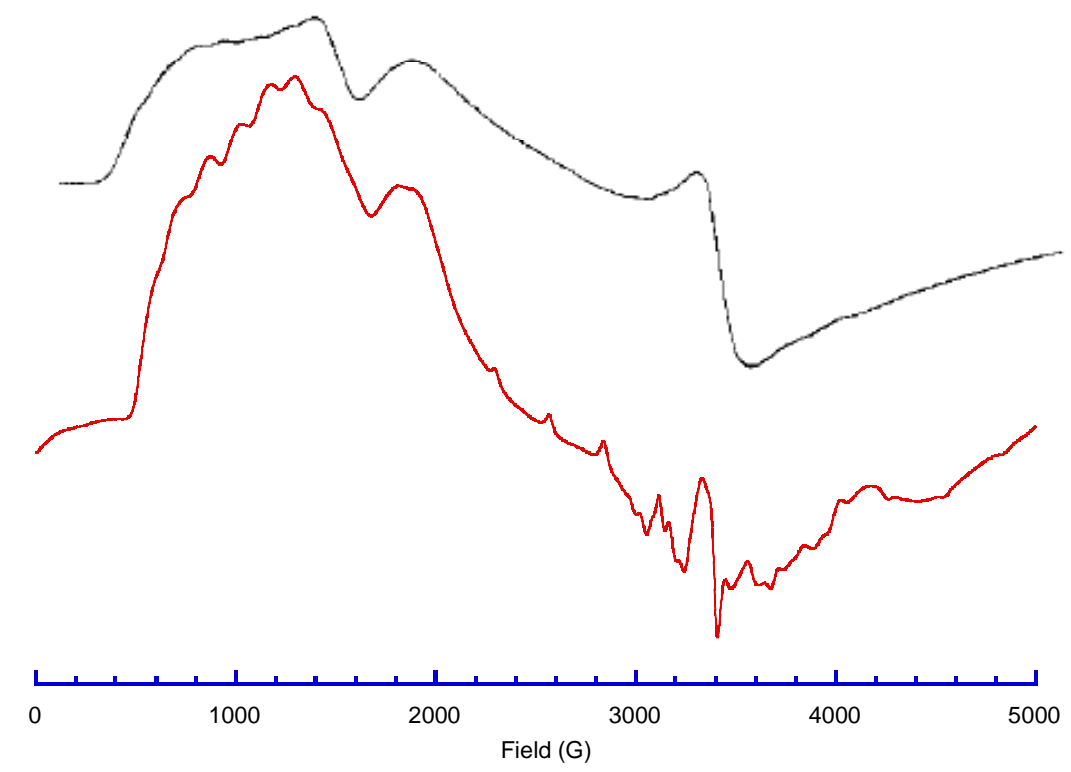

Figure 5.11. Wide Field Sweep EPR Spectrum of the $\left[\mathrm{TcOCl}_{4}\right]^{-/}\left[\mathrm{TcOCl}_{5}\right]^{2-}$ Sample at $5 \mathrm{~K}$ (red trace). A literature spectrum (Baldas et al. 1996) is reproduced for comparison (black trace). This view shows that a very broad spectrum, most likely from a spin $>1 / 2$ species, becomes evident at low temperatures, while the spin $=1 / 2$ species centered at $\mathrm{g} \sim 2$, shown in Figure 5.10, is only faintly visible. Baldas et al. (1996) reported a similar spectrum for $\left[\mathrm{Bu}_{4} \mathrm{~N}\right]_{2}\left[\mathrm{Tc}(\mathrm{IV}) \mathrm{Cl}_{6}\right]$, also in methylene chloride, at $5.7 \mathrm{~K}$.

The spin Hamiltonian parameters derived from fitting the experimental spectra are shown in Table 5.3, along with literature and theory values for $\mathrm{TcOCl}_{5}{ }^{-}$, and literature values for the neutral $\mathrm{TcOCl}_{4}$ compound with its $\mathrm{Tc}(\mathrm{VI})$ center. Literature values, which have been reported in several reviews (Kirmse and Abram 1990; Baldas et al. 1997), for Tc(VI) compounds of the form $\operatorname{TcOX}_{\mathrm{x}}$ and $\mathrm{TcNX}_{\mathrm{x}}$ all have axial $\mathrm{g}$ and $\mathrm{A}$ values with magnitudes very close to the fit values here. The small amount of rhombicity observed here may merely be the result of our use of spectral fitting, a technique not available in the time frame of the bulk of the literature. While the g values from theory are very reasonable, the A values cannot be reconciled with either experiment or literature. At this point, it is clear that the spectrum results from a compound of the type $\left[\mathrm{Tc}(\mathrm{VI}) \mathrm{OCl}_{\mathrm{x}}\right]^{\mathrm{y}-}$, but the elucidation of $\mathrm{x}$ and $\mathrm{y}$ will require further refinement through theoretical methods.

The low-temperature, very broad spectrum likely results from the species with spin $>1 / 2$; either $\mathrm{Tc}(\mathrm{V})$, which can have either a spin of 0 or 1 , or Tc(IV), with a spin of $3 / 2$. No Tc(V) EPR spectra have been reported in the literature even though some compounds have had a measurable magnetic moment, which is indicative of the presence of unpaired spin. Various Tc(IV) EPR spectra have been reported; an example spectrum of $\left[\mathrm{Bu}_{4} \mathrm{~N}_{2}\left[\mathrm{Tc}(\mathrm{IV}) \mathrm{Cl}_{6}\right]\right.$, extracted from Figure 2 in Baldas et al. (1996) and scaled to have the same field axis as our experimental data, is shown in Figure 5.2. While theoretical calculations are underway, the very close resemblance and similar temperature behavior allow us to tentatively identify this species as $\left[\mathrm{Tc}(\mathrm{IV}) \mathrm{Cl}_{6}\right]^{2-}$. 
Table 5.3. Comparison of the Experimental, Calculated, and Literature Magnetic Parameters for $\left[\mathrm{TcOCl}_{\mathrm{x}}\right]^{\mathrm{y}-}$ Species

\begin{tabular}{|l|c|c|c|c|}
\hline \multicolumn{1}{|c|}{ Parameter } & Experiment & $\begin{array}{c}\text { Theory }^{\mathbf{a}} \\
\text { TcOCl }^{-}\end{array}$ & $\begin{array}{c}\text { Literature }^{\mathbf{b}} \\
\text { TcOCl}_{5}{ }^{-}\end{array}$ & $\begin{array}{c}\text { Literature }^{\mathbf{c}} \\
\text { TcOCl }_{\mathbf{4}}\end{array}$ \\
\hline $\mathrm{g}_{\mathrm{x}}$ & 1.9213 & 1.951 & 1.938 & 1.935 \\
\hline $\mathrm{g}_{\mathrm{y}}$ & 1.9356 & 1.951 & 1.938 & 1.935 \\
\hline $\mathrm{g}_{\mathrm{z}}$ & 1.9943 & 2.084 & 2.057 & 2.0535 \\
\hline $\mathrm{g}_{\text {iso }}$ & 1.950 & 1.996 & 1.978 & 1.9745 \\
\hline $\mathrm{A}_{\mathrm{x}}(\mathrm{MHz})$ & -264 & -97.5 & -288 & -276 \\
\hline $\mathrm{A}_{\mathrm{y}}(\mathrm{MHz})$ & -310 & -97.7 & -288 & -276 \\
\hline $\mathrm{A}_{\mathrm{z}}(\mathrm{MHz})$ & -756 & -450.9 & -689 & -683 \\
\hline $\mathrm{A}_{\text {iso }}(\mathrm{MHz})$ & -443 & -215.4 & -422 & -413 \\
\hline
\end{tabular}

a. All calculations, geometry optimization, and magnetic response properties, were performed at the B3LYP-DFT level of theory with the Def-TZVPP basis set. Spin-orbit coupling and relativistic effects were included with the zeroth order regular approximation (ZORA). Solvent effects were included with the implicit solvation model Conductor-like Screening Model (COSMO). The dielectric constant of methylene chloride, 9.08 at $20{ }^{\circ} \mathrm{C}$, was used for the COSMO model. The gauge-including atomic orbital (GIAO) approach was used to calculate the EPR related magnetic response properties, $\mathrm{g}$ and the hyperfine coupling constants (A).

b. Taken from Kirmse and Abram (1990).

c. Taken from Baldas et al. (1996).

\subsection{Stability of the $\left[\mathrm{Tc}(\mathrm{CO})_{3}\right]^{+}$Species at High Nitrate Concentrations}

The stability of aqueous $\mathrm{Tc}(\mathrm{I})$ coordination compounds over time with respect to their oxidation to pertechnetate, $\mathrm{TcO}_{4}^{-}$, was monitored by ${ }^{99} \mathrm{Tc}$ NMR spectroscopy. Monitoring started in April 2014 and is currently continuing for the high-stability Tc(I)-tricarbonyl solutions. Speciation stability for these $\left[\mathrm{Tc}(\mathrm{CO})_{3}\right]^{+}$compounds was examined in matrices from $2-5.7 \mathrm{M} \mathrm{NaNO}_{3}$ and in $5 \mathrm{M} \mathrm{NaNO}_{3} / 0.01-2 \mathrm{M}$ $\mathrm{NaOH}$. The results obtained to date (August 2014) are summarized below. Note that the analyses presented assume that Tc mass balance is based on the ${ }^{99} \mathrm{Tc}$ NMR-active species, a method that may be silent with respect to some plausible Tc species such as Tc(IV). The absence of the Tc(IV) species was supported by the observation that no precipitate (e.g., $\mathrm{TcO}_{2}$ ) was found in any of the stability samples. However, the formation of soluble Tc(IV) cannot be ruled out and should be investigated in future testing.

It might be of interest to note the qualitative changes in the signal-to-noise ratios that are observed in some cases (e.g., Figure 5.13 through Figure 5.19). Often such features are ascribed to the presence of species with relatively highly broad signals, interconversions between multiple species occurring on the ${ }^{99} \mathrm{Tc}$ NMR time scale, or the presence of Tc in ${ }^{99} \mathrm{Tc}$ silent oxidation states. However, here the change corresponds to a change to an NMR spectrometer of greater sensitivity and should not be taken as evidence of additional chemical complexity. 


\subsubsection{Stability of $\left[\mathrm{Tc}(\mathrm{CO})_{3}\right]^{+}$species in $\mathrm{NaNO}_{3}$ solutions}

Synthesized $\left[\mathrm{Et}_{4} \mathrm{~N}\right]_{2}\left[\mathrm{Tc}(\mathrm{CO})_{3} \mathrm{Cl}_{3}\right]$ was directly dissolved in aqueous solutions in air containing 2, 5, and 5.7 $\mathrm{M}$ concentrations of $\mathrm{NaNO}_{3}$ salt under atmospheric conditions and monitored for their oxidative stability, especially with respect to conversion to $\mathrm{TcO}_{4}{ }^{-}$. The $\mathrm{pH}$ was not adjusted and estimated to be at around 7 for each solution. The results of the ${ }^{99} \mathrm{Tc}$ NMR monitoring over a three-month period are summarized in Table 5.4 and representative spectra are shown in Figure 5.12, Figure 5.13, and Figure 5.14 below.

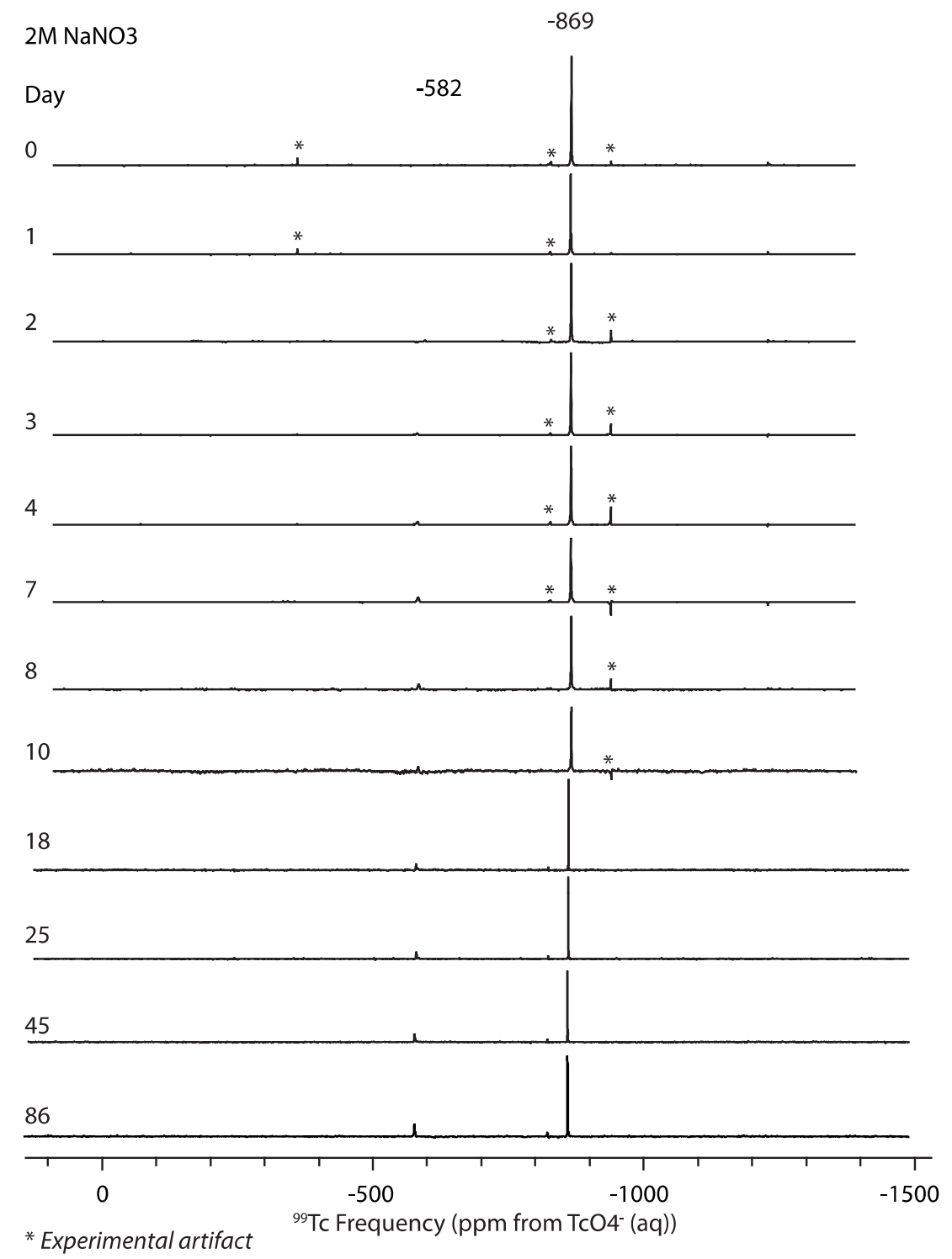

Figure 5.12. Monitoring the Stability of $\left[\mathrm{Tc}(\mathrm{CO})_{3}\right]^{+}$Species in $2 \mathrm{M} \mathrm{NaNO}_{3}$ with Time 


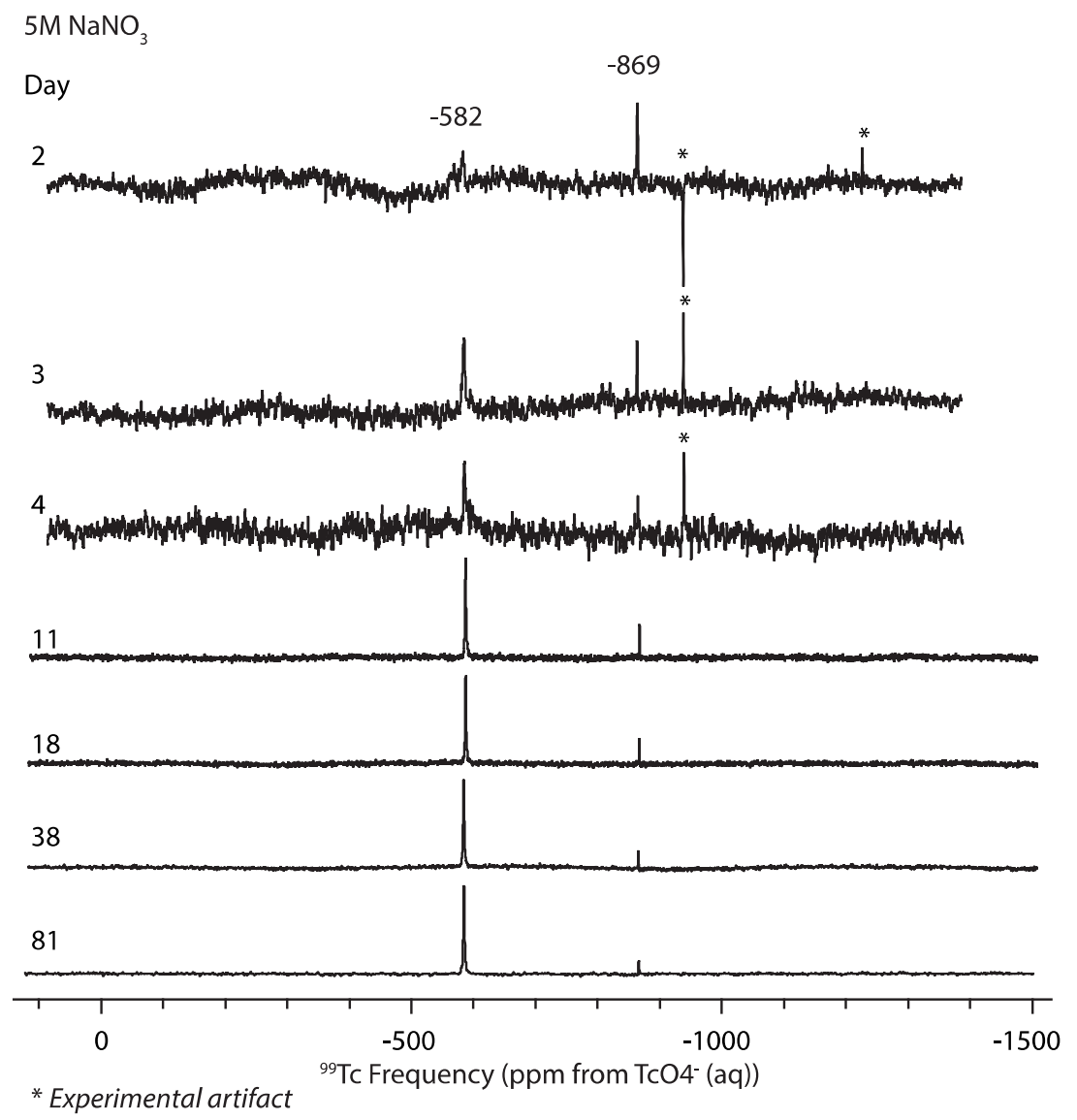

Figure 5.13. Monitoring the Stability of $\left[\mathrm{Tc}(\mathrm{CO})_{3}\right]^{+}$Species in $5 \mathrm{M} \mathrm{NaNO}_{3}$ with Time 


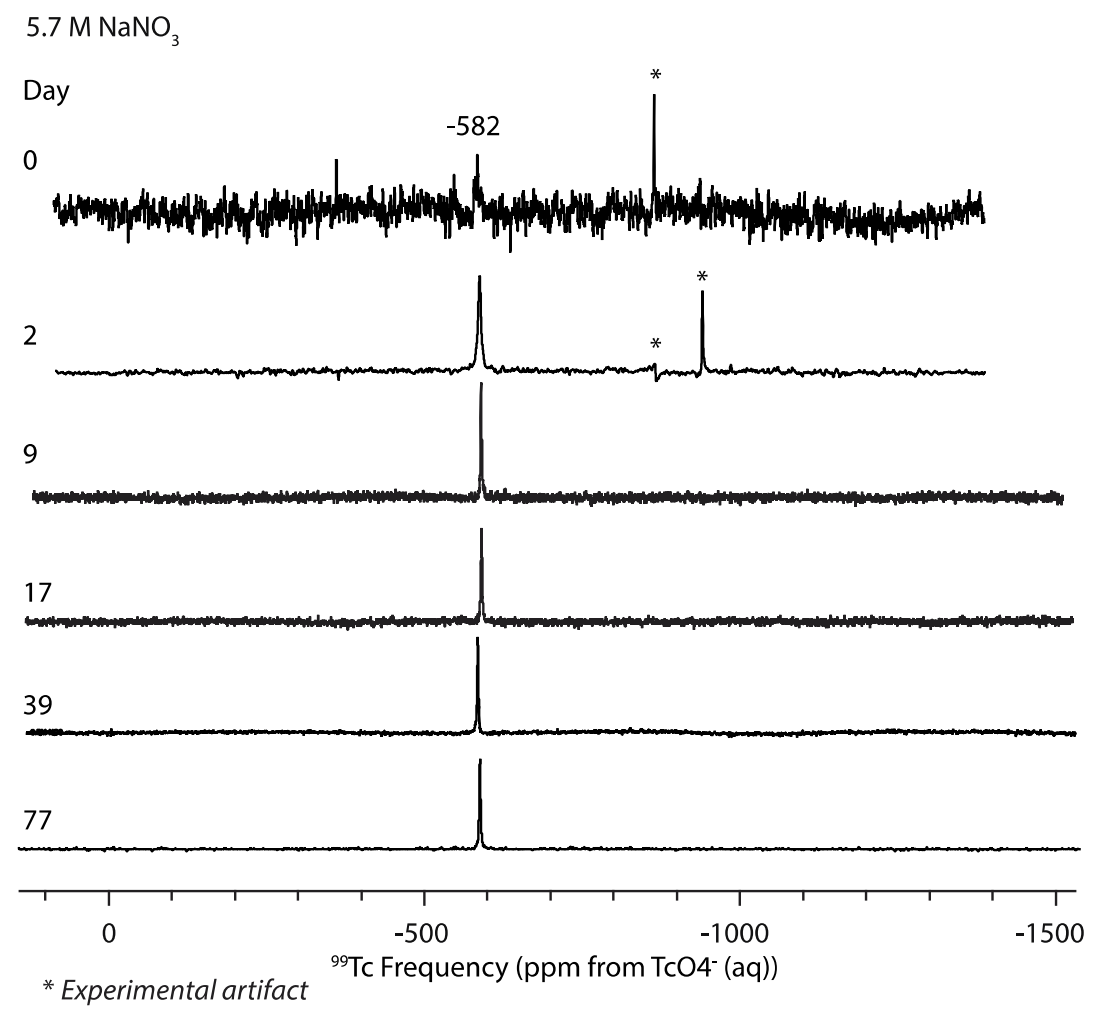

Figure 5.14. Monitoring the Stability of $\left[\mathrm{Tc}(\mathrm{CO})_{3}\right]^{+}$Species in $5.7 \mathrm{M} \mathrm{NaNO}_{3}$ with Time 
Table 5.4. Time Stability of $\left[\mathrm{Tc}(\mathrm{CO})_{3}\right]^{+}$Species in $\mathrm{NaNO}_{3} / \mathrm{NaOH}$ Solutions Monitored by ${ }^{99} \mathrm{Tc}$ NMR Spectroscopy. Relative quantities of the Tc(I) species $\left[\mathrm{Tc}(\mathrm{CO})_{3}\left(\mathrm{H}_{2} \mathrm{O}\right)_{3}\right]^{+}$and $\left[\mathrm{Tc}(\mathrm{CO})_{3}(\mathrm{OH})\right]_{4}$ were determined by the integration of the corresponding resonances at about -868 and $-585 \mathrm{ppm}$, respectively (Figure 5.12, Figure 5.13, and Figure 5.14).

\begin{tabular}{|c|c|c|c|}
\hline \multirow{3}{*}{ Time Elapsed } & \multicolumn{3}{|c|}{ Percent Fraction } \\
\hline & \multicolumn{2}{|c|}{ Non-pertechnetate Tc(I) Species } & \multirow{2}{*}{$\mathrm{TcO}_{4}$} \\
\hline & {$\left[\mathrm{Tc}(\mathrm{CO})_{3}\left(\mathrm{H}_{2} \mathrm{O}\right)_{3}\right]^{+}$} & {$\left[\mathrm{Tc}(\mathrm{CO})_{3}(\mathrm{OH})\right]_{4}$} & \\
\hline \multicolumn{4}{|c|}{$2 \mathrm{M} \mathrm{NaNO}_{3}, 0.028 \mathrm{mM} \mathrm{Tc}$} \\
\hline Start day & 1 & 0 & 0 \\
\hline Day 1 & 1 & 0 & 0 \\
\hline Day 2 & 1 & 0 & 0 \\
\hline Day 3 & 0.95 & 0.05 & 0 \\
\hline Day 4 & 0.92 & 0.08 & 0 \\
\hline Day 7 & 0.84 & 0.16 & 0 \\
\hline Day 8 & 0.82 & 0.18 & 0 \\
\hline Day 10 & 0.80 & 0.20 & 0 \\
\hline Day 18 & 0.73 & 0.27 & 0 \\
\hline Day 25 & 0.65 & 0.35 & 0 \\
\hline Day 45 & 0.62 & 0.38 & 0 \\
\hline Day 86 & 0.61 & 0.39 & 0 \\
\hline \multicolumn{4}{|c|}{$5 \mathrm{M} \mathrm{NaNO}_{3}, 0.19 \mathrm{mM} \mathrm{Tc}$} \\
\hline Start day & 0.51 & 0.49 & 0 \\
\hline Day 1 & 0.28 & 0.72 & 0 \\
\hline Day 2 & 0.19 & 0.81 & 0 \\
\hline Day 9 & 0.08 & 0.92 & 0 \\
\hline Day 16 & 0.07 & 0.93 & 0 \\
\hline Day 36 & 0.05 & 0.95 & 0 \\
\hline Day 75 & 0.03 & 0.97 & 0 \\
\hline \multicolumn{4}{|c|}{$5.7 \mathrm{M} \mathrm{NaNO}_{3}, 0.21 \mathrm{mM} \mathrm{Tc}$} \\
\hline Start day & 0.58 & 0.42 & 0 \\
\hline Day 2 & 0.08 & 0.92 & 0 \\
\hline Day 9 & 0 & 1 & 0 \\
\hline Day 17 & 0 & 1 & 0 \\
\hline Day 39 & 0 & 1 & 0 \\
\hline Day 77 & 0 & 1 & 0 \\
\hline
\end{tabular}


Technetium-99 NMR measurements indicated that all initial solutions prepared for stability monitoring contained only $\left[\mathrm{Tc}(\mathrm{CO})_{3}\right]^{+}$species. No presence of $\mathrm{TcO}_{4}{ }^{-}$was observed as shown from the absence of the corresponding resonance around $0 \mathrm{ppm}$. Upon dissolution of the $\left[\mathrm{Tc}(\mathrm{CO})_{3} \mathrm{Cl}_{3}\right]^{2-}$, the $\left[\mathrm{Tc}(\mathrm{CO})_{3}\left(\mathrm{H}_{2} \mathrm{O}\right)_{3}\right]^{+}$species appearing at $-869 \mathrm{ppm}$ in the NMR spectra was predominantly formed in $2 \mathrm{M}$ $\mathrm{NaNO}_{3}$ (Figure 5.12). The hydrolyzed tetramer, $\left[\mathrm{Tc}(\mathrm{CO})_{3}(\mathrm{OH})\right]_{4}$, corresponding to the $-585 \mathrm{ppm}$ resonance, started to form on day 3 post-solution preparation, and its concentration gradually increased with time. The initial dissolution of the $\left[\mathrm{Tc}(\mathrm{CO})_{3} \mathrm{Cl}_{3}\right]^{2-}$ in the 5 and $5.7 \mathrm{M} \mathrm{NaNO}_{3}$ solutions generated nearly equal fractions of the $\left[\mathrm{Tc}(\mathrm{CO})_{3}\left(\mathrm{H}_{2} \mathrm{O}\right)_{3}\right]^{+}$and $\left[\mathrm{Tc}(\mathrm{CO})_{3}(\mathrm{OH})\right]_{4}$ species (Table 5.4). In $5 \mathrm{M} \mathrm{NaNO}_{3}$, the $\left[\mathrm{Tc}(\mathrm{CO})_{3}\left(\mathrm{H}_{2} \mathrm{O}\right)_{3}\right]^{+}$conversion to the tetrameric species was nearly completed after 75 days post-solution preparation. In the $5.7 \mathrm{M} \mathrm{NaNO}_{3}$ solution this process was significantly faster; at day 9 only the $\left[\mathrm{Tc}(\mathrm{CO})_{3}(\mathrm{OH})\right]_{4}$ species was observed. It is known that at near-neutral $\mathrm{pH}$, the $\left[\mathrm{Tc}(\mathrm{CO})_{3}\left(\mathrm{H}_{2} \mathrm{O}\right)_{3}\right]^{+}$ complex undergoes partial hydrolysis to generate $\left[\mathrm{Tc}(\mathrm{CO})_{3}(\mathrm{OH})\left(\mathrm{H}_{2} \mathrm{O}\right)_{2}\right]$ species, which in turn readily aggregates and forms a tetrameric hydrolysis product $\left[\mathrm{Tc}(\mathrm{CO})_{3}(\mathrm{OH})\right]_{4}$ (Alberto et al. 1998c; Gorshkov et al. 2000) as summarized in an FY 2013 report (Rapko et al. 2013b). The equilibrium between the parent $\left[\mathrm{Tc}(\mathrm{CO})_{3}\left(\mathrm{H}_{2} \mathrm{O}\right)_{3}\right]^{+}$species and its first hydrolysis product $\left[\mathrm{Tc}(\mathrm{CO})_{3}(\mathrm{OH})\left(\mathrm{H}_{2} \mathrm{O}\right)_{2}\right]$ is sensitive to even small variations in the solution $\mathrm{pH}$, while the formation of the $\left[\mathrm{Tc}(\mathrm{CO})_{3}(\mathrm{OH})\right]_{4}$ tetramer primarily depends on the $\mathrm{Tc}(\mathrm{I})$ concentration. In 5 and $5.7 \mathrm{M} \mathrm{NaNO}_{3}$ solutions, the concentration of $\mathrm{Tc}(\mathrm{I})$ was about 7 times greater than in $2 \mathrm{M} \mathrm{NaNO}_{3}$ solution and undoubtedly led to the enhanced formation of the $\left[\mathrm{Tc}(\mathrm{CO})_{3}(\mathrm{OH})\right]_{4}$ species. It is likely that most of the changes in the rate and extent of tetramer formation can be attributed to varying amounts of the first hydrolysis product coupled with perhaps slight changes in $\mathrm{pH}$ as opposed to ionic strength changes.

To date, no formation of $\mathrm{TcO}_{4}{ }^{-}$has been observed. This lack of information indicates high resistance to reoxidation of these $\left[\mathrm{Tc}(\mathrm{CO})_{3}\right]^{+}$species in the concentrated $\mathrm{NaNO}_{3}$ solutions at near-neutral $\mathrm{pH}$, a stability that is present regardless of the presence of either $\left[\mathrm{Tc}(\mathrm{CO})_{3}\left(\mathrm{H}_{2} \mathrm{O}\right)_{3}\right]^{+}$or $\left[\mathrm{Tc}(\mathrm{CO})_{3}(\mathrm{OH})\right]_{4}$.

\subsubsection{Stability of $\left[\mathrm{Tc}(\mathrm{CO})_{3}\right]^{+}$species in $5 \mathrm{M} \mathrm{NaNO}_{3} / 0.01-2 \mathrm{M} \mathrm{NaOH}$ solutions}

To monitor stability of the $\left[\mathrm{Tc}(\mathrm{CO})_{3}\right]^{+}$species in solutions containing high nitrate and variable hydroxide concentrations, a stock solution containing the Tc(I)-tricarbonyl complex in $5 \mathrm{M} \mathrm{NaNO}_{3}$ matrix was prepared. This stock solution was added to the $5 \mathrm{M} \mathrm{NaNO}_{3}$ solutions containing $0.01,0.1,0.5,1$, or 2. $\mathrm{M} \mathrm{NaOH}$.

The results of the ${ }^{99} \mathrm{Tc}$ NMR monitoring over a 2.5-month period are summarized in Figure 5.15 through Figure 5.19 and in Table 5.5. 


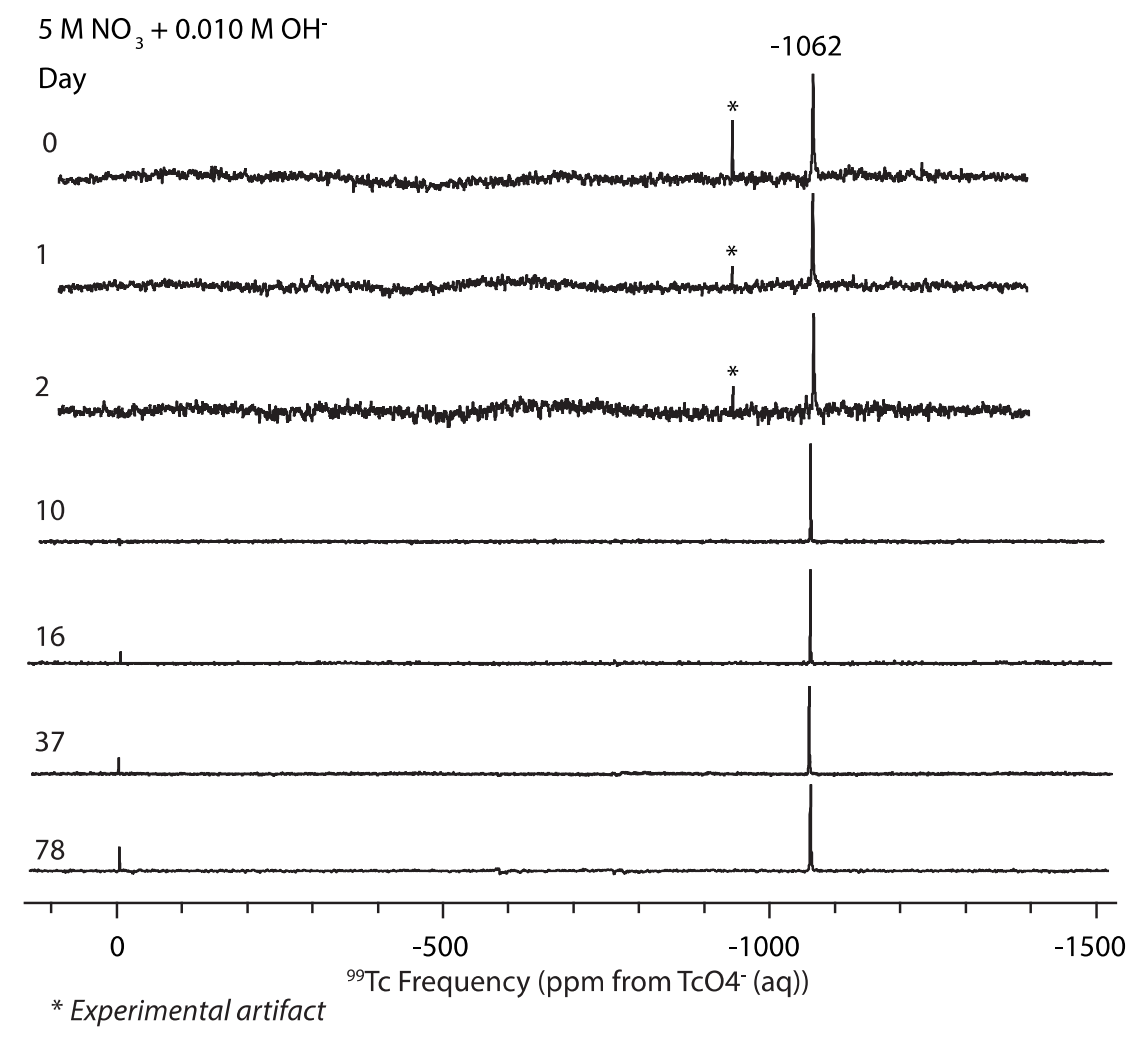

Figure 5.15. Monitoring the Stability of $\left[\mathrm{Tc}(\mathrm{CO})_{3}\right]^{+}$Species in $5 \mathrm{M} \mathrm{NaNO}_{3} / 0.01 \mathrm{M} \mathrm{NaOH}$ with Time 


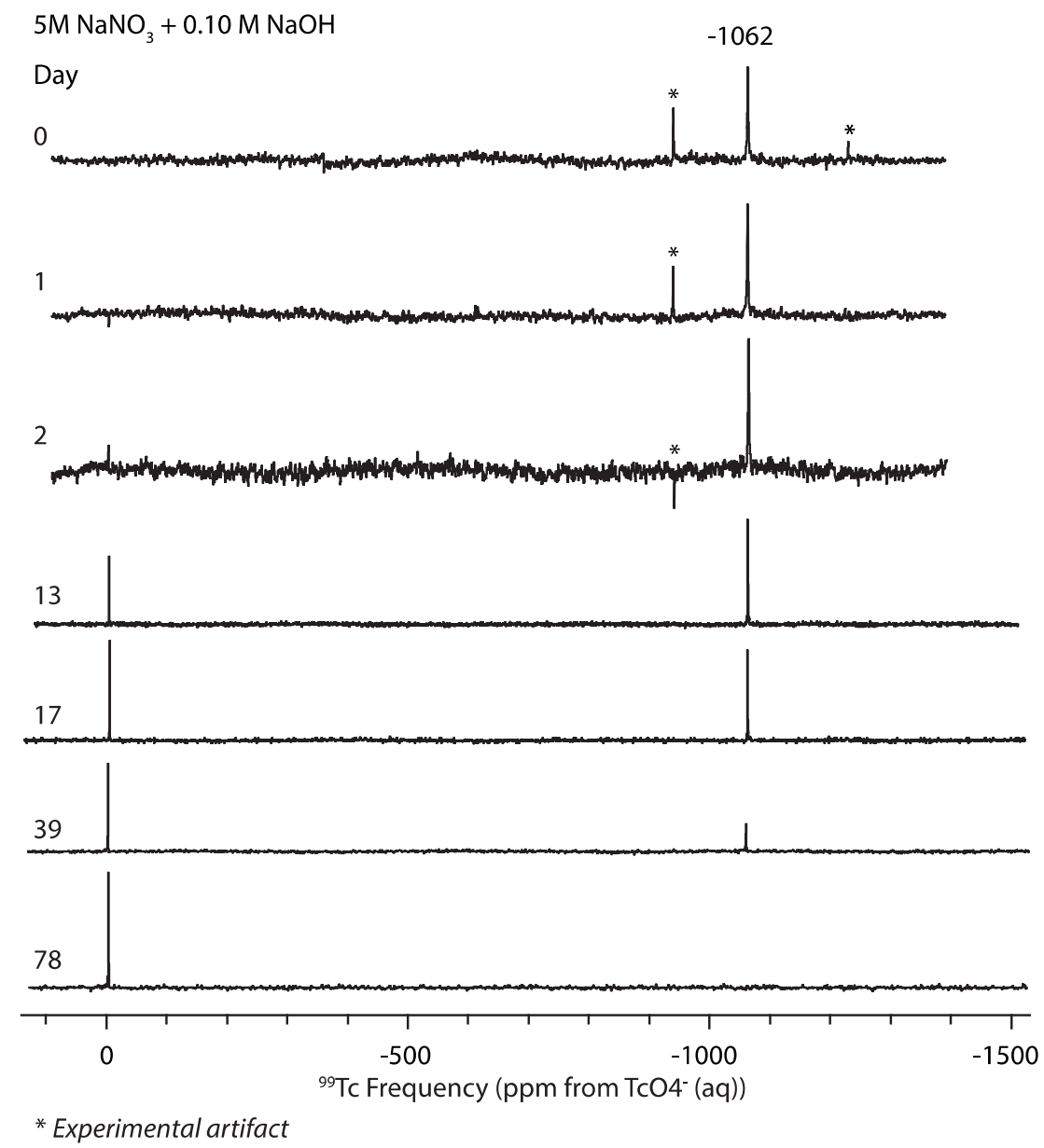

Figure 5.16. Monitoring the Stability of $\left[\mathrm{Tc}(\mathrm{CO})_{3}\right]^{+}$Species in $5 \mathrm{M} \mathrm{NaNO}_{3} / 0.1 \mathrm{M} \mathrm{NaOH}$ with Time 


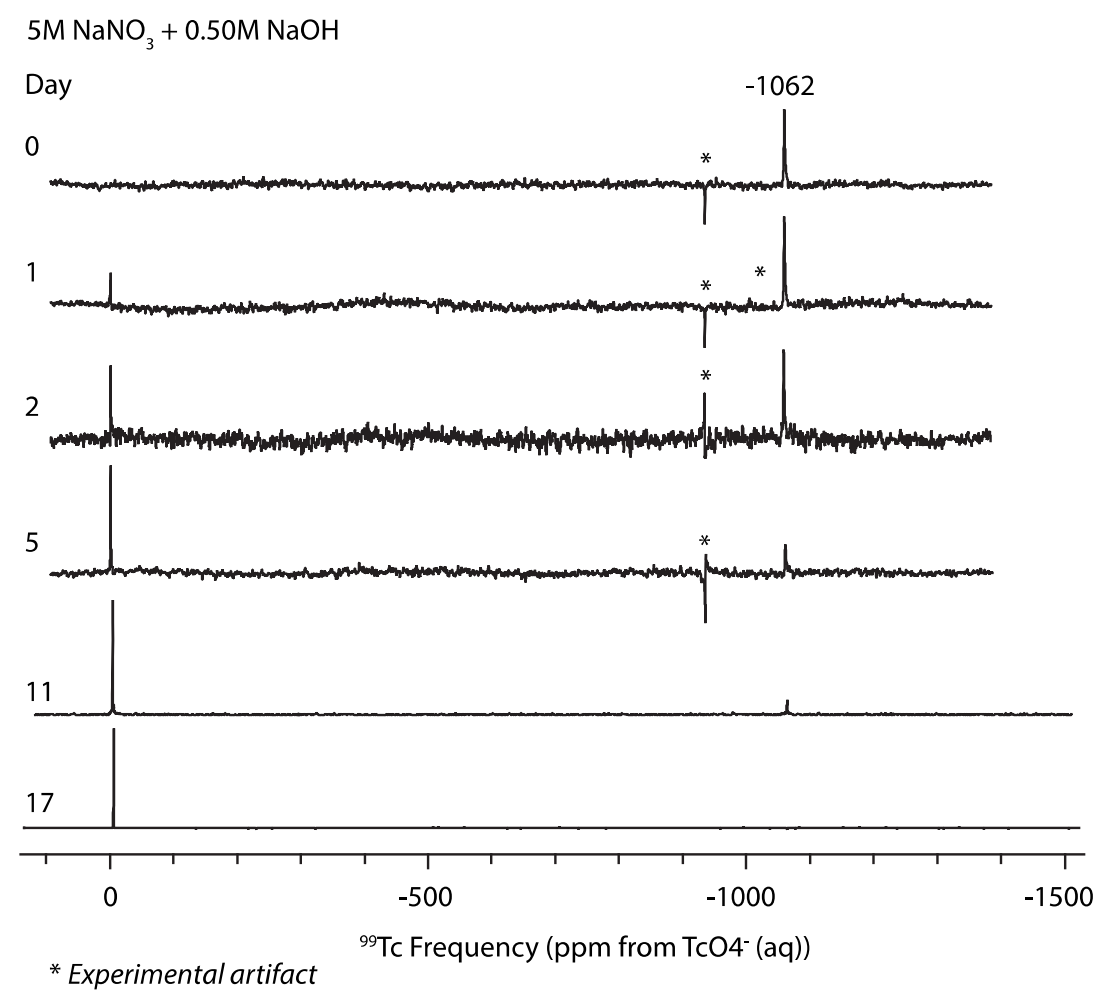

Figure 5.17. Monitoring the Stability of $\left[\mathrm{Tc}(\mathrm{CO})_{3}\right]^{+}$Species in $5 \mathrm{M} \mathrm{NaNO}_{3} / 0.5 \mathrm{M} \mathrm{NaOH}$ with Time 


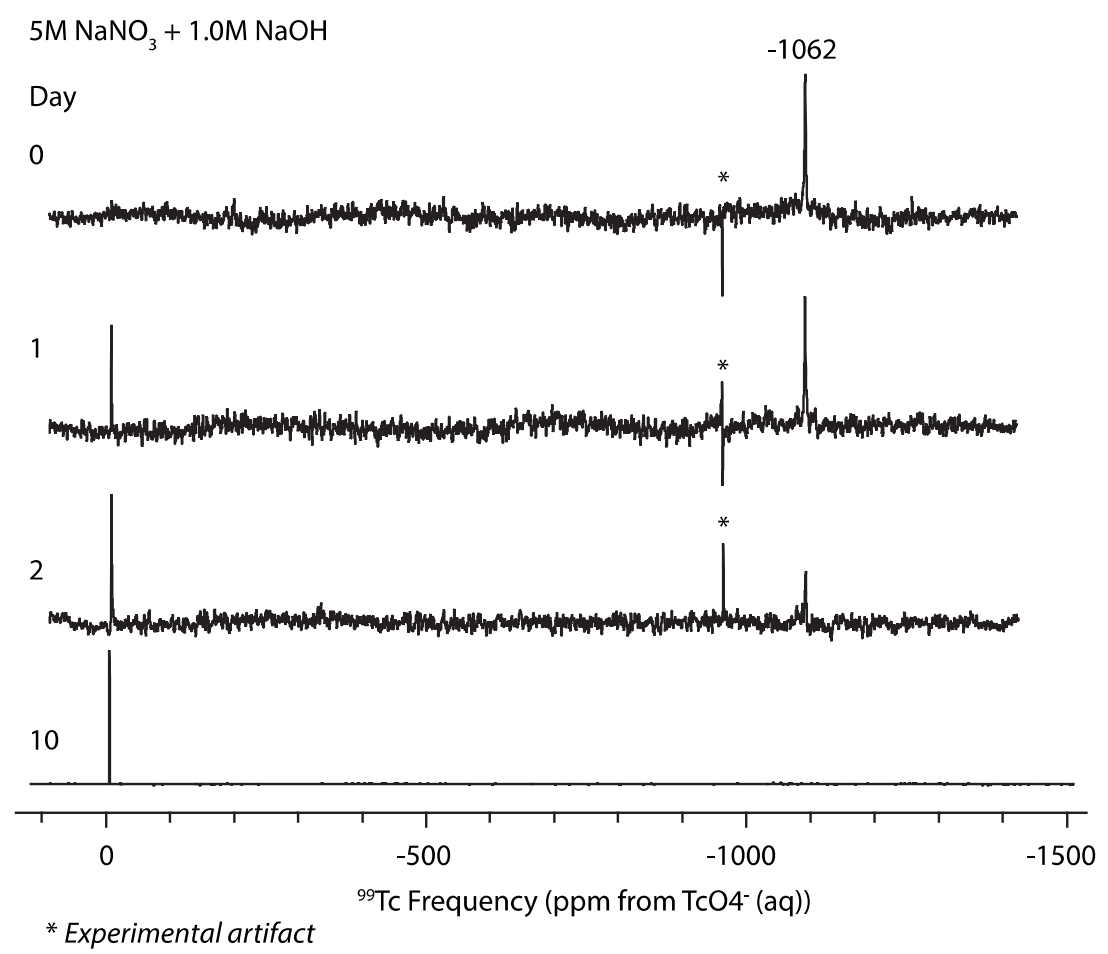

Figure 5.18. Monitoring the Stability of $\left[\mathrm{Tc}(\mathrm{CO})_{3}\right]^{+}$Species in $5 \mathrm{M} \mathrm{NaNO}_{3} / 1 \mathrm{M} \mathrm{NaOH}$ with Time

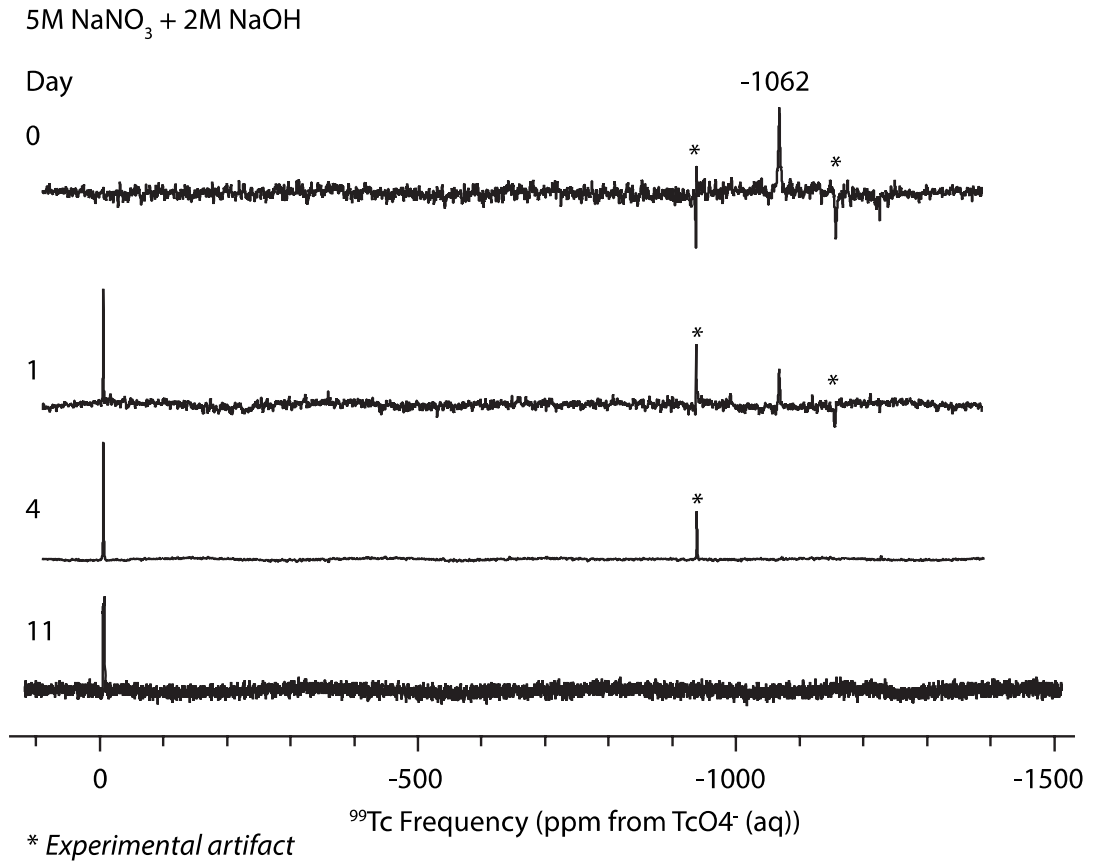

Figure 5.19. Monitoring the Stability of $\left[\mathrm{Tc}(\mathrm{CO})_{3}\right]^{+}$Species in $5 \mathrm{M} \mathrm{NaNO}_{3} / 2 \mathrm{M} \mathrm{NaOH}$ with Time 
Table 5.5. Time Stability of $\left[\mathrm{Tc}(\mathrm{CO})_{3}\right]^{+}$Species in $\mathrm{NaNO}_{3} / \mathrm{NaOH}$ Solutions Monitored by ${ }^{99} \mathrm{Tc} \mathrm{NMR}$ Spectroscopy. Relative quantities of the $\mathrm{Tc}(\mathrm{I})\left[\mathrm{Tc}(\mathrm{CO})_{3}(\mathrm{OH})\left(\mathrm{H}_{2} \mathrm{O}\right)_{2}\right]$ and pertechnetate $\mathrm{TcO}_{4}{ }^{-}$ species were determined by the integration of the corresponding resonances at about -1062 and 0 ppm, respectively (Figure 5.15 through Figure 5.19).

\begin{tabular}{|c|c|c|}
\hline \multirow{2}{*}{ Time Elapsed } & \multicolumn{2}{|c|}{ Percent Fraction } \\
\hline & {$\left[\mathrm{Tc}(\mathrm{CO})_{3}(\mathrm{OH})\left(\mathrm{H}_{2} \mathrm{O}\right)_{2}\right]$} & $\mathrm{TcO}_{4}$ \\
\hline \multicolumn{3}{|c|}{$5 \mathrm{M} \mathrm{NaNO}_{3} / 0.01 \mathrm{M} \mathrm{NaOH}, 0.19 \mathrm{mM} \mathrm{Tc}$} \\
\hline Start day & 1 & 0 \\
\hline Day 1 & 1 & 0 \\
\hline Day 2 & 1 & 0 \\
\hline Day 10 & 1 & 0 \\
\hline Day 16 & 0.95 & 0.05 \\
\hline Day 37 & 0.90 & 0.10 \\
\hline Day 74 & 0.89 & 0.11 \\
\hline \multicolumn{3}{|c|}{$5 \mathrm{M} \mathrm{NaNO}_{3} / 0.1 \mathrm{M} \mathrm{NaOH}, 0.19 \mathrm{mM} \mathrm{Tc}$} \\
\hline Start day & 1 & 0 \\
\hline Day 1 & 0.97 & 0.03 \\
\hline Day 2 & 0.92 & 0.08 \\
\hline Day 10 & 0.79 & 0.21 \\
\hline Day 17 & 0.71 & 0.29 \\
\hline Day 39 & 0.50 & 0.50 \\
\hline Day 74 & 0 & 1 \\
\hline \multicolumn{3}{|c|}{$5 \mathrm{M} \mathrm{NaNO}_{3} / 0.5 \mathrm{M} \mathrm{NaOH}, 0.19 \mathrm{mM} \mathrm{Tc}$} \\
\hline Start day & 1 & 0 \\
\hline Day 1 & 0.80 & 0.20 \\
\hline Day 2 & 0.69 & 0.31 \\
\hline Day 5 & 0.47 & 0.53 \\
\hline Day 11 & 0.34 & 0.66 \\
\hline Day 17 & 0 & 1 \\
\hline \multicolumn{3}{|c|}{$5 \mathrm{M} \mathrm{NaNO}_{3} / 1 \mathrm{M} \mathrm{NaOH}, 0.19 \mathrm{mM} \mathrm{Tc}$} \\
\hline Start day & 1 & 0 \\
\hline Day 1 & 0.75 & 0.25 \\
\hline Day 2 & 0.50 & 0.50 \\
\hline Day 10 & 0 & 1 \\
\hline \multicolumn{3}{|c|}{$5 \mathrm{M} \mathrm{NaNO}_{3} / 2 \mathrm{M} \mathrm{NaOH}, 0.19 \mathrm{mM} \mathrm{Tc}$} \\
\hline Start day & 1 & 0 \\
\hline Day 1 & 0.12 & 0.88 \\
\hline Day 4 & 0 & 1 \\
\hline
\end{tabular}

In all alkaline solutions, formation of the single $\left[\mathrm{Tc}(\mathrm{CO})_{3}(\mathrm{OH})\left(\mathrm{H}_{2} \mathrm{O}\right)_{2}\right]$ hydrolyzed monomeric species appearing at -1062 ppm in the NMR spectra was observed. No $\left[\mathrm{Tc}(\mathrm{CO})_{3}(\mathrm{OH})\right]_{4}$ tetramer was found in 
these solutions. This finding is consistent with the previous reports (Alberto et al. 1999 and references therein) that tetrameric species exist only in a limited $\mathrm{pH}$ range in the vicinity of the first $\mathrm{pK}_{\mathrm{a}}$ value of the parent $\left[\mathrm{Tc}(\mathrm{CO})_{3}\left(\mathrm{H}_{2} \mathrm{O}\right)_{3}\right]^{+}$species, which was estimated to be 7.75 in the low-ionic-strength solutions in our FY 2013 studies (Rapko et al. 2013b).

The ${ }^{99} \mathrm{Tc}$ NMR results indicated gradual oxidative decomposition of the $\left[\mathrm{Tc}(\mathrm{CO})_{3}(\mathrm{OH})\left(\mathrm{H}_{2} \mathrm{O}\right)_{2}\right]$ species and in-growth of $\mathrm{TcO}_{4}{ }^{-}$in all samples. The relative concentrations of the $\left[\mathrm{Tc}(\mathrm{CO})_{3}(\mathrm{OH})\left(\mathrm{H}_{2} \mathrm{O}\right)_{2}\right]$ species and $\mathrm{TcO}_{4}{ }^{-}$were determined by integrations of the respective resonances in each spectrum. As is evident from the results shown in Table 5.5, the oxidation of the Tc(I) inversely correlates with the $\mathrm{OH}$. concentration. The $5 \mathrm{M} \mathrm{NaNO}_{3} / 0.01 \mathrm{M} \mathrm{NaOH}$ exhibited the greatest stability of the $\left[\mathrm{Tc}(\mathrm{CO})_{3}(\mathrm{OH})\left(\mathrm{H}_{2} \mathrm{O}\right)_{2}\right]$ species among other alkaline solutions so that about only $11 \%$ of $\mathrm{Tc}(\mathrm{I})$ was oxidized to Tc(VII) in 74 days. By way of comparison, in $5 \mathrm{M} \mathrm{NaNO}_{3} / 0.1 \mathrm{M} \mathrm{NaOH}$ solution, $50 \%$ and $100 \% \mathrm{Tc}(\mathrm{I})$ was oxidized to Tc(VII) in 39 and 74 days, respectively. In $5 \mathrm{M} \mathrm{NaNO}_{3} / 0.5 \mathrm{M} \mathrm{NaOH}$ solution only $34 \% \mathrm{Tc}(\mathrm{I})$ remained at day 11 , and no Tc(I) species remained in the solution at day 17. Both exhibited fast oxidation of $\mathrm{Tc}(\mathrm{I})$ in $5 \mathrm{M} \mathrm{NaNO}_{3} / 1 \mathrm{M} \mathrm{NaOH}$ and $5 \mathrm{M} \mathrm{NaNO}_{3} / 2 \mathrm{M} \mathrm{NaOH}$ solutions, so that in 24 hours, respective $50 \%$ and $88 \%$ Tc(I) converted to $\mathrm{Tc}(\mathrm{VII})$.

To compare rates of the $\left[\mathrm{Tc}(\mathrm{CO})_{3}(\mathrm{OH})\left(\mathrm{H}_{2} \mathrm{O}\right)_{2}\right]$ conversion to $\mathrm{TcO}_{4}{ }^{-}$, the kinetic plots were constructed for the $5 \mathrm{M} \mathrm{NaNO}_{3}$ solutions containing $0.01,0.1,0.5$, or $1 \mathrm{M} \mathrm{NaOH}$ (Figure 5.20). Even though the oxidation mechanism has not been elucidated yet, it was found that the initial increase of the $\mathrm{TcO}_{4}{ }^{-}$ concentration over time can be reasonably fitted by a linear equation. The obtained slope values quantifying the rate of the Tc(I) oxidation with time (fraction per hour) exhibited nearly linear dependence on the $\mathrm{OH}^{-}$concentration in the solution (Figure 5.21) consistent with an oxidation rate that is first-order in hydroxide. 


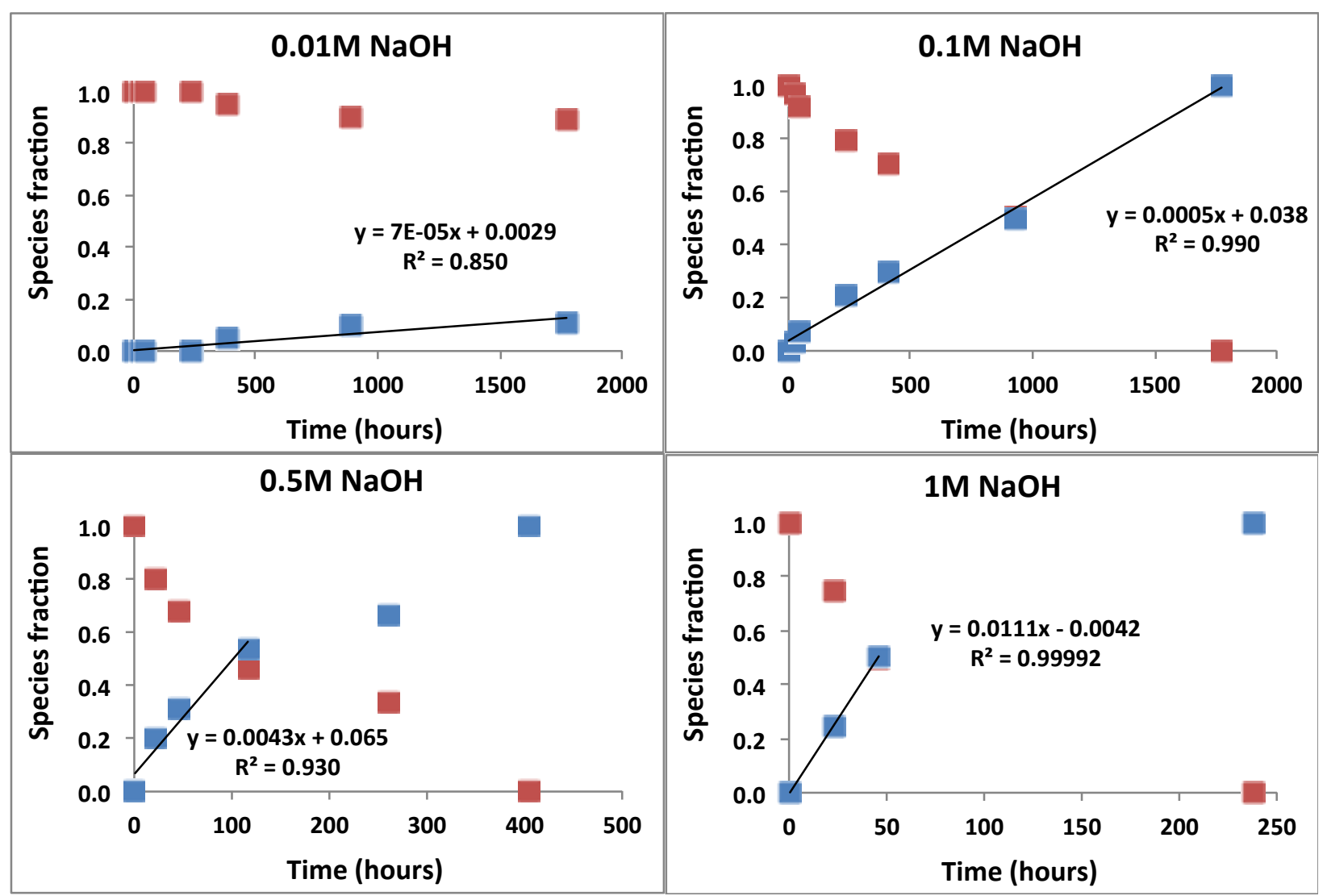

Figure 5.20. Technetium-99 Time Speciation in $5 \mathrm{M} \mathrm{NaNO}_{3} /$ Variable Hydroxide Solutions Containing $0.01 \mathrm{M}$ (top left), $0.1 \mathrm{M}$ (top right), $0.5 \mathrm{M}$ (bottom left) or $1 \mathrm{M}$ (bottom right) $\mathrm{NaOH}$. Red symbols: $\left[\mathrm{Tc}(\mathrm{CO})_{3}(\mathrm{OH})\left(\mathrm{H}_{2} \mathrm{O}\right)_{2}\right]$. Blue symbols: $\mathrm{TcO}_{4}^{-}$.

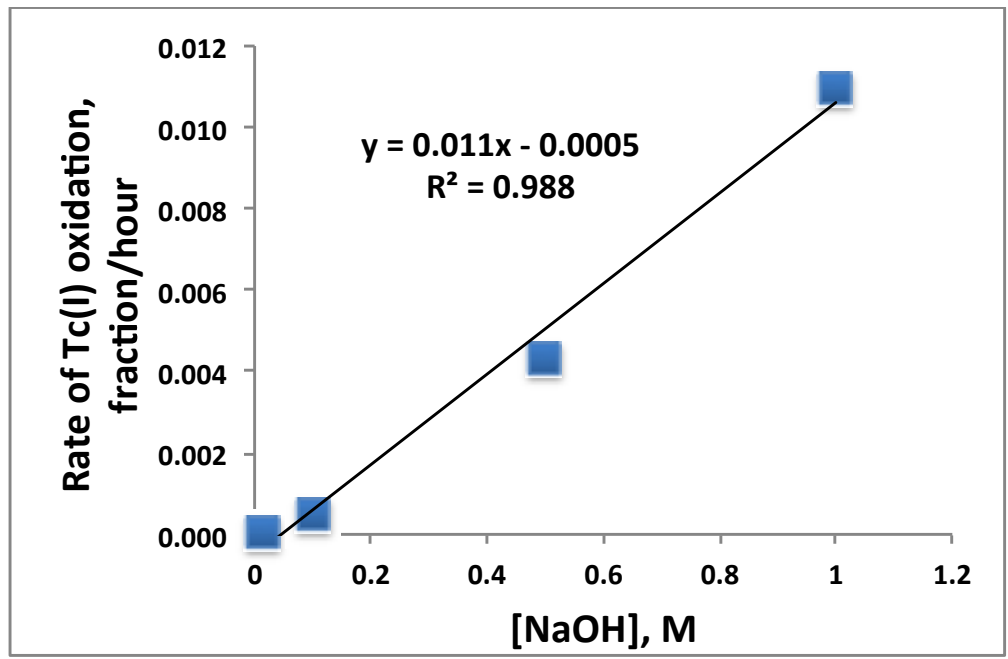

Figure 5.21. Dependence of the Kinetics of $\mathrm{Tc}(\mathrm{I})$ Oxidation to $\mathrm{TcO}_{4}{ }^{-}$on the $\mathrm{OH}^{-}$Concentration in $5 \mathrm{M} \mathrm{NaNO}_{3}$ 


\subsubsection{Stability of $\left[\mathrm{Tc}(\mathrm{CO})_{3}\right]^{+}$species in $5 \mathrm{M} \mathrm{NaNO}_{3} / 0.01-0.5 \mathrm{M} \mathrm{NaOH} / 0.5 \mathrm{M}$ sodium gluconate solutions}

To evaluate the effect of gluconate on the oxidative stability of Tc(I) species in alkane solutions containing high nitrate concentration, three $5 \mathrm{M} \mathrm{NaNO}_{3} / 0.5 \mathrm{M}$ sodium gluconate solutions with the 0.01 , 0.1 , or $0.5 \mathrm{M} \mathrm{NaOH}$ were prepared. To each solution, a Tc(I)-tricarbonyl stock solution in $5 \mathrm{M} \mathrm{NaNO}_{3}$ was added. The oxidative stability of these samples was monitored by ${ }^{99} \mathrm{Tc}$ NMR spectroscopy. The observed results are summarized in Table 5.6 and some representative spectra are shown in Figure 5.22.
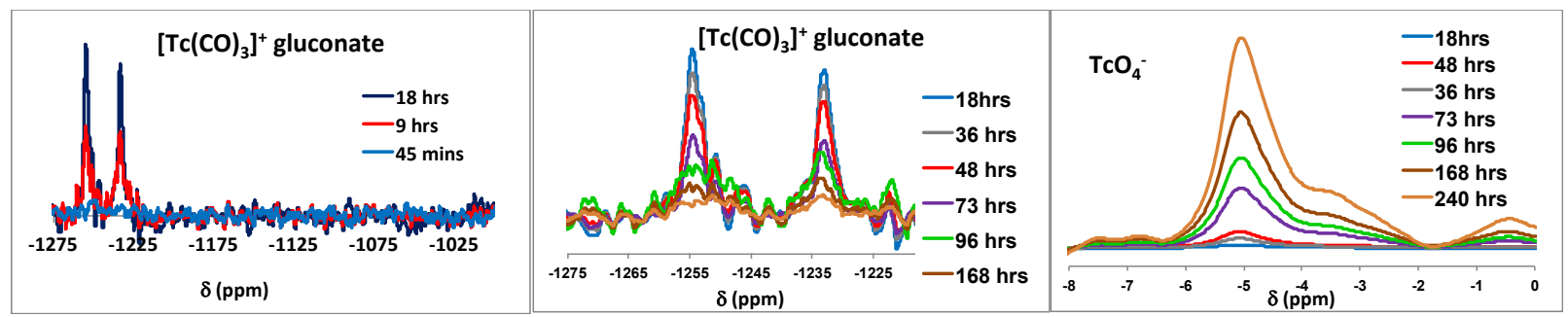

Figure 5.22. Selected Spectral Regions of Representative Spectra from Monitoring the Stability of $\left[\mathrm{Tc}(\mathrm{CO})_{3}\right]^{+}$Species in $5 \mathrm{M} \mathrm{NaNO}_{3} / 0.1 \mathrm{M} \mathrm{NaOH} / 0.5 \mathrm{M}$ Sodium Gluconate with Time 
Table 5.6. Time Stability of $\left[\mathrm{Tc}(\mathrm{CO})_{3}\right]^{+}$Species in $5 \mathrm{M} \mathrm{NaNO}_{3} / 0.01-0.5 \mathrm{M} \mathrm{NaOH} / 0.5 \mathrm{M}$ Sodium Gluconate Solutions as Monitored by ${ }^{99} \mathrm{Tc}$ NMR Spectroscopy. Relative quantities of the $\mathrm{Tc}(\mathrm{I})\left[\mathrm{Tc}(\mathrm{CO})_{3}\right]^{+}$gluconate complex species and pertechnetate $\mathrm{TcO}_{4}{ }^{-}$were determined by the integration of the corresponding resonances at about -1232/-1254 (combined integration) and 0 ppm, respectively (Figure 5.22).

\begin{tabular}{|c|c|c|}
\hline \multirow{2}{*}{ Time Elapsed } & \multicolumn{2}{|c|}{ Percent Fraction } \\
\cline { 2 - 3 } & {$\left[\mathbf{T c}(\mathbf{C O})_{3}\right]^{+}$} & TcO $_{4}{ }^{-}$ \\
\hline 5 $\mathrm{M} \mathrm{NaNO}_{3} / 0.01 \mathrm{M} \mathrm{NaOH} / 0.5 \mathrm{M} \mathrm{NaGluconate}, 0.28 \mathrm{mM} \mathrm{Tc}$ \\
\hline 12 hours & 1 & 0 \\
\hline 36 hours & 0.97 & 0.03 \\
\hline 48 hours & 0.92 & 0.08 \\
\hline 3 days & 0.85 & 0.15 \\
\hline 5 days & 0.74 & 0.26 \\
\hline 8 days & 0.57 & 0.43 \\
\hline 10 days & 0.34 & 0.66 \\
\hline 12 days & 0.17 & 0.83 \\
\hline 14 days ${ }^{\text {a) }}$ & 0 & 1 \\
\hline
\end{tabular}

$5 \mathrm{M} \mathrm{NaNO}_{3} / 0.1 \mathrm{M} \mathrm{NaOH} / 0.5 \mathrm{M} \mathrm{NaGluconate,} 0.28 \mathrm{mM}$ Tc

\begin{tabular}{|c|c|c|}
\hline 18 hours & 1 & 0 \\
\hline 36 hours & 0.97 & 0.03 \\
\hline 48 hours & 0.95 & 0.05 \\
\hline 3 days & 0.82 & 0.18 \\
\hline 4 days & 0.73 & 0.27 \\
\hline 7 days & 0.45 & 0.54 \\
\hline 10 days & 0.27 & 0.73 \\
\hline 12 days $^{\text {a) }}$ & 0 & 1 \\
\hline
\end{tabular}

$5 \mathrm{M} \mathrm{NaNO}_{3} / 0.5 \mathrm{M} \mathrm{NaOH} / 0.5 \mathrm{M} \mathrm{NaGluconate,} 0.28 \mathrm{mM} \mathrm{Tc}$

\begin{tabular}{|c|c|c|}
\hline 12 hours & 1 & 0 \\
\hline 24 hours & 0.96 & 0.05 \\
\hline 48 hours & 0.85 & 0.15 \\
\hline 3 days & 0.69 & 0.31 \\
\hline 6 days & 0.36 & 0.64 \\
\hline 8 days & 0.17 & 0.83 \\
\hline 9 days $^{\text {a }}$ & 0 & 1 \\
\hline
\end{tabular}

a. Obtained by extrapolation of the graphical data shown in Figure 5.22. 
Consistent with our previous observations (Rapko et al. 2013), the ${ }^{99} \mathrm{Tc}-\mathrm{NMR}$ spectrum of the $\left[\mathrm{Tc}(\mathrm{CO})_{3}\right]^{+}$complex with gluconate is characterized by the presence of two resonances at -1232 and -1253 ppm revealing the presence of two distinct Tc(I) centers. Interestingly, the initial solutions, NMR spectra of which were recorded within $1-2$ hours post-preparation, contained no Tc peaks attributed to either $\left[\mathrm{Tc}(\mathrm{CO})_{3}\right]^{+} /$gluconate complex or $\mathrm{TcO}_{4}{ }^{-}$. The resonance due to the $\left[\mathrm{Tc}(\mathrm{CO})_{3}\right]^{+} /$gluconate species appeared in the spectra a few hours later and continued to grow, reaching maximum intensity at $12-18$ hours post-solution preparation (Figure 5.22, left pane). This observation suggests that upon addition of the $\mathrm{Tc}(\mathrm{I})$-tricarbonyl/5 $\mathrm{M} \mathrm{NaNO}_{3}$ stock solution, the gluconate test solution intermediate species formed which slowly converted to the $\left[\mathrm{Tc}(\mathrm{CO})_{3}\right]^{+} /$gluconate complex. Moreover, no concomitant generation of $\mathrm{TcO}_{4}{ }^{-}$was observed, indicating that these intermediate species are resistant to oxidation. In our previous FY 2013 study, the simultaneous formation of the hydrolyzed (and unstable to oxidation) $\left[\mathrm{Tc}(\mathrm{CO})_{3}(\mathrm{OH})\left(\mathrm{H}_{2} \mathrm{O}\right)_{2}\right]$ species and of the $\left[\mathrm{Tc}(\mathrm{CO})_{3}\right]^{+} /$gluconate complex was observed in the alkaline solutions; such simultaneous species formation was not the case in this test.

In about $24-36$ hours post-solution preparation, about $3-5 \%$ of $\mathrm{Tc}(\mathrm{I})$ had oxidized to $\mathrm{TcO}_{4}{ }^{-}$in all tested solutions as was evident from the appearance of the corresponding $\mathrm{TcO}_{4}{ }^{-}$resonance (Figure 5.22, right pane). The percent-fraction of the $\left[\mathrm{Tc}(\mathrm{CO})_{3}\right]^{+} /$gluconate complex continued to decrease with time in all three solutions (Figure 5.22, middle pane). The relative quantities of the $\mathrm{Tc}(\mathrm{I})\left[\mathrm{Tc}(\mathrm{CO})_{3}\right]^{+} /$gluconate complex species and pertechnetate $\mathrm{TcO}_{4}{ }^{-}$were determined by the integration of the corresponding resonances at about $-1232 /-1254$ (combined integration) and $0 \mathrm{ppm}$, respectively (Table 5.6). Fast oxidation of the $\left[\mathrm{Tc}(\mathrm{CO})_{3}\right]^{+} /$gluconate complex species to $\mathrm{TcO}_{4}{ }^{-}$was observed so that the conversion was estimated to be completed in 14,12 , and 9 days for $0.01,0.1$, and $0.5 \mathrm{M} \mathrm{NaOH}$ solutions, respectively.

It was discovered that the decrease of $\mathrm{Tc}(\mathrm{I})$ concentration and the corresponding increase of $\mathrm{Tc}(\mathrm{VII})$ concentration were nearly linear with time as evident from the high values of the observed linear regression $\mathrm{R}^{2}$ values. The obtained slope correlates the rate of $\mathrm{Tc}(\mathrm{I})$ oxidation with the solution composition; the slope values then were plotted against $\mathrm{OH}^{-}$concentration, and a linear dependence was observed (Figure 5.24). Consistent with the results obtained for the $\left[\mathrm{Tc}(\mathrm{CO})_{3}(\mathrm{OH})\left(\mathrm{H}_{2} \mathrm{O}\right)_{2}\right]$ conversion to $\mathrm{TcO}_{4}{ }^{-}$in $5 \mathrm{M} \mathrm{NaNO}_{3} / 0.01-2 \mathrm{M} \mathrm{NaOH}$ solutions, this finding suggests that the oxidation of the $\left[\mathrm{Tc}(\mathrm{CO})_{3}\right]^{+}$gluconate complex to $\mathrm{Tc}(\mathrm{VII})$ and formation of $\mathrm{TcO}_{4}{ }^{-}$is facilitated by the hydroxide ion .
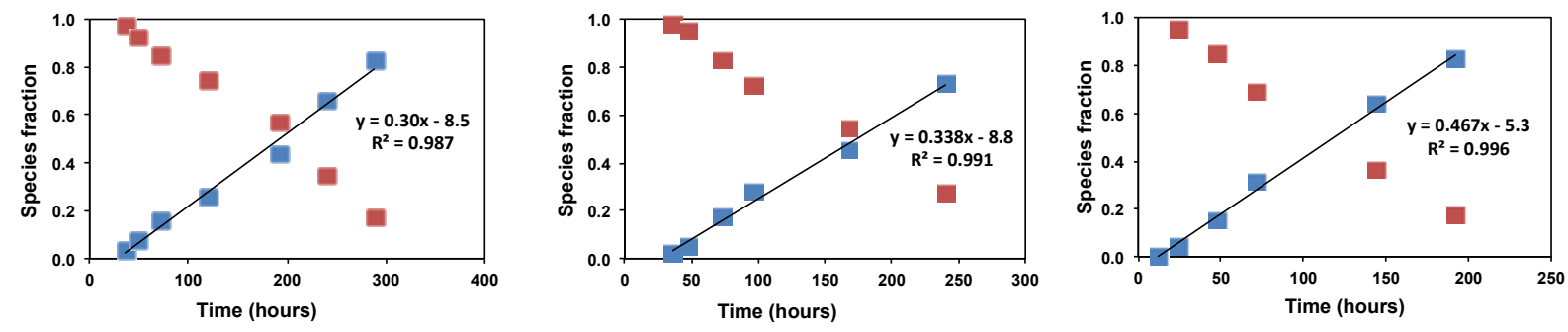

Figure 5.23. Technetium-99 Time Speciation in $5 \mathrm{M} \mathrm{NaNO}_{3} / 0.5 \mathrm{M}$ Sodium Gluconate Solutions Containing $0.01 \mathrm{M}$ (left), $0.1 \mathrm{M}$ (middle), or $0.5 \mathrm{M}$ (right) $\mathrm{NaOH}$. Red symbols: $\left[\mathrm{Tc}(\mathrm{CO})_{3}\right]^{+} /$gluconate complex. Blue symbols: $\mathrm{TcO}_{4}^{-}$. 


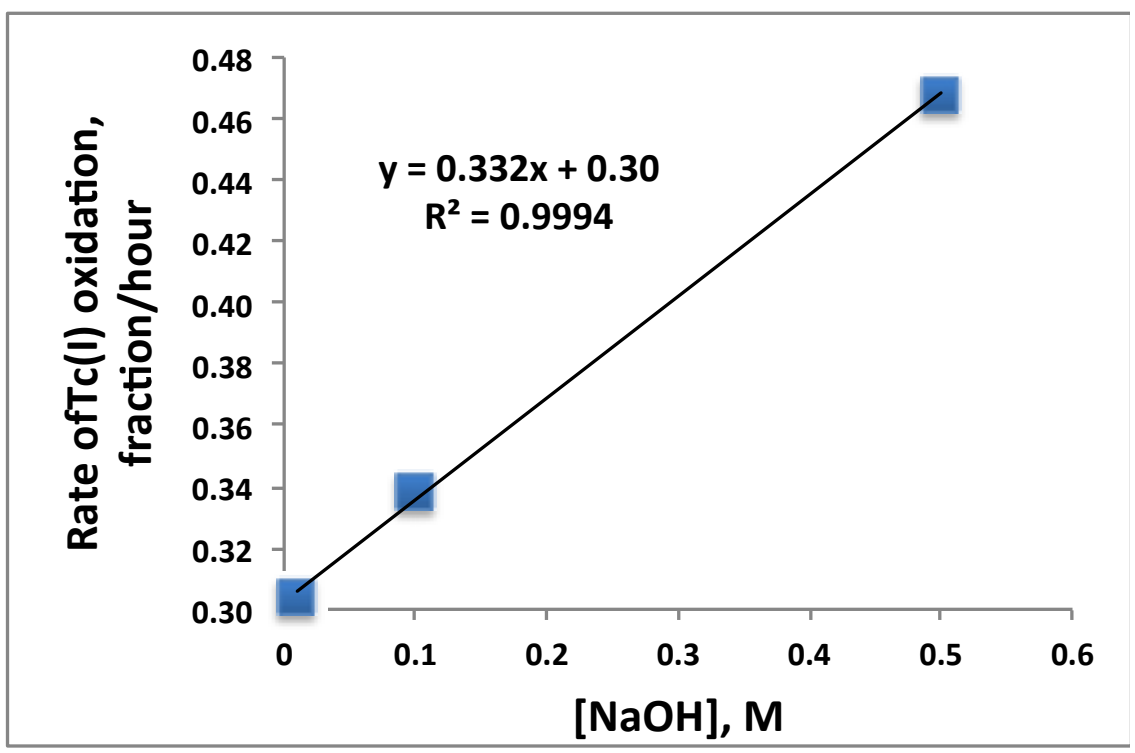

Figure 5.24. Dependence of the Kinetics of $\mathrm{Tc}(\mathrm{I})$ Oxidation to $\mathrm{TcO}_{4}{ }^{-}$on the $\mathrm{OH}^{-}$Concentration in the $5 \mathrm{M} \mathrm{NaNO}_{3} / 0.5 \mathrm{M}$ Sodium Gluconate Solution

Comparison of the $\mathrm{Tc}(\mathrm{I})$ oxidative stability in the $5 \mathrm{M} \mathrm{NaNO}_{3} / 0.01 \mathrm{M} \mathrm{NaOH}$ and $5 \mathrm{M} \mathrm{NaNO}_{3} / 0.01 \mathrm{M}$ $\mathrm{NaOH} / 0.5 \mathrm{M} \mathrm{NaGluconate}$ clearly indicates that the $\left[\mathrm{Tc}(\mathrm{CO})_{3}(\mathrm{OH})\left(\mathrm{H}_{2} \mathrm{O}\right)_{2}\right]$ species exhibit significantly greater stability than the $\left[\mathrm{Tc}(\mathrm{CO})_{3}\right]^{+}$gluconate complex in these high ionic strength solutions. Only about $11 \% \mathrm{Tc}(\mathrm{I})$ was oxidized to $\mathrm{Tc}(\mathrm{VII})$ in $5 \mathrm{M} \mathrm{NaNO}_{3} / 0.01 \mathrm{M} \mathrm{NaOH}$ solution over a 2.5 month time period (Table 5.5) while the presence of gluconate in this solution results in the complete oxidation of Tc(I) in about 2 weeks (Table 5.6).

\subsubsection{Stability of $\left[\mathrm{Tc}(\mathrm{CO})_{3}\right]^{+}$species in a pseudo-Hanford tank supernatant simulant}

To test the stability of the $\left[\mathrm{Tc}(\mathrm{CO})_{3}\right]^{+}$species in a pseudo-Hanford tank supernatant simulant composition (which is given in Table 4.3), three samples were prepared by the direct dissolution of the $\left[\mathrm{Et}_{4} \mathrm{~N}\right]_{2}\left[\mathrm{Tc}(\mathrm{CO})_{3} \mathrm{Cl}_{3}\right]$ compound into the average PEP simulant and into modified PEP simulants. Specifically, the samples were: 1) one Tc(I) sample in the original simulant matrix described in Table 4.3; 2) one Tc(I) sample in an average PEP simulant containing added noble metals and gluconate; and 3 ) one Tc(I) sample in the average PEP simulant containing added noble metals and gluconate under a $\mathrm{CO}$ atmosphere. The oxidative stability of these samples was monitored by ${ }^{99} \mathrm{Tc}$ NMR spectroscopy. The observed results are shown in Table 5.7.

To investigate the effect of hydroxide concentration on the stability of the $\left[\mathrm{Tc}(\mathrm{CO})_{3}\right]^{+}$species in a pseudo-Hanford tank supernatant simulant, three additional simulant samples were prepared with variable $\mathrm{OH}^{-}$concentrations. The results of $\left[\mathrm{Tc}(\mathrm{CO})_{3}\right]^{+}$species monitoring at these variable hydroxide concentrations also are summarized in Table 5.7. 
Table 5.7. Stability of $\left[\mathrm{Tc}(\mathrm{CO})_{3}\right]^{+}$Species in a Pseudo-Hanford Tank Supernatant Simulant Monitored by ${ }^{99} \mathrm{Tc}$ NMR Spectroscopy as a Function of Time. Relative quantities of the $\mathrm{TcO}_{4}{ }^{-}$and $\mathrm{Tc}(\mathrm{I})$ species, including $\left[\mathrm{Tc}(\mathrm{CO})_{3}(\mathrm{OH})\left(\mathrm{H}_{2} \mathrm{O}\right)_{2}\right](-1061 \mathrm{ppm})$ observed in the PEP simulant with variable hydroxide concentration and $\left[\mathrm{Tc}(\mathrm{CO})_{3}\right]^{+} /$gluconate complex species $(-1232 /-1254 \mathrm{ppm})$ observed in the simulant containing noble metals and gluconate, were determined by the integration of the corresponding resonances.

\begin{tabular}{|c|c|c|}
\hline \multirow{2}{*}{ Time Elapsed } & \multicolumn{2}{|c|}{ Percent Fraction } \\
\hline & {$\left[\mathrm{Tc}(\mathrm{CO})_{3}\right]^{+}$} & $\mathrm{TcO}_{4}^{-}$ \\
\hline \multicolumn{3}{|c|}{ Simulant $0.42 \mathrm{M} \mathrm{NaOH}, 12.2 \mathrm{mM} \mathrm{Tc}$} \\
\hline Start day & 0.94 & 0.06 \\
\hline Day 1 & 0.92 & 0.08 \\
\hline Day 2 & 0.89 & 0.11 \\
\hline Day 3 & 0.88 & 0.12 \\
\hline Day 6 & 0.79 & 0.21 \\
\hline Day 10 & 0.72 & 0.28 \\
\hline Day 14 & 0.63 & 0.37 \\
\hline Day 20 & 0.48 & 0.52 \\
\hline \multicolumn{3}{|c|}{ Simulant $0.42 \mathrm{M} \mathrm{NaOH} / \mathrm{Pd}, \mathrm{Pt}, \mathrm{Rh}, \mathrm{Ru} / 0.05 \mathrm{M}$ NaGluconate, $13.7 \mathrm{mM} \mathrm{T}$} \\
\hline Start day & $0.87^{\text {a) }}$ & 0.13 \\
\hline Day 1 & 0.70 & 0.30 \\
\hline Day 2 & 0.68 & 0.32 \\
\hline Day 3 & 0.62 & 0.38 \\
\hline Day 6 & 0.73 & 0.27 \\
\hline Day 10 & 0.42 & 0.58 \\
\hline Day 16 & 0.34 & 0.66 \\
\hline \multicolumn{3}{|c|}{$\begin{array}{c}\text { Simulant } 0.42 \mathrm{M} \mathrm{NaOH} / \mathrm{Pd}, \mathrm{Pt}, \mathrm{Rh}, \mathrm{Ru} / 0.05 \mathrm{M} \mathrm{NaGluconate} / \mathrm{CO} \text {, } \\
13.7 \mathrm{mM} \mathrm{Tc}\end{array}$} \\
\hline Start day & $0.79^{\mathrm{a}}$ & 0.21 \\
\hline Day 1 & 0.65 & 0.33 \\
\hline Day 2 & 0.61 & 0.39 \\
\hline Day 3 & 0.58 & 0.42 \\
\hline Day 6 & 0.57 & 0.43 \\
\hline Day 10 & 0.42 & 0.58 \\
\hline Day 16 & 0.34 & 0.66 \\
\hline
\end{tabular}


Table 5.7. (con't)

\begin{tabular}{|c|c|c|}
\hline \multirow{3}{*}{ Time Elapsed } & \multicolumn{2}{|c|}{ Percent Fraction } \\
\hline & {$\left[\mathrm{Tc}(\mathrm{CO})_{3}\right]^{+}$} & $\mathrm{TcO}_{4}$ \\
\hline & \multicolumn{2}{|c|}{ Simulant $0.83 \mathrm{M} \mathrm{NaOH}, 13.2 \mathrm{mM} \mathrm{Tc}$} \\
\hline Start day & 0.96 & 0.04 \\
\hline Day 1 & 0.89 & 0.11 \\
\hline Day 3 & 0.78 & 0.22 \\
\hline \multicolumn{3}{|c|}{ Simulant $1.47 \mathrm{M} \mathrm{NaOH}, 10.7 \mathrm{mM}$ Tc } \\
\hline Start day & 0.95 & 0.05 \\
\hline Day 1 & 0.82 & 0.18 \\
\hline Day 3 & 0.63 & 0.37 \\
\hline Day 6 & 0.27 & 0.73 \\
\hline \multicolumn{3}{|c|}{ Simulant 3.0 M NaOH, 9.4 mM Tc } \\
\hline Start day & 0.90 & 0.10 \\
\hline Day 1 & 0.68 & 0.32 \\
\hline Day 2 & 0.44 & 0.56 \\
\hline Day 3 & 0.38 & 0.62 \\
\hline Day 4 & 0.12 & 0.88 \\
\hline Day 7 & 0.03 & 0.97 \\
\hline Day 8 & 0 & 1 \\
\hline
\end{tabular}

a. Combined concentration of $\left[\mathrm{Tc}(\mathrm{CO})_{3}(\mathrm{OH})\left(\mathrm{H}_{2} \mathrm{O}\right)_{2}\right](-1061 \mathrm{ppm})$ and $\left[\mathrm{Tc}(\mathrm{CO})_{3}\right]^{+} /$gluconate complex.

The ${ }^{99} \mathrm{Tc}$ NMR spectrum of the starting $\left[\mathrm{Tc}(\mathrm{CO})_{3}\right]^{+}$solution in the simulant solutions containing variable $\mathrm{OH}^{-}$concentration showed formation of the $\left[\mathrm{Tc}(\mathrm{CO})_{3}(\mathrm{OH})\left(\mathrm{H}_{2} \mathrm{O}\right)_{2}\right]$ species appearing at about $-1062 \mathrm{ppm}$ and a small fraction of $\mathrm{TcO}_{4}{ }^{-}$. The concentration of $\mathrm{TcO}_{4}{ }^{-}$gradually increased with time due to the slow oxidation of the $\left[\mathrm{Tc}(\mathrm{CO})_{3}(\mathrm{OH})\left(\mathrm{H}_{2} \mathrm{O}\right)_{2}\right]$ species. Interestingly, the kinetics of $\left[\mathrm{Tc}(\mathrm{CO})_{3}(\mathrm{OH})\left(\mathrm{H}_{2} \mathrm{O}\right)_{2}\right.$ ] oxidation in the simulants containing $0.42,0.83$, or $1.47 \mathrm{M} \mathrm{OH}^{-}$was slower than that in the $5 \mathrm{M} \mathrm{NaNO}_{3} / 0.5-2 \mathrm{M} \mathrm{NaOH}$ solutions (Tables 5.7 and 5.5). Further, in the simulant containing 3M hydroxide, the full decomposition of the $\left[\mathrm{Tc}(\mathrm{CO})_{3}(\mathrm{OH})\left(\mathrm{H}_{2} \mathrm{O}\right)_{2}\right]$ species was observed in 8 days while in the $5 \mathrm{M} \mathrm{NaNO}_{3} / 2 \mathrm{M} \mathrm{NaOH}$ solution, the same process was completed before day 4 .

To compare rates of the $\left[\mathrm{Tc}(\mathrm{CO})_{3}(\mathrm{OH})\left(\mathrm{H}_{2} \mathrm{O}\right)_{2}\right]$ conversion to $\mathrm{TcO}_{4}{ }^{-}$, the kinetic plots were constructed for the simulant solutions containing variable $\mathrm{OH}^{-}$concentrations (Figure 5.25). As for simple $5 \mathrm{M}$ $\mathrm{NaNO}_{3} / \mathrm{NaOH}$ solutions, it was found that the initial increase of the $\mathrm{TcO}_{4}{ }^{-}$concentration over time can be reasonably fitted by a linear equation. For $0.42,0.83$, and $1.47 \mathrm{M} \mathrm{OH}^{-}$the obtained slope values quantifying the rate of the Tc(I) oxidation with time (fraction per hour) exhibited nearly linear dependence on the $\mathrm{OH}^{-}$concentration in the solution (Figure 5.26). A comparison with the corresponding slope observed for the $5 \mathrm{M} \mathrm{NaNO}_{3} / \mathrm{NaOH}$ solutions indicates that effect of the hydroxide on the 
generation of $\mathrm{TcO}_{4}{ }^{-}$is significantly suppressed in the PEP simulant. The reason for this behavior is currently unclear.
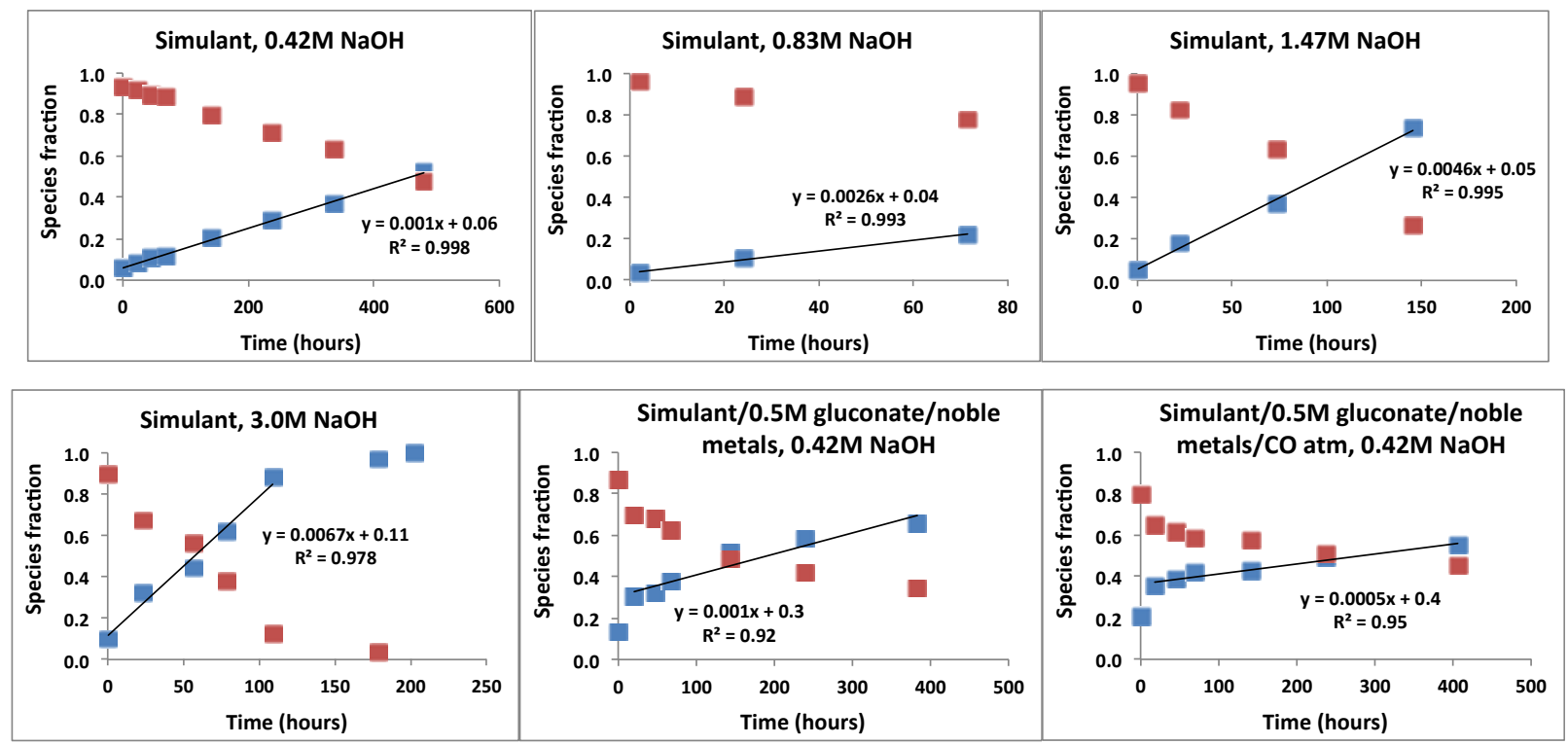

Figure 5.25. Effect of Variable Hydroxide Solutions and Presence of Noble Metals/0.05 M NaGluconate on Tc Time Speciation in PEP Simulant. Red symbols: $\left[\mathrm{Tc}(\mathrm{CO})_{3}\right]^{+}$species. Blue symbols: $\mathrm{TcO}_{4}{ }^{-}$.

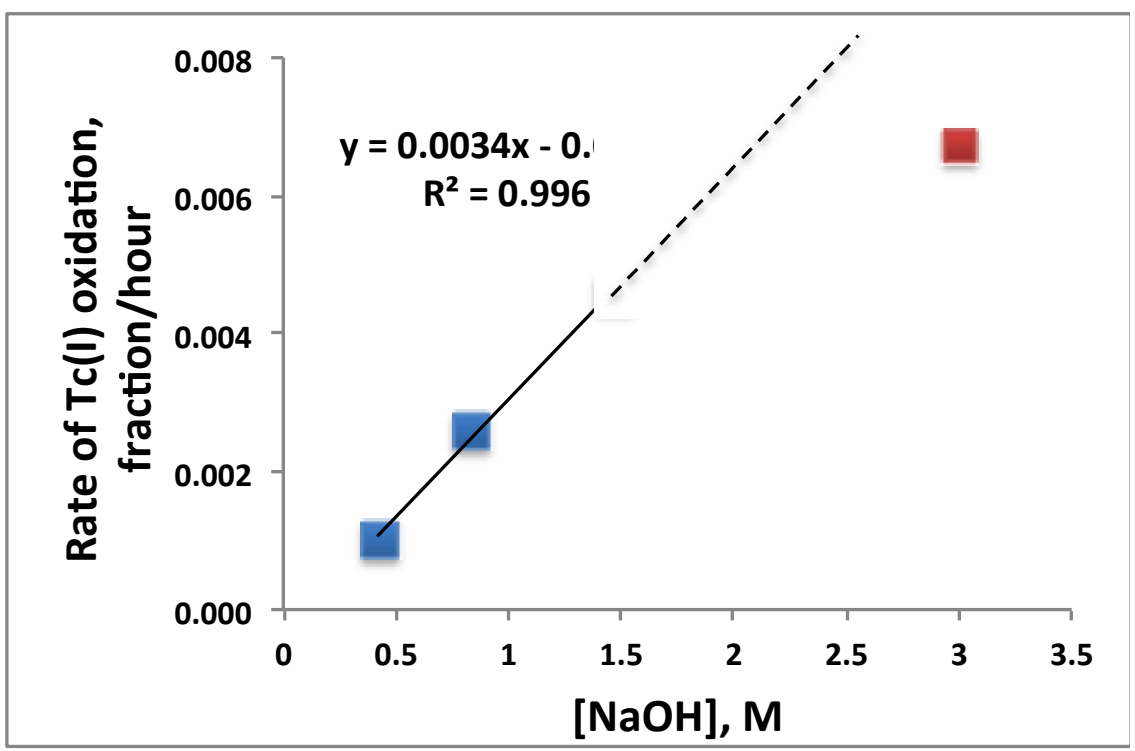

Figure 5.26. Dependence of the Kinetics of $\mathrm{Tc}(\mathrm{I})$ Oxidation to $\mathrm{TcO}_{4}{ }^{-}$on the $\mathrm{OH}^{-}$Concentration in the PEP Simulant. Blue symbols: $0.4-1.5 \mathrm{M} \mathrm{OH}^{-}$. Red symbol: $3 \mathrm{M} \mathrm{OH}^{-}$. 
Both samples prepared in simulants containing noble metals and gluconate, with one being under air and one under a $\mathrm{CO}$ atmosphere, exhibited the formation of the $\left[\mathrm{Tc}(\mathrm{CO})_{3}\right]^{+} /$gluconate complex as evident from the $\mathrm{Tc}(\mathrm{I})$ resonances at -1232 and $-1247 \mathrm{ppm}$. The starting solutions, whose NMR spectra were recorded within $0.5-2$ hours post-preparation, contained $\mathrm{Tc}(\mathrm{I})$ in two forms, $\left[\mathrm{Tc}(\mathrm{CO})_{3}(\mathrm{OH})\left(\mathrm{H}_{2} \mathrm{O}\right)_{2}\right]$ and the $\left[\mathrm{Tc}(\mathrm{CO})_{3}\right]^{+} /$gluconate complex. Both starting solutions contained appreciable concentrations of $\mathrm{TcO}_{4}{ }^{-}$ as well, indicating that 13 and $20 \%$ of $\mathrm{Tc}(\mathrm{I})$ were oxidized in the simulants under air and $\mathrm{CO}$ atmosphere, respectively. NMR analysis revealed that the conversion of the $\left[\mathrm{Tc}(\mathrm{CO})_{3}(\mathrm{OH})\left(\mathrm{H}_{2} \mathrm{O}\right)_{2}\right]$ species to the $\left[\mathrm{Tc}(\mathrm{CO})_{3}\right]^{+} /$gluconate complex and $\mathrm{TcO}_{4}{ }^{-}$was completed in 18 hours post-solution preparation. This result is different from the findings reported herein that the formation of the $\left[\mathrm{Tc}(\mathrm{CO})_{3}\right]^{+} /$gluconate complex in the $5 \mathrm{M} \mathrm{NaNO}_{3} / 0.01-0.5 \mathrm{M} \mathrm{NaOH} / 0.5 \mathrm{M} \mathrm{NaGluconate}$ solutions involved some different oxidation-resistant intermediate species (see Section 5.2.3). An explanation as to the cause of these differing behaviors in the two studies remains unknown.

In the simulant containing noble metals and gluconate, initial oxidation of the $\left[\operatorname{Tc}(\mathrm{CO})_{3}\right]^{+}$species and $\mathrm{TcO}_{4}{ }^{-}$generation was fast and then significantly slowed down after about 24 hours post-solution preparation. By day 6 , about $50 \%$ of the $\left[\mathrm{Tc}(\mathrm{CO})_{3}\right]^{+}$gluconate complex decomposed while only about $20 \%\left[\mathrm{Tc}(\mathrm{CO})_{3}(\mathrm{OH})\left(\mathrm{H}_{2} \mathrm{O}\right)_{2}\right]$ underwent oxidation in the original simulant. However, a comparison of the kinetic plots (Figure 5.25) clearly indicates that the rate of pertechnetate generation in the original simulant $\left(0.42 \mathrm{M} \mathrm{OH}^{-}\right)$was nearly the same as in the aerated simulant containing added noble metals and gluconate but was significantly reduced in the simulant containing noble metals and gluconate under $\mathrm{CO}$ atmosphere.

Oxidation of the $\left[\mathrm{Tc}(\mathrm{CO})_{3}\right]^{+} /$gluconate complex was considerably slower in the simulant than in the $5 \mathrm{M} \mathrm{NaNO}_{3} / 0.5 \mathrm{M} \mathrm{NaOH} / 0.5 \mathrm{M} \mathrm{NaGluconate} \mathrm{solution} \mathrm{(Table} 5.7$ and Table 5.6) as seen from the corresponding kinetic plots (Figure 5.23 and Figure 5.25).

\subsection{Reduction of $\mathrm{TcO}_{4}{ }^{-}$in a Pseudo-Hanford Tank Supernatant Simulant}

The purpose of this test was to evaluate the reductive stability of pertechnetate and the potential of generation of non-pertechnetate species, such as Tc(I)-tricarbonyl, in a pseudo-Hanford tank supernatant simulant considered to be well suited to observe these phenomena. Specifically, to facilitate $\mathrm{TcO}_{4}{ }^{-}$ reduction, noble metals, including $0.13 \mathrm{mM} \mathrm{Pt}, 0.57 \mathrm{mM} \mathrm{Pd}, 0.014 \mathrm{mM} \mathrm{Rh}$, and $1.04 \mathrm{mM} \mathrm{Ru}$, were added to the simulant. The simulant was also adjusted to contain $0.05 \mathrm{M}$ sodium gluconate. To the resulting solution, a concentrated stock of $\mathrm{NH}_{4} \mathrm{TcO}_{4}$ solution was added to achieve a $5 \mathrm{mM} \mathrm{Tc}$ concentration in the simulant. The resulting solution was analyzed by ${ }^{99} \mathrm{Tc} \mathrm{NMR}$. Its spectrum (Figure 5.27) exhibited a very strong $\mathrm{TcO}_{4}{ }^{-}$resonance at about $-2 \mathrm{ppm}$ and was the only observed Tc species. The solution was placed in an unstirred pressure vessel, flushed with $\mathrm{CO}$, and pressurized with $\mathrm{CO}$ gas that contained approximately $75 \mathrm{ppm} \mathrm{H}_{2}$.

The simulant was kept at $80{ }^{\circ} \mathrm{C}$ and 1300 psi for 12 days. Upon conclusion of the test, the solution was returned to room temperature and pressure, unsealed, and sampled soon after exposure to the atmosphere. ${ }^{99} \mathrm{Tc}$ NMR spectroscopy revealed that $>99 \% \mathrm{TcO}_{4}{ }^{-}$was reduced, this estimate being based on the proportional reduction of the pertechnetate resonance after being normalized to the number of scans (Figure 5.26). 
The NMR spectrum of the $\mathrm{CO} / \mathrm{H}_{2}$-reacted simulant containing $0.05 \mathrm{M}$ gluconate exhibited two $\mathrm{Tc}(\mathrm{I})$ resonances at -1232 and -1254 ppm corresponding to the Tc(I)-tricarbonyl gluconate species, with an additional resonance at $-1094 \mathrm{ppm}$ (Figure 5.28). The resonance at $-1094 \mathrm{ppm}$ was speculatively attributed to also be a species derived from $\left[\mathrm{Tc}(\mathrm{CO})_{3}\right]^{+}$as it appeared in the frequency range typical for the Tc(I)-tricarbonyl compounds. However, the exact composition of these species has not been elucidated. The $\left[\mathrm{Tc}(\mathrm{CO})_{3}\right]^{+} /$gluconate complex resonances at -1232 and $-1254 \mathrm{ppm}$ observed in the reacted simulant are nearly identical to those generated by the dissolution of the $\operatorname{Tc}(\mathrm{I})\left[\mathrm{Tc}(\mathrm{CO})_{3} \mathrm{Cl}_{3}\right]^{2-}$ compound in either the $5 \mathrm{M} \mathrm{NaNO}_{3} / 0.5 \mathrm{M} \mathrm{NaOH} / 0.5 \mathrm{M}$ sodium gluconate (green trace) solution or in the simulant (red trace) (Figure 5.28). One difference between these spectra is the narrow line widths associated with resonances found in the $\mathrm{CO} / \mathrm{H}_{2}$-reacted simulant. This feature, along with the inability to simultaneously phase all of the resonances in the sample, is attributed to the presence of paramagnetic constituents, such as Tc(IV).

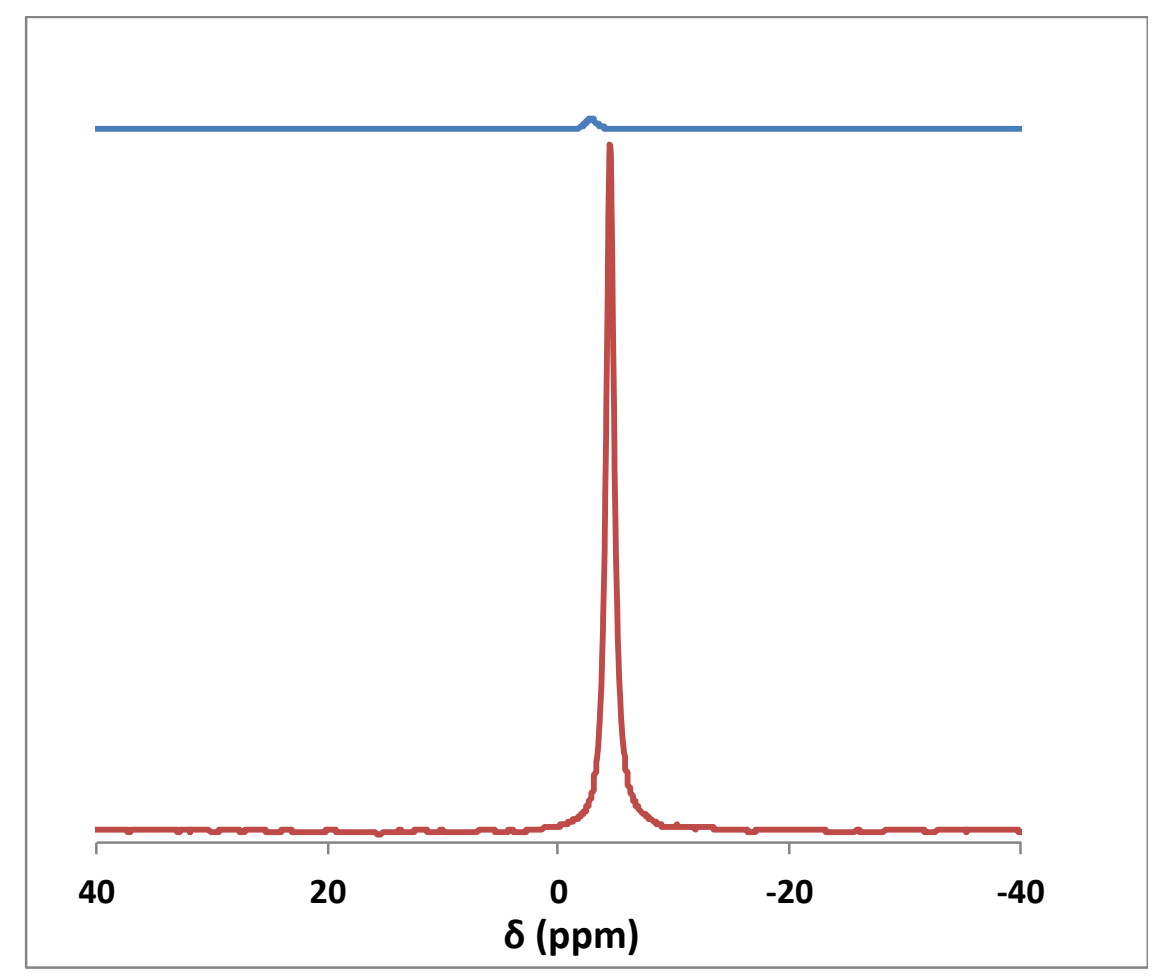

Figure 5.27. Comparison of the Pertechnetate Resonances in the ${ }^{99} \mathrm{Tc}$ NMR Spectra of the Pseudo-Hanford Tank Supernatant Simulant Containing Noble Metals and Gluconate Before (red trace) and After (blue trace) the $\mathrm{TcO}_{4}{ }^{-}$Reduction by $\mathrm{CO} / \mathrm{H}_{2}$ 


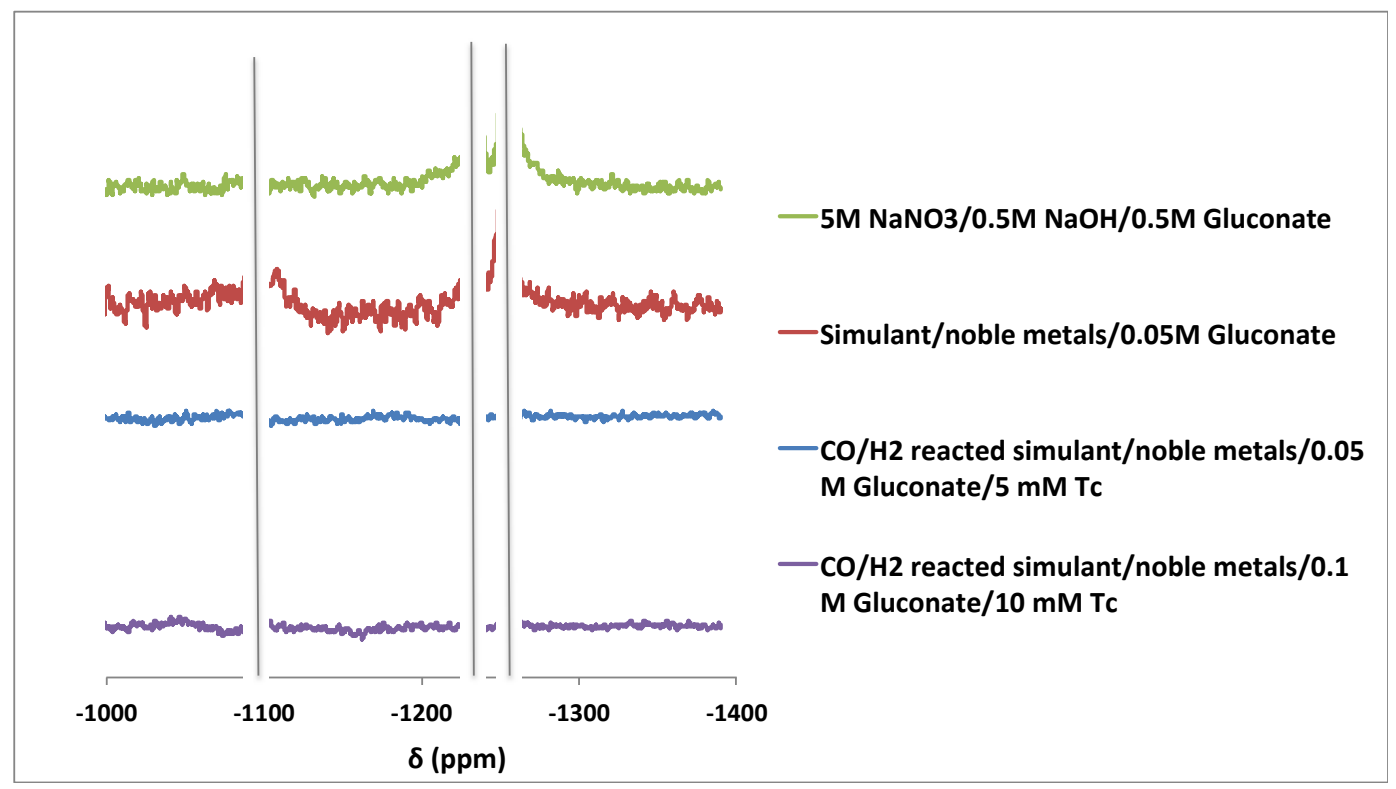

Figure 5.28. Comparison of the ${ }^{99} \mathrm{Tc} \mathrm{NMR}$ Spectra of the $\left[\mathrm{Tc}(\mathrm{CO})_{3}\right]^{+}$Gluconate Complex Generated by the Reduction of $\mathrm{TcO}_{4}{ }^{-}$in the $\mathrm{CO} / \mathrm{H}_{2}$-reacted Pseudo-Hanford Tank Supernatant Simulant Solutions Containing Noble Metals and 0.05M Gluconate $/ 5 \mathrm{mM}$ Tc (blue trace) or $0.1 \mathrm{M}$ Gluconate/10 mM Tc (purple trace) with the Spectra of Tc(I) Solutions Obtained by the Dissolution of the $\left[\mathrm{Et}_{4} \mathrm{~N}\right]_{2}\left[\mathrm{Tc}(\mathrm{CO})_{3} \mathrm{Cl}_{3}\right]$ Compound in the $5 \mathrm{M} \mathrm{NaNO}_{3} / 0.5 \mathrm{M} \mathrm{NaOH} / 0.5 \mathrm{M}$ Sodium Gluconate (green trace) and in the Pseudo-Hanford Tank Supernatant Simulant Containing Noble Metals and 0.05M Gluconate (red trace). The phase correction of the $\mathrm{CO} / \mathrm{H}_{2}$-reacted simulant spectra was not possible and is believed to be due to the presence of paramagnetic constituents, presumably Tc(IV).

The major $\mathrm{TcO}_{4}{ }^{-}$reduction product in the $\mathrm{CO} / \mathrm{H}_{2}$-reacted simulants was tentatively assigned to the ${ }^{99}$ Tc NMR-inactive Tc(IV) species as no additional resonances were found in the NMR spectrum. This assumption was also supported by the visual inspection of the reacted simulant solution, which contained a significant amount of black precipitate similar to that observed with insoluble $\mathrm{TcO}_{2}$. The ${ }^{99} \mathrm{Tc} \mathrm{NMR}$ spectrum, collected over a positive chemical shift window characteristic of $\mathrm{Tc}(\mathrm{V})$ compounds, did not reveal the presence of any $\mathrm{Tc}(\mathrm{V})$ species.

The $\mathrm{CO} / \mathrm{H}_{2}$-reacted simulant was monitored by ${ }^{99} \mathrm{Tc}$ NMR spectroscopy following exposure to the atmosphere, and the observed results are shown in Table 5.8. The area of each observed resonance was determined by the integration and normalized for the number of scans. The integrals of the resonances corresponding to the $\left[\mathrm{Tc}(\mathrm{CO})_{3}\right]^{+} /$gluconate complex species at $-1094,-1232$, and $-1254 \mathrm{ppm}$ were summed. Surprisingly, the concentration of the $\left[\mathrm{Tc}(\mathrm{CO})_{3}\right]^{+} /$gluconate increased from the time the reaction was stopped, reached the maximum at day 4 post-reaction, and decreased after that. The concentration of the $\mathrm{TcO}_{4}{ }^{-}$gradually increased with time. This increase in pertechnetate cannot be explained solely by the decomposition of the $\left[\mathrm{Tc}(\mathrm{CO})_{3}\right]^{+} /$gluconate complex and was tentatively attributed to the oxidation of Tc(IV). 
Table 5.8. Time Monitoring of the Observed ${ }^{99} \mathrm{Tc}$ NMR Resonances in the $\mathrm{CO} / \mathrm{H}_{2}$-reacted Pseudo-Hanford Tank Supernatant Simulant. The composition of the simulant is given in Table 4.3. Each band area was determined by the integration and normalized for the number of scans. The integrals of the resonances corresponding to the $\left[\mathrm{Tc}(\mathrm{CO})_{3}\right]^{+} /$gluconate complex are shown as a sum of integrals of the individual -1094, -1232, and -1254 ppm resonances.

\begin{tabular}{|c|c|c|}
\hline \multirow[t]{2}{*}{ Time Elapsed } & \multicolumn{2}{|c|}{$\begin{array}{c}\text { Resonance Area Normalized for Number of Scans, } \\
\text { Integral/Scan }\end{array}$} \\
\hline & {$\left[\mathrm{Tc}(\mathrm{CO})_{3}\right]^{+}$} & $\mathrm{TcO}_{4}^{-}$ \\
\hline \multicolumn{3}{|c|}{$\begin{array}{c}\mathrm{CO} / \mathrm{H}_{2} \text {-reacted simulant } / \mathrm{Pd}, \mathrm{Pt}, \mathrm{Rh}, \mathrm{Ru} / 0.05 \mathrm{M} \mathrm{NaGluconate}, \\
5 \mathrm{mM} \mathrm{Tc}\end{array}$} \\
\hline Start day & 39 & 141 \\
\hline Day 1 & 38 & 144 \\
\hline Day 4 & 81 & 214 \\
\hline Day 7 & 64 & 247 \\
\hline Day 9 & 29 & 244 \\
\hline Day 14 & 21 & 300 \\
\hline Day 17 & 13 & 347 \\
\hline Day 21 & 14 & 353 \\
\hline \multicolumn{3}{|c|}{$\begin{array}{c}\mathrm{CO} / \mathrm{H}_{2} \text {-reacted simulant/Pd, } \mathrm{Pt}, \mathrm{Rh}, \mathrm{Ru} / 0.1 \mathrm{M} \mathrm{NaGluconate}, \\
10 \mathrm{mM} \mathrm{Tc}\end{array}$} \\
\hline Start day: $0.5 \mathrm{hr}$ & 2090 & 0 \\
\hline Start day: $4 \mathrm{hr}$ & 1980 & 12 \\
\hline Day 1 & 1760 & 49 \\
\hline Day 3 & 1860 & 244 \\
\hline Day 5 & 1720 & 380 \\
\hline Day 8 & 1660 & 397 \\
\hline
\end{tabular}

The reaction to reduce $\mathrm{TcO}_{4}{ }^{-}$in the supernatant simulant was repeated under slightly modified conditions. In this test, the concentration of gluconate in the simulant was $0.1 \mathrm{M}$, double the first test. The concentration of $\mathrm{TcO}_{4}{ }^{-}$was doubled as well to improve the NMR signal-to-noise ratio for the $\mathrm{Tc}(\mathrm{I})$ reaction product. The simulant was kept at $80{ }^{\circ} \mathrm{C}$ and $1300 \mathrm{psi}$ of $\mathrm{CO} / \mathrm{H}_{2}$ mixed gas atmosphere for 12 days. The visual examination of the reaction mixture indicated the presence of a significantly smaller amount of the black solids that have tentatively been attributed to the $\mathrm{TcO}_{2}$ reduction product. Interestingly, in this test $100 \% \mathrm{TcO}_{4}{ }^{-}$was reduced, as was apparent from the absence of the $\mathrm{TcO}_{4}{ }^{-}$ resonance in the reacted simulant. The concentration of the $\mathrm{Tc}(\mathrm{I})$ products was significantly increased as compared with the first reaction. Only two resonances at -1096 and -1254 were observed in the spectrum (Figure 5.28) with the $\left[\mathrm{Tc}(\mathrm{CO})_{3}\right]^{+}$compound corresponding to the $-1094 \mathrm{ppm}$ resonance being the dominant product. The time monitoring of the composition and stability of this $\mathrm{CO} / \mathrm{H}_{2}$-reacted simulant is shown in Table 5.8; the integrals of the resonances corresponding to the $\left[\mathrm{Tc}(\mathrm{CO})_{3}\right]^{+} /$gluconate complex species at -1094 and $-1254 \mathrm{ppm}$ were summed. The concentration of the $\left[\mathrm{Tc}(\mathrm{CO})_{3}\right]^{+}$gradually decreased. 
The $\mathrm{TcO}_{4}{ }^{-}$concentration increased with time, which again was attributed to the combined $\mathrm{Tc}(\mathrm{I})$ and $\mathrm{Tc}(\mathrm{IV})$ oxidation to pertechnetate. The monitoring of this is continuing at the time of writing. 


\subsection{Discussion}

The synthetic effort conducted in FY 2014 resulted in an optimized two-step reduction procedure for the preparation of the $\mathrm{Tc}(\mathrm{I})\left[\mathrm{Tc}(\mathrm{CO})_{3} \mathrm{Cl}_{3}\right]^{2-}$ compound from $\mathrm{TcO}_{4}{ }^{-}$in $75 \%$ yield based on $\mathrm{Tc}-99$. The $\left[\mathrm{Tc}(\mathrm{CO})_{3} \mathrm{Cl}_{3}\right]^{2-}$ is a convenient precursor to various aqueous $\left[\mathrm{Tc}(\mathrm{CO})_{3}\right]^{+}$species, which can easily be prepared by $\mathrm{Cl}^{-}$exchange with $\mathrm{H}_{2} \mathrm{O}$ or $\mathrm{OH}^{-}$at room temperature. Both $\left[\mathrm{Tc}(\mathrm{CO})_{3} \mathrm{Cl}_{3}\right]^{2-}$ and the aqueous $\left[\mathrm{Tc}(\mathrm{CO})_{3}\right]^{+}$species were characterized by ${ }^{99} \mathrm{Tc}$ NMR, FTIR, and UV-vis spectroscopic techniques.

Comparison of the $\left[\mathrm{Tc}(\mathrm{CO})_{3}\right]^{+}$spectral data collected in water and $5 \mathrm{M} \mathrm{NaNO}_{3}$ (Table 6.1) revealed that the same species are formed in both solutions and implies there is no significant formation of $\left[\mathrm{Tc}(\mathrm{CO})_{3}\right]^{+}$nitrate complexes.

Table 6.1. $\left[\mathrm{Tc}(\mathrm{CO})_{3}\right]^{+}$Speciation in Water and $5 \mathrm{M} \mathrm{NaNO}_{3}$ by ${ }^{99} \mathrm{Tc}-\mathrm{NMR}$ Spectroscopy

\begin{tabular}{|c|c|c|}
\hline Species & $\begin{array}{c}\text { Chemical Shift (ppm) } \\
\text { in Water }\end{array}$ & $\begin{array}{c}\text { Chemical Shift (ppm) } \\
\text { in } \mathbf{~ M ~ N a N O ~}_{3}\end{array}$ \\
\hline $\mathrm{TcO}_{4}^{-}$ & $\approx 0$ & $\approx 0$ \\
\hline$\left[\mathrm{Tc}(\mathrm{CO})_{3}\left(\mathrm{H}_{2} \mathrm{O}\right)_{3}\right]^{+}$ & $\approx-869$ & $\approx-869$ \\
\hline$\left[\mathrm{Tc}(\mathrm{CO})_{3}(\mathrm{OH})\left(\mathrm{H}_{2} \mathrm{O}\right)_{2}\right]$ & $\approx-1060$ & $\approx-1062$ \\
\hline$\left[\mathrm{Tc}(\mathrm{CO})_{3}(\mathrm{OH})_{2}\left(\mathrm{H}_{2} \mathrm{O}\right)\right]^{-}$ & $\approx-1146$ & Not measured \\
\hline$\left[\mathrm{Tc}(\mathrm{CO})_{3}(\mathrm{OH})\right]_{4}$ & $\approx-585$ & $\approx-585$ \\
\hline$\left[\mathrm{Tc}(\mathrm{CO})_{4}\left(\mathrm{H}_{2} \mathrm{O}\right)_{2}\right]^{+}$ & $\approx-901$ & $\approx-902$ \\
\hline$\left[\mathrm{Tc}(\mathrm{CO})_{3}\right]^{+} / \mathrm{gluconate}$ & $-1230,-1247$ & $-1232,-1253$ \\
\hline
\end{tabular}

The $\mathrm{pH}$ speciation of the $\left[\mathrm{Tc}(\mathrm{CO})_{3}\right]^{+}$aqua complexes was found to be similar in water and in $5 \mathrm{M}$ $\mathrm{NaNO}_{3}$. The triaqua $\left[\mathrm{Tc}(\mathrm{CO})_{3}\left(\mathrm{H}_{2} \mathrm{O}\right)_{3}\right]^{+}$ion exists only in acidic aqueous solutions and undergoes extensive hydrolysis starting at near-neutral pH. Consistent with literature reports (Gorshkov et al. 2000; Alberto et al. 1998), the mono-hydrolyzed $\left[\mathrm{Tc}(\mathrm{CO})_{3}(\mathrm{OH})\left(\mathrm{H}_{2} \mathrm{O}\right)_{2}\right]$ species was observed to undergo oligomerization readily and form the neutral, tetrameric $\left[\mathrm{Tc}(\mathrm{CO})_{3}(\mathrm{OH})\right]_{4}$ species. This oligomerization takes place over the relatively narrow $\mathrm{pH}$ range from about 6.5 to about 8 . In more alkaline solutions, the monomeric $\left[\mathrm{Tc}(\mathrm{CO})_{3}(\mathrm{OH})\left(\mathrm{H}_{2} \mathrm{O}\right)_{2}\right]$ species persists in solution. Theoretical COSMO calculations resulted in excellent agreement of the predicted and experimental ${ }^{99} \mathrm{Tc}$ NMR chemical shifts of these Tc(I) $\left[\mathrm{Tc}(\mathrm{CO})_{3}\right]^{+}$aqua complexes.

This work demonstrated that the $\left[\mathrm{Tc}(\mathrm{CO})_{3}\right]^{+} /$gluconate complex is formed in alkaline solutions containing no to high concentrations of nitrate. The theoretical calculations revealed that this complex is unlikely to have chemical composition of $\left[\mathrm{Tc}(\mathrm{CO})_{3}\right.$ (gluconate $\left.)\right]^{2-}$; formation of a mixed hydroxo/gluconate $\left[\mathrm{Tc}(\mathrm{CO})_{3}(\mathrm{OH})_{\mathrm{n}}(\text { gluconate })\right]^{\mathrm{n}-2}$ species is feasible but is by no means the only alternative. This conclusion is supported by the appearance of two resonances in the NMR spectrum suggesting the existence of two non-equivalent Tc(I) centers. The positions of these resonances are shifted up-field from the calculated position of the single resonance predicted by the theory due to the shielding effect of $\mathrm{OH}^{-}$ligand. Additional studies are warranted to elucidate the structure of the $\left[\mathrm{Tc}(\mathrm{CO})_{3}\right]^{+} /$gluconate complex. 
Relatively slow rates of formation for the $\left[\mathrm{Tc}(\mathrm{CO})_{3}\right]^{+} /$gluconate complex in solution were observed. The mechanism of this process currently is unclear. As described in this report, the initial generation of the hydrolyzed $\left[\mathrm{Tc}(\mathrm{CO})_{3}(\mathrm{OH})\left(\mathrm{H}_{2} \mathrm{O}\right)_{2}\right]$ intermediate species and its subsequent conversion to a $\left[\mathrm{Tc}(\mathrm{CO})_{3}\right]^{+} /$gluconate complex were observed upon dissolution of the solid $\left[\mathrm{Tc}(\mathrm{CO})_{3} \mathrm{Cl}_{3}\right]^{2-}$ compound in the pseudo-Hanford supernatant simulant (Section 5.2.4) and in our previous experiments involving the mixing of the aqueous $\left[\mathrm{Tc}(\mathrm{CO})_{3}\left(\mathrm{H}_{2} \mathrm{O}\right)_{3}\right]^{+}$and gluconate/ $\mathrm{NaOH}$ solutions (Rapko et al. 2013). This process proceeds with the concomitant oxidation of $\mathrm{Tc}(\mathrm{I})$ to $\mathrm{Tc}(\mathrm{VII})$ and generation of $\mathrm{TcO}_{4}{ }^{-}$. Intriguingly, the other pathway of the formation of the $\left[\mathrm{Tc}(\mathrm{CO})_{3}\right]^{+}$gluconate complex was observed in this work. When the solid $\left[\mathrm{Tc}(\mathrm{CO})_{3} \mathrm{Cl}_{3}\right]^{2-}$ material was first dissolved in the $5 \mathrm{M} \mathrm{NaNO}_{3}$ solution and then added to a $5 \mathrm{M} \mathrm{NaNO}_{3} / 0.01-0.5 \mathrm{M} \mathrm{NaOH} / 0.5 \mathrm{M}$ sodium gluconate solution, ${ }^{99} \mathrm{Tc} \mathrm{NMR}$ measurements demonstrated an initial absence of any Tc resonances followed by the slow in-growth of the $\left[\mathrm{Tc}(\mathrm{CO})_{3}\right]^{+}$gluconate complex. Since no resonances due to the $\left[\mathrm{Tc}(\mathrm{CO})_{3}(\mathrm{OH})\left(\mathrm{H}_{2} \mathrm{O}\right)_{2}\right]$ species were observed in the spectra, a different mechanism for gluconate complex formation should be considered here. In addition, no $\mathrm{Tc}(\mathrm{I})$ oxidation to $\mathrm{TcO}_{4}{ }^{-}$was observed during this reaction. Further studies are needed to understand the various mechanistic aspects of $\left[\mathrm{Tc}(\mathrm{CO})_{3}\right]^{+} /$gluconate complex formation.

In this work, extensive testing has been conducted in monitoring the oxidative stability of aqueous $\left[\mathrm{Tc}(\mathrm{CO})_{3}\right]^{+}$species in different matrices. Our initial studies indicate that both $\left[\mathrm{Tc}(\mathrm{CO})_{3}\left(\mathrm{H}_{2} \mathrm{O}\right)_{3}\right]^{+}$and its oligomerized first hydrolysis product $\left[\mathrm{Tc}(\mathrm{CO})_{3}(\mathrm{OH})\right]_{4}$ are stable to oxidation in strong $\mathrm{NaNO}_{3}$ solutions at near-neutral $\mathrm{pH}$ for months. This stands in marked contrast to the results of our previous testing, which indicated poor oxidative stability of the $\left[\mathrm{Tc}(\mathrm{CO})_{3}\right]^{+}$species in aqueous solutions of low ionic strength regardless of the solution's pH (Rapko et al. 2013). One possible explanation for the increased stability of the aqueous $\left[\mathrm{Tc}(\mathrm{CO})_{3}\right]^{+}$species in the concentrated $\mathrm{NaNO}_{3}$ solutions could be the lower levels of the dissolved oxygen in these solutions as compared with water. The solubility of oxygen significantly decreases as an electrolyte concentration in solution increases so that the concentration of the dissolved oxygen in the $5 \mathrm{M} \mathrm{NaNO}_{3}$ solution is about half of that in water (Tromans 2000 ). The $5 \mathrm{M} \mathrm{NaNO}_{3} / 0.01 \mathrm{M}$ $\mathrm{NaOH}$ solution also exhibited high stability for the aqueous $\left[\mathrm{Tc}(\mathrm{CO})_{3}\right]^{+}$species so that only about $11 \%$ $\left[\mathrm{Tc}(\mathrm{CO})_{3}(\mathrm{OH})\left(\mathrm{H}_{2} \mathrm{O}\right)_{2}\right.$ ] was oxidized to $\mathrm{TcO}_{4}{ }^{-}$in 74 days. Moreover, the rate of oxidation of this species reduced with time, and its concentration remained nearly constant after 34 days from the time of solution preparation. This finding suggests similar stability for any simple $\left[\mathrm{Tc}(\mathrm{CO})_{3}\right]^{+}$species in the low-alkalinity, high-ionic-strength, Hanford liquid waste.

Higher $\mathrm{NaOH}$ concentrations significantly reduce the oxidative stability of the $\left[\mathrm{Tc}(\mathrm{CO})_{3}\right]^{+}$species, even in highly concentrated sodium nitrate solutions. For example, the $5 \mathrm{M} \mathrm{NaNO}_{3} / 0.1 \mathrm{M} \mathrm{NaOH}$ solution exhibited $50 \%$ and complete oxidation of the $\left[\mathrm{Tc}(\mathrm{CO})_{3}(\mathrm{OH})\left(\mathrm{H}_{2} \mathrm{O}\right)_{2}\right]$ species to pertechnetate in 39 and 74 days, respectively. No Tc(I) remained in the $5 \mathrm{M} \mathrm{NaNO}_{3} / 0.5 \mathrm{M} \mathrm{NaOH}$ and $5 \mathrm{M} \mathrm{NaNO}_{3} / 1 \mathrm{M} \mathrm{NaOH}$ solution at days 17 and 10 after solution preparation, respectively. The quantitative oxidation of $\mathrm{Tc}(\mathrm{I})$ to pertechnetate was observed in $5 \mathrm{M} \mathrm{NaNO}_{3} / 2 \mathrm{M} \mathrm{NaOH}$ solution within 4 days. Interestingly, a pseudo-Hanford supernatant simulant (average PEP simulant) with the free hydroxide concentration of $0.42 \mathrm{M}$ exhibited an enhanced stability of the $\left[\mathrm{Tc}(\mathrm{CO})_{3}(\mathrm{OH})\left(\mathrm{H}_{2} \mathrm{O}\right)_{2}\right]$ species over that observed in the simpler $5 \mathrm{M} \mathrm{NaNO}_{3} / 0.5 \mathrm{M} \mathrm{NaOH}$ solution.

The oxidative stability of the $\left[\mathrm{Tc}(\mathrm{CO})_{3}\right]^{+}$gluconate complex species in alkaline solutions containing $5 \mathrm{M} \mathrm{NaNO}_{3}$ was diminished as compared to the Tc-tricarbonyl species present in analogous solutions that lacked gluconate. The same trend was observed with the supernatant simulant with and without gluconate. 
One possible mechanism for the reduced oxidative stability of the $\left[\mathrm{Tc}(\mathrm{CO})_{3}\right]^{+}$species in these alkaline solutions could be hydrolytic destruction of the Tc-CO backbone via hydroxide attack at the carbonyl carbon. In the near-neutral, weakly alkaline solutions, deprotonation of the bound water present in the triaqua $\left[\mathrm{Tc}(\mathrm{CO})_{3}\left(\mathrm{H}_{2} \mathrm{O}\right)_{3}\right]^{+}$cation changes the compound's charge via equilibrium reaction 4.

$$
\left[\mathrm{Tc}(\mathrm{CO})_{3}\left(\mathrm{H}_{2} \mathrm{O}\right)_{3}\right]^{+}+\mathrm{H}_{2} \mathrm{O} \Leftrightarrow\left[\mathrm{Tc}(\mathrm{CO})_{3}(\mathrm{OH})\left(\mathrm{H}_{2} \mathrm{O}\right)_{2}\right]+\mathrm{H}_{3} \mathrm{O}^{+}
$$

In more strongly alkaline solutions, two hydrolysis mechanisms can be envisioned as described in reactions 5 and 6 .

$$
\begin{gathered}
{\left[\mathrm{Tc}(\mathrm{CO})_{3}(\mathrm{OH})\left(\mathrm{H}_{2} \mathrm{O}\right)_{2}\right]+\mathrm{H}_{2} \mathrm{O} \Leftrightarrow\left[\mathrm{Tc}(\mathrm{CO})_{3}(\mathrm{OH})_{2}\left(\mathrm{H}_{2} \mathrm{O}\right)\right]^{-}+\mathrm{H}_{3} \mathrm{O}^{+}} \\
{\left[\mathrm{Tc}(\mathrm{CO})_{3}(\mathrm{OH})\left(\mathrm{H}_{2} \mathrm{O}\right)_{2}\right]+2 \mathrm{OH}^{-} \Leftrightarrow\left[\mathrm{Tc}(\mathrm{CO})_{2}(\mathrm{COO})(\mathrm{OH})\left(\mathrm{H}_{2} \mathrm{O}\right)\right]^{2-}+\mathrm{H}_{2} \mathrm{O}}
\end{gathered}
$$

Reaction 6 involves the well-known nucleophilic attack at the carbonyl carbon atom to form a metal carboxylate (Ungerman et al. 1979; Darensbourg et al. 1973) and has been suggested previously for $\left[\mathrm{Tc}(\mathrm{CO})_{6}\right]^{+}$(Sidorenko et al. 2011). The next step would be decarboxylation to form a metal hydride and destruction of the tricarbonyl moiety, which, once destroyed, may lead to the rapid oxidation of $\mathrm{Tc}(\mathrm{I})$.

Initial investigations were undertaken to determine whether $\mathrm{TcO}_{4}{ }^{-}$reduction and formation of the $\left[\mathrm{Tc}(\mathrm{CO})_{3}\right]^{+}$species in the alkaline supernatant simulant under a $\mathrm{CO}$ gas containing $75 \mathrm{ppm}_{2}$ is plausible. Previous studies have documented radiolytic (Lukens et al. 2001) and hydrogen-induced (Bernard et al. 2001) reduction of $\mathrm{TcO}_{4}{ }^{-}$in the alkaline simulated waste solutions containing organic complexants. In these instances, technetium(IV) was proposed as the $\mathrm{TcO}_{4}{ }^{-}$reduction product. The latter study was conducted in the presence of organic complexants and the noble metals $\mathrm{Ru}, \mathrm{Rh}$, and $\mathrm{Pd}$, which are byproducts of uranium fission and often catalysts for reduction reactions involving hydrogen. Under selected conditions of noble metals and complexants, quantitative reduction of $\mathrm{Tc}(\mathrm{VII})$ was observed (Bernard et al. 2001). Since radiolytic decomposition of the organic complexants in the tank's waste involves generation of $\mathrm{CO}$ in addition to $\mathrm{H}_{2}$, we sought to investigate the feasibility of formation of Tc-tricarbonyl species from pertechnetate. Our $\mathrm{TcO}_{4}{ }^{-}$reduction was conducted under high $\mathrm{CO} / \mathrm{H}_{2}$ pressure and at an elevated temperature to accelerate the reductive processes potentially occurring in the tank waste over prolonged time. In this report, two tests using the pseudo-Hanford supernatant simulant containing noble metals and 0.05 or $0.1 \mathrm{M}$ gluconate are described. In both experiments, nearly quantitative $\mathrm{Tc}(\mathrm{VII})$ reduction and formation of $\mathrm{Tc}(\mathrm{IV})$ and $\left[\mathrm{Tc}(\mathrm{CO})_{3}\right]^{+}$products was observed. The simulant containing the greater, $0.1 \mathrm{M}$, gluconate concentration qualitatively generated a greater amount of the $\left[\mathrm{Tc}(\mathrm{CO})_{3}\right]^{+}$products. Two Tc-tricarbonyl compounds were identified, including both the $\left[\mathrm{Tc}(\mathrm{CO})_{3}\right]^{+}$gluconate complex and an additional $\left[\mathrm{Tc}(\mathrm{CO})_{3}\right]^{+}$species. The composition of the latter is currently being investigated. Nonetheless, the identification of soluble Tc(I)-tricarbonyl species in a tank waste supernatant simulant provides significant support to the hypothesis that a Tc-tricarbonyl species of some sort is the source of "soluble, non-pertechnetate Tc". Further multiparametric reduction studies are warranted to identify the $\mathrm{TcO}_{4}{ }^{-}$reduction mechanism and the exact composition of $\mathrm{Tc}(\mathrm{I})$ species. Such elucidation of the $\mathrm{Tc}(\mathrm{VII})$ reduction mechanism will necessitate the further development of an EPR characterization method, as this will allow characterization of the Tc intermediates in the even oxidation states invisible to our characterization method of choice, Tc-99 NMR spectroscopy. 


\subsection{Summary and Conclusions}

This report summarizes work done in FY 2014 exploring the chemistry of a low-valence technetium(I) species, $\left[(\mathrm{CO})_{3} \mathrm{Tc}\left(\mathrm{H}_{2} \mathrm{O}\right)_{3}\right]^{+}$, a compound of interest due to its implication in the speciation of alkaline-soluble technetium in several Hanford tank waste supernatants.

Key findings from this year's task are summarized below:

1. A procedure for the formation of $\left(\mathrm{Et}_{4} \mathrm{~N}\right)_{2}\left[(\mathrm{CO})_{3} \mathrm{TcCl}_{3}\right]$, an isolable solid which in mildly acidic solution forms the target starting compound $\left[(\mathrm{CO})_{3} \mathrm{Tc}\left(\mathrm{H}_{2} \mathrm{O}\right)_{3}\right]^{+}$, in an overall $75 \%$ yield based on ammonium pertechnetate, was achieved. This new synthetic route more than doubles the yields observed in the previous FY 2013 study and provides a source of Tc(I)-tricarbonyl free of pertechnetate, which alleviates a troublesome problem unresolved at the end of FY 2013. The compound has been characterized not only by the Tc-99 NMR and infrared spectroscopy first explored in FY 2013, but also now by UV-vis spectroscopy and electrospray ionization mass spectroscopy. Examination of the ESI-MS spectrum in particular shows features consistent with the presence of a Tc(I)-tricarbonyl functionality.

The Tc-99 NMR assignments in this report were substantiated through calculation of the expected Tc-99 NMR chemical shift using ab initio quantum mechanical methods. Good agreement between the calculated and found chemical shifts was observed, with the exception of the $\left[(\mathrm{CO})_{3} \mathrm{Tc}(\text { gluconate })\right]^{2-}$ complex. The agreement with all other calculated versus found $\mathrm{Tc}(\mathrm{I})$ species leads us to propose that the proposed structure for $\left[(\mathrm{CO})_{3} \mathrm{Tc}(\text { gluconate })\right]^{2-}$ is incorrect. Structural identification of the products from the reaction of Tc(I)-tricarbonyl with gluconate becomes of particular interest for future studies.

2. Initial studies examining the use of EPR spectroscopy for the detection and identification of those Tc species present in even, NMR-silent, oxidation states was initiated. The $\mathrm{Tc}(\mathrm{V})$ system, $\left[\mathrm{Tc}(\mathrm{O}) \mathrm{Cl}_{4}\right]^{-}$, was chosen as a test case and well-defined spectra and other information was shown to be extractable from the spectra. Further developmental work with this method seems worthwhile.

3. In FY 2013, the oxidative stability and speciation of $\left[(\mathrm{CO})_{3} \mathrm{Tc}\left(\mathrm{H}_{2} \mathrm{O}\right)_{3}\right]^{+}$as a function of $\mathrm{pH}$ was investigated. In this report, such studies were extended to high-ionic-strength solutions as a function of $\mathrm{pH} /$ free hydroxide concentration. The oxidative stability and speciation of $\left[(\mathrm{CO})_{3} \mathrm{Tc}\left(\mathrm{H}_{2} \mathrm{O}\right)_{3}\right]^{+}$was studied in a more complicated system as well by examining the effect of the additional of an organic complexing agent, gluconate, to the solution. Finally, the oxidative stability and speciation of $\left[(\mathrm{CO})_{3} \mathrm{Tc}\left(\mathrm{H}_{2} \mathrm{O}\right)_{3}\right]^{+}$in an alkaline Hanford (PEP) waste simulant was studied. The method used for these studies was primarily Tc-99 NMR spectroscopy.

The results of these investigations were intriguing. Contrary to expectations, the oxidative stability of $\left[(\mathrm{CO})_{3} \mathrm{Tc}\left(\mathrm{H}_{2} \mathrm{O}\right)_{3}\right]^{+}$and its hydrolysis products are markedly enhanced in high-ionic-strength solutions over low-ionic-strength solutions at similar $\mathrm{pH} /$ free hydroxide regions. There was no evidence for a change in speciation resulting from addition of $\mathrm{NaNO}_{3}$, which was used. Therefore, the explanation behind this enhanced stability remains unknown.

However, this enhanced oxidative stability may address a troublesome feature observed in FY 2013. The source of "alkaline-soluble, non-pertechnetate Tc" found in the actual Hanford tank supernatants is resistant to reoxidation, with a half-life for reoxidation for SY-103 at approximately $33{ }^{\circ} \mathrm{C}$ having been reported as $230 \pm 24$ days (Schroeder et al. 2001). Work on the alkaline stability of the 
Tc(I)-tricarbonyl-containing species in FY 2013 only suggested a half-life for reoxidation back to pertechnetate of a few days, which is inconsistent with the observations with SY-103 noted above. At high ionic strengths, however, and even in the absence of complexants, the Tc(I) products from the hydrolysis of $\left[(\mathrm{CO})_{3} \mathrm{Tc}\left(\mathrm{H}_{2} \mathrm{O}\right)_{3}\right]^{+}$in the neutral to low-hydroxide/high-ionic-strength solutions typical of Hanford tank supernatants are much more stable to reoxidation. In this FY 2014 study, under optimum conditions (neutral $\mathrm{pH} / 5 \mathrm{M}$ sodium nitrate), almost three months have gone by without any detectable pertechnetate formation, a half-life for reoxidation compatible with those found in actual Hanford tank sludge. These interesting results require further exploration in future studies to better understand the basis for the enhanced resistance to reoxidation of Tc(I)-tricarbonyl observed in high-ionic-strength-solutions. Understanding of this resistance could lead to potential strategies to overcome it and more rapidly oxidize the lower-oxidation-state $\mathrm{Tc}$ species to $\mathrm{TcO}_{4}{ }^{-}$, opening the possibility to remove it by established methods.

4. The previous point describes results from a comparison of FY 2013 work in low-ionic-strength solutions versus this FY 2014 study in high-ionic-strength solutions. In addition, comparison between simulant solution studies and simple nitrate/hydroxide studies shows the same phenomena. This observation implies that if the conditions required for formation of the Tc(I)-tricarbonyl compounds exist in the tank, organic complexants are not required for the product to be stable in condition associated with Hanford tank supernatants. The Tc(I)-tricarbonyl hydrolysis products, of general composition $\left[\mathrm{Tc}(\mathrm{CO})_{3}(\mathrm{OH})_{n}\left(\mathrm{H}_{2} \mathrm{O}\right)_{m}\right]^{1-n}$ in the absence of organic complexing agents, are anticipated to exist in the alkaline waste.

5. A proof-of-principle demonstration was performed to investigate the feasibility of Tc(I)-tricarbonyl formation from pertechnetate under what were deemed to be optimum conditions for such formation. These conditions include an atmosphere of carbon monoxide with a small amount of hydrogen present for possible use as a reductant.

The simulant used was based on the previously used PEP simulant formulation, albeit with altered free hydroxide concentrations and with the addition of some fission-produced noble metals to catalyze any needed reduction of Tc(VII) by hydrogen and gluconate as a reductant/complexant.

Reaction conditions were approximately $1300 \mathrm{psi}$ atmosphere, at $80{ }^{\circ} \mathrm{C}$ for about 12 days. Depending on the exact conditions, the bulk to all of the pertechnetate disappeared following this treatment and the Tc(I)-tricarbonyl/gluconate compound was observed by Tc-99 NMR spectroscopy. The same product can be prepared independently by the reaction of $\left[\mathrm{Tc}(\mathrm{CO})_{3} \mathrm{Cl}_{3}\right]^{2-}$ with gluconate in water. Formation of a large amount of black solid suggests the concomitant reduction of $\mathrm{Tc}$ (VII) to $\mathrm{Tc}(\mathrm{IV})$ dioxide. In short, these proof-of-principle tests support the concept of alkaline-soluble, low-valent Tc being prepared by pertechnetate reduction under conditions consistent with those found in Hanford tank supernatants, with the exception of the high CO pressures used to drive the reaction over a relatively short time.

6. The influence of an organic complexant, gluconate, and free hydroxide on the oxidative stability of Tc(I)-tricarbonyl species was investigated. Stability to the reformation of pertechnetate was found to decrease as the hydroxide concentrations increase and, surprisingly, the presence of gluconate was found to increase susceptibility to reoxidation back to pertechnetate. A second unexplained feature is that the PEP simulant seems to stabilize the Tc(I)-tricarbonyl species to reoxidation as compared to a simpler nitrate/hydroxide system under conditions of comparable ionic strength and free hydroxide. The simulant components that drive the enhanced resistance of Tc(I)-tricarbonyl to reoxidation are currently unknown. 
In this FY, considerable achievements were made toward verifying that the Tc(I)-tricarbonyl species is a viable candidate for the source of alkaline-soluble, non-pertechnetate Tc in the Hanford tank supernatants. However, considerable work remains. Perhaps first on the list is to quantify the various soluble and insoluble species observed during formation and reoxidation. Understanding in greater detail how various Hanford tank components affect Tc speciation with a view toward identifying the physical and chemical markers characteristic for the formation and continued presence of alkaline-soluble, non-pertechnetate Tc in the Hanford tank supernatants is an overall objective. 


\subsection{References}

Alberto RR Schibli, A Egli, PA Schubiger, WA Herrmann, G Artus, U Abram, and TA Kaden. 1995. Metal carbonyl syntheses XXII. Low pressure carbonylation of $\left[\mathrm{MOC1}_{4}\right]^{-}$and $\left[\mathrm{MO}_{4}\right]^{-}$the technetium(I) and rhenium(I) complexes $\left[\mathrm{NEt}_{4}\right]_{2}\left[\mathrm{MCl}_{3}(\mathrm{CO})_{3}\right.$. Journal of Organometallic Chemistry 493:119-127.

Alberto RR Schibli, A Egli, U Abram, S Abram, TA Kaden, and PA Schubiger. 1998. "Steps Towards $\left[\left(\mathrm{C}_{5} \mathrm{Me}_{5}\right) \mathrm{TcO}_{3}\right]$ : Novel Synthesis of $\left[\left(\mathrm{C}_{5} \mathrm{Me}_{5}\right) \mathrm{Tc}(\mathrm{CO})_{3}\right]$ from $\left[\left\{\mathrm{Tc}\left(\mu^{3}-\mathrm{OH}\right)(\mathrm{CO})_{3}\right\}_{4}\right]$ and Oxidation of $\left[\left(\mathrm{C}_{5} \mathrm{Me}_{5}\right) \mathrm{M}(\mathrm{CO})_{3}\right](\mathrm{M}=\mathrm{Tc}, \mathrm{Re})$ with $\mathrm{Br}_{2} . "$ Polyhedron 17(7):1133-40.

http://dx.doi.org/10.1016/S0277-5387(97)00500-7.

Alberto RR Schibli, R Waibel, U Abram, and AP Schubiger. 1999. "Basic Aqueous Chemistry of $\left[\mathrm{M}\left(\mathrm{OH}_{2}\right)(\mathrm{CO})_{3}\right]^{+}(\mathrm{M}=\mathrm{Re}, \mathrm{Tc})$ Directed Towards Radiopharmaceutical Application." Coordination Chemistry Reviews 190:901-19.

Baldas J, JF Boas, and GA Williams. 1996. "EPR Studies of Technetium Complexes in Frozen Solution." Applied Magnetic Resonance, 11:499-508.

Baldas J, JF Boas, and Z Ivanov. 1997. "EPR evidence for the formation of the six-coordinate penta-fuoronitridotechnetate(VI) anion in solution." Transition Metal Chemistry, 22:74-78.

Bernard JG, E Bauer, MP Richards, JB Arterburn, and RM Chamberlin. 2001. "Catalytic reduction of pertechnetate $\left({ }^{99} \mathrm{TcO}_{4}{ }^{-}\right)$in simulated alkaline nuclear wastes." Radiochim. Acta, 89, $59-61$.

Brown CF, JH Westsik Jr., RJ Serne, BM Rapko, WR Wilmarth, DJ McCabe, CA Nash, and AD Cozzi. 2013. "Preliminary Assessment of the Low-Temperature Waste Form Technology Coupled with Technetium Removal.” PNNL-22103, Pacific Northwest National Laboratory, Richland, WA.

Dattelbaum DM, KM Omberg, JR Schoonover, RL Martin, and TJ Meyer. 2002. Application of Time-Resolved Infrared Spectroscopy to Electronic Structure in Metal-to-Ligand Charge-Transfer Excited States. Inorganic Chemistry, 41:6071-6079.

Darensbourg MY, HL Conder, DJ Darensbourg, and C Hasday. 1973. "Electronic and Steric Control of Reactions of Benzylmagnesium Chloride with Substituted Metal Carbonyls.” J. Am. Chem. Soc., 95, pp. $5919-5924$.

Gorshkov NI, AA Lumpov, AE Miroslavov, and DN Suglobov. 2000. Synthesis of $\left[\mathrm{Tc}(\mathrm{CO})_{3}{ }^{+} \cdot\left(\mathrm{H}_{2} \mathrm{O}\right)_{3}\right]^{+}$ ion and investigation of its reaction with hydroxyl ion in the aqueous solutions. Radiochemistry, 45(2):116-119.

Gorshkov NI, AE Miroslavov, AA Lumpov, DN Suglobov, and VA Mikhalev. 2003. "Complexation of Tricarbonyltechnetium(I) Ion with Halide and Thiocyanate Ions in Aqueous Solution: ${ }^{99}$ Tc NMR Study." Radiochemistry 45(2):127-30. 10.1023/A:1023868806380.

Johnstone EV, PE Weck, F Poineau, U Kim, PM Foster, AP Sattelberger, and KR Czerwinski. 2013. "X-ray Crystallographic and First-Principles Theoretical Studies of $\mathrm{K}_{2}\left[\mathrm{TcOCl}_{5}\right]$ and UV/Vis Investigation of the $\left[\mathrm{TcOCl}_{5}\right]^{2-}$ and $\left[\mathrm{TcOCl}_{4}\right]^{-}$Ions." European Journal of Inorganic Chemistry, 2013:1097-1104. 
Kirmse R and U Abram. 1990. "EPR on Technetium Complexes - A Review." Isotopenpraxis 26(4):151-159.

Kirmse R, J Stach, and U Abram. 1985. "The Pentachlorooxotechnetate(V1) Anion, [TcOCl 5$]$ ": An EPR Study.” Inorganic Chemistry, 24:2196-2198.

Kurtz P, D Rattat, D Angst, H Schmalle, B Springler, R Alberto, H Berke, and W Beck. 2005. The chemistry of the fac-[Re(CO)2(NO)]2+ fragment in aqueous solution. Dalton Transactions 4: 804-810.

Lukens WW, DK Shuh, NC Schroeder, and KR Ashley. 2004. "Identification of the Non-Pertechnetate Species in Hanford Waste Tanks, Tc(I)-Carbonyl Complexes." Environmental Science \& Technology 38(1):229-33. 10.1021/es034318d.

Mikhalev VA. 2005. "99 Tc NMR Spectroscopy." Radiochemistry 47(4):319-33. 10.1007/s11137-005-0097-3.

Miroslavov AE, GB Sidorenko, IV Borisova, EK Legin, AA Lychev, and DN Suglobov. 1990. Principal Features of Formation Conditions and Properties of the Lowest Technetium Carbonylhalides. Radiochemistry, 32(6): 573-579.

Rapko BM, SA Bryan, JL Bryant, S Chatterjee, MK Edwards, JY Houchin, TJ Janik, TG Levitskaia, JM Peterson, RA Peterson, SI Sinkov, FN Smith, and RS Wittman. 2013a. Development of a ChemistryBased, Predictive Method for Determining the Amount of Non-Pertechnetate Technetium in the Hanford Tanks: FY 2012 Progress Report. PNNL-22173, Pacific Northwest National Laboratory, Richland, WA.

Rapko BM, SA Bryan, S Chatterjee, TG Levitskaia, JM Peterson, RA Peterson, and SI Sinkov. 2013 b. Investigations into the Nature of Alkaline Soluble, Non-Pertechnetate, Technetium. PNNL-22957, EMSP-RPT-018, Pacific Northwest National Laboratory, Richland, WA.

Rattat D, AP Schubiger, HG Berke, H Schmalle, and R Alberto. 2001. Dicarbonyl-Nitrosyl-Complexes of Rhenium (Re) and Technetium (Tc), a Potentially New Class of Compounds for the Direct Radiolabeling of Biomoledules. Cancer Biotherapy and Radiopharmaceuticals 16: 339-343.

Rattat D, A Verbruggen, H Schmalle, H Berke, and R Alberto. 2004. [M(CO)2(NO)]2+, a new core in bioorganometallic chemistry: model complexes of $[\operatorname{Re}(\mathrm{CO}) 2(\mathrm{NO})] 2+$ and $[99 \mathrm{mTc}(\mathrm{CO}) 2(\mathrm{NO})] 2+$. Tetrahedron Letters 45: 4089-4092

Scheele RD, DE Kurath, and GN Brown. 2009. Scale-Up, Production, and Procurement of PEP Simulants. PNNL-18678, WTP-RPT-204, Rev 0, Pacific Northwest National Laboratory, Richland WA.

Schroeder NC, SD Radzinski, KR Ashley, AP Truong, and GD Whitener. 2001. "Feed adjustment chemistry for Hanford 101-SY and 103-SY tank waste: Attempts to oxidize the non-pertechnetate species." J. Radioanal. Nucl. Chem., 250, 271-284.

Serne RJ and BM Rapko. 2014. Technetium Inventory, Distribution, and Speciation in Hanford Tanks. PNNL-23319, EMSP-RPT-022, Pacific Northwest National Laboratory, Richland, WA. 
Sidorenko GV, AE Miroslavov, MS Grigorev, VV Gurzhiy, AA Limpov, VA Mikhalev, and DN Suglobov. 2011. "Hydrolysis of $\mathrm{Tc}(\mathrm{CO})_{6}{ }^{+}$Cation in Aqueous Solutions. Crystal and Molecular Structures of the Identified Products: $\mathrm{Tc}_{2}(\mathrm{CO})_{10}$ and $\mathrm{Tc}_{3} \mathrm{H}_{3}(\mathrm{CO})_{12}$." Radiochemistry 53(1):42-47.

Stoll S and A Schweiger. 2006. "EasySpin, a comprehensive software package for spectral simulation and analysis in EPR.” Journal of Magnetic Resonance, 178(1), 42-55.

Tromans D. 2000. "Modeling Oxygen Solubility in Water and Electrolyte Solutions." Industrial Engineering Chemistry Research 39:805-812.

Ungerman C, V Landis, SA Moya, H Cohen, H Walker, RG Pearson, RG Rinker, and PC Ford. 1979. "Homogeneous Catalysis of the Water Gas Shift Reaction By Ruthenium and Other Metal Carbonyls. Studies in Alkaline Solutions.” J. Am. Chem. Soc. 101, 5922 - 5929.

Yang Y, JX Zhang, JJ Wang, L Zhu. 2007. Two novel procedures of preparation for [Tc(CO)2(NO)]2+ labeled by EHIDA and its biodistribution. Journal of Radioanalytical and Nuclear Chemistry 273: 31-36. 



\section{Appendix A}

Efforts to Prepare $\left[(\mathrm{CO})_{3} \mathrm{Tc}\left(\mathrm{H}_{2} \mathrm{O}\right)_{3}\right]^{+}$

Through High-Pressure Synthetic Routes 



\section{For Information Only}

\section{$\underline{\text { INTRODUCTION }}$}

As noted in the main body of the document, the preparation of a stable precursor for the Tc(I)-tricarbonyl moiety is a key need of the synthesis program. The method preferably would be robust; require little time; be amenable to scale-up to batches sized in the hundreds of $\mathrm{mg}$ of Tc; be efficient in the use of Tc; yield chemically, and more important, radiochemically pure product; and be time-efficient.

The work in FY 2014 developed a method that meets many of these criteria: it provides a stable source of $\left[(\mathrm{CO})_{3} \mathrm{Tc}\left(\mathrm{H}_{2} \mathrm{O}\right)_{3}\right]^{+}$in $\left(\mathrm{Et}_{4} \mathrm{~N}\right)_{2}\left[\mathrm{Tc}(\mathrm{CO})_{3} \mathrm{Cl}_{3}\right]$, it is efficient in the use of Tc with an isolated yield based on Tc of approximately $75 \%$ based on pertechnetate, it is reproducible, and can provide with common laboratory-scale equipment product in the low 100s of mg scale, and it yields a Tc product free from pertechnetate.

But there is still room for improvement. There is some evidence (primarily from the ESI-MS), that a mixed tetraethylammonium/tetrabutylammonium salt (or, alternatively, some tetrabutylammonium chloride physically mixed with the tetraethylammonium salt of the Tc(I)-tricarbonyl trichloride compound) is formed, so determining the exact amount of Tc present by compound weight is somewhat uncertain. Second, the synthesis typically takes a full week for completion; a more time-efficient synthesis would be of benefit.

With this in mind, additional exploratory tests were performed to evaluate potential alternative routes to either $\left[(\mathrm{CO})_{3} \mathrm{Tc}\left(\mathrm{H}_{2} \mathrm{O}\right)_{3}\right]^{+}$or a suitable precursor compound. Two methods were considered; both use elevated pressures and temperatures to reduce pertechnetate to $\mathrm{Tc}(\mathrm{I})$ in the presence of a carbon monoxide atmosphere. However, only one approach was examined this fiscal year. The approach is one described by Miroslavov and co-workers (see Miroslavov et al. 2011, Miroslavov et al. 2008, Sidorenko et al. 2005, and Suglobov et al. 2005 for recent leading references).

Unfortunately, literature details as to the experimental approach are scarce. Typical is the report from Sidorenko (2009), the entirety of which is given here: "The compounds $\left[\mathrm{TcX}(\mathrm{CO})_{5}\right]$ were prepared by heating a solution of potassium pertechnetate in a mixture of formic and the corresponding halohalic acids in a pressure vessel." Questions abound for any effort to repeat this work: What ratio of acids? What ratio of pertechnetate to total volume? How long to heat? What temperature to heat to?

The two most detailed explanations available address some of these concerns. In Miroslavov (2008), which is the paper usually cited for additional details as to Tc-carbonyl syntheses, the following is given for $\mathrm{Tc}(\mathrm{CO})_{5} \mathrm{I}$ (with the other halides being "prepared similarly"). "A $0.02 \mathrm{M}$ solution of $\mathrm{KTcO}_{4}$ in aqueous $(1: 1 \mathrm{v} / \mathrm{v})$ was carbonylated with $\mathrm{CO}\left(P=160 \mathrm{~atm}, T=170^{\circ} \mathrm{C}, t=40\right.$ minutes $)$ in the presence of 1 M HI."

To make reconstruction/development more challenging, it was decided that due to the additional difficulties with working in a radiological environment, as well as because of the scarcity of available pertechnetate during most of FY 2014, these survey experiments would use Re instead of Tc. The obstacle that this change introduces is that Re is known to be more difficult to reduce than Tc; hence the conditions reported for Tc may well not be sufficient to reduce $\operatorname{Re}(\mathrm{VII})$ to $\operatorname{Re}(\mathrm{I})$. Apples-to-apples comparisons of Tc versus Re reduction to form metal carbonyls are not plentiful, but one exists. 


\section{For Information Only}

Calderazzo (1989) describes the reduction of both pertechnetate and perrhenate by a $\mathrm{CO} /$ trace hydrogen mixture at elevated temperatures and pressures. Reduction of perrhenate to $\operatorname{Re}_{2}(\mathrm{CO})_{10} \mathrm{Was}$ accomplished in toluene at 90 atmospheres $\mathrm{CO}$ (at room temperature) after 40 hours contact at $290{ }^{\circ} \mathrm{C}$ with a ca. $60 \%$ isolated yield. It is noted that if the heating is performed at $250{ }^{\circ} \mathrm{C}$, no product is formed. This can be compared to pertechnetate reduction, which, after contact at 90 atmospheres $\mathrm{CO}$ (at room temperature) for 4 hours in toluene at $200{ }^{\circ} \mathrm{C}$ generates $\mathrm{Tc}_{2}(\mathrm{CO})_{10}$ in quantitative yield. With this literature in mind, a series of scoping experiments were performed to evaluate the ability to reduce perrhenate to Re tricarbonyl or a tricarbonyl precursor by a high-pressure reduction with carbon monoxide.

As noted previously, this work was not done in accordance with the EMSP QA program requirements; rather it was performed according to PNNL's general laboratory practices. Therefore, the results of the experimental work presented in this Appendix do not have the NQA-1 pedigree of results produced under the EMSP QA program and must be considered "For Information Only."

\section{EXPERIMENTAL}

Reagents: All reagents, unless noted otherwise, were purchased from Sigma-Aldrich and were of reagent grade or better. Carbon monoxide was obtained from the same vendor as reported in Section 4.1 of this report.

Equipment: All balances were calibrated and checked according to standard RPL practices as outlined in the procedure ADM-RSEG-BALANCES, Rev. 1, Balance Performance Checks. General laboratory operations were performed under procedure RPL-OP-001, Rev. 10, Routine Research Operations. Use of high-pressure equipment was performed according to procedure RPL-TP-EMSP-0314, Rev. 0, Performing Metal Carbonyl Reactions Using the Parr Model 4790 Stirrerless Pressure Vessel.

Raman and IR spectroscopy were performed using standard equipment in the RPL. Pressure work was done using a $100 \mathrm{~mL}$ volume Parr Model 4790 Stirrerless Pressure vessel with either a borosilicate glass or PTFE liner as indicated. PTFE gaskets were used for each seal. Temperatures were monitored using Type $\mathrm{K}$ thermocouples located in a thermal well that reaches into the reaction chamber. Over-temperature control was maintained using a Type K thermocouple secured to the heating mantle. Heating was performed with a heating mantle sized for the reaction vessel and was purchased from Parr Instruments, Inc. Temperature control was maintained using a J-KEM Model 270 temperature controller.

\section{Experiment 1}

0.575 gram of ammonium perrhenate (FW $268.24 \mathrm{~g} / \mathrm{mol}, 2.14 \mathrm{mmol}$ ), was combined in a $70 \mathrm{~mL}$ glass liner with $30 \mathrm{~mL}$ water and $0.25 \mathrm{~mL}(3 \mathrm{mmol})$ of $12 \mathrm{M} \mathrm{HCl}$. The system, placed in the Parr pressure vessel, was purged with $\mathrm{CO}$ for about 5 minutes and then was pressurized to $675 \mathrm{psi}$ (ca. 46 atmospheres) carbon monoxide. The system was heated to $180^{\circ} \mathrm{C}$ for 3 days (final total pressure 2850 psi at $180{ }^{\circ} \mathrm{C}$ ). After cooling and venting to the atmosphere, the solution was evaporated to dryness with rotary evaporation. An IR spectrum (KBr matrix) showed several bands in the 2100 to $1900 \mathrm{~cm}^{-1}$ region commonly associated with metal carbonyl vibrations. 


\section{For Information Only}

\section{Experiment 2}

0.857 gram $(3.1 \mathrm{mmol})$ of ammonium perrhenate was dissolved in $30 \mathrm{~mL}$ of water in a $70 \mathrm{~mL}$ glass pressure vessel liner. $0.25 \mathrm{~mL}$ ( $3 \mathrm{mmol}$ ) of concentrated $\mathrm{HCl}$ was added, the pressure vessel sealed, and the system purged with $\mathrm{CO}$ for about 5 minutes. The system was pressurized with $\mathrm{CO}$ at room temperature to about $1300 \mathrm{psi}$ (about 88 atmospheres). The system was heated to $175-180{ }^{\circ} \mathrm{C}$ (system pressure $1800 \mathrm{psi}$ ) for about 4 hours and then allowed to cool to room temperature overnight, and was vented to the atmosphere. The solution was removed by rotary evaporation under dynamic vacuum of about 50 mtorr at $60{ }^{\circ} \mathrm{C}$ to yield 0.747 gram of white solid.

\section{$\underline{\text { Reactivity Test on Product from Experiment } 2}$}

A saturated solution of the product in acetonitrile was mixed with about $100 \mathrm{mg}$ of various bipyridyl ligands (see Figure A.1), which were introduced as a solid. The system was then checked for fluorescence by shining with either a 302 or $365 \mathrm{~nm}$ light. The results of this qualitative test are shown in Table A.1 below.

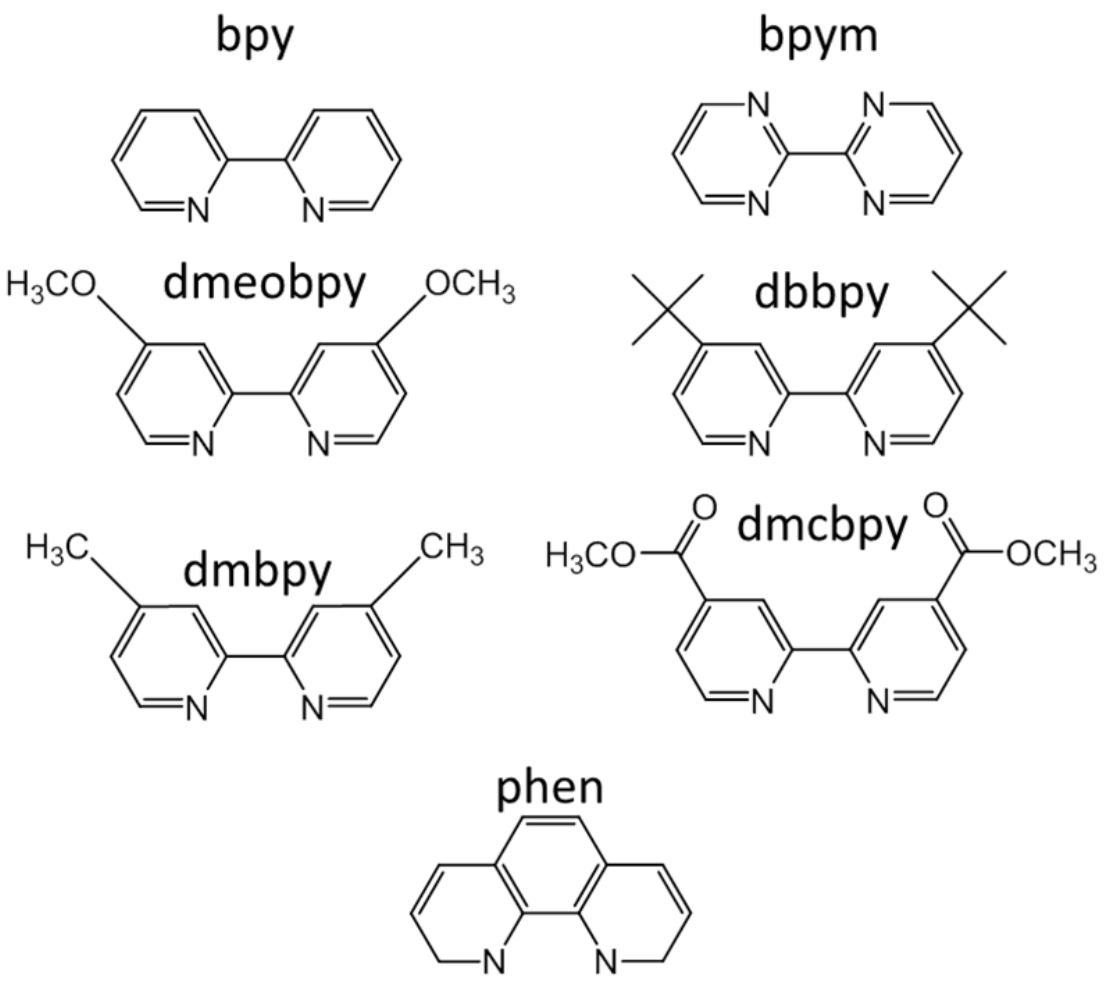

Figure A.1. Test Ligands and Abbreviations: 2,2'-bipyridine (bpy); 2,2'-bipyrimidine (bpym); 4,4'-dimethoxy-2,2'-bpy (dmeobpy); 4,4'-di-tert-butyl-2,2'-bpy (dbbpy); 4,4'-dimethyl-bpy (dmbpy); 4,4'-dimethylcarboy-2,2'-bpy (dmcbpy); and 1,10-phenanthroline (phen) 


\section{For Information Only}

Table A.1. Qualitative Fluorescence Test of Re-Carbonyl Synthesis Product with Bipyridyl Ligands in Acetonitrile

\begin{tabular}{|l|c|}
\hline \multicolumn{1}{|c|}{ Ligand } & Fluorescence at $\mathbf{3 6 5} \mathbf{~ n m ? ~}$ \\
\hline dmbpy & Yes \\
\hline bpy & Yes \\
\hline dmeobpy & No \\
\hline phen & Yes \\
\hline Free ligands & No \\
\hline $\mathrm{NH}_{4} \mathrm{ReO}_{4} \&$ phen & No \\
\hline $\mathrm{NH}_{4} \mathrm{ReO}_{4} \&$ dmbpy & No \\
\hline
\end{tabular}

The existence of fluorescence when bypridyl ligands are mixed with Re and Tc carbonyl compound is characteristic of formation of the tricarbonyl complex. Further details are supplied in Bryan et al. $(2014)^{1}$.

Crystallization of the reaction product was attempted from either water/methanol, acetone/water, or methanol/acetone and diethyl ether using vapor diffusion techniques. Only the acetone/water system gave a crystalline solid but Raman spectroscopy only showed bands associated with perrhenate.

Unfortunately a repeat of this reaction gave a product with no indication of carbonyl bands but strong bands associated with perrhenate were observed.

\section{Experiment 3}

The literature reports noted above indicate that formic acid/HX mixtures can be used in the absence of added $\mathrm{CO}$ gas to generate Tc-carbonyl complexes. As formic acid is known to decompose either to $\mathrm{CO}$ and water (predominantly at relatively low temperatures) or carbon dioxide and hydrogen (at higher temperatures), a high-pressure synthesis of Re-carbonyl compounds from this system was attempted.

1.18 grams ( $4.4 \mathrm{mmol})$ of ammonium perrhenate was combined with $8 \mathrm{~mL}$ of formic acid $(\mathrm{FW}=46.03 \mathrm{~g} / \mathrm{mol}$, density $=1.22 \mathrm{~g} / \mathrm{mL}, 0.21 \mathrm{~mole})$ and $0.25 \mathrm{~mL}(3 \mathrm{mmol}) 12 \mathrm{M} \mathrm{HCl}$, and $30 \mathrm{~mL}$ of water in a $70 \mathrm{~mL}$ glass liner. This was transferred to the pressure vessel, closed, and the system purged with $\mathrm{CO}$ for about 5 minutes. The system was heated to $180{ }^{\circ} \mathrm{C}$ (final system pressure of $3000 \mathrm{psi}$ ) for two days. The system was allowed to cool for two hours and then dismantled. The solution was removed by rotary evaporation at $50{ }^{\circ} \mathrm{C}$ at $50 \mathrm{~m}$ torr dynamic pressure. $0.707 \mathrm{~g}$ of green-tinged solid was isolated. The Raman spectrum of this solid showed multiple bands in the carbonyl region along with bands characteristic of perrhenate. The residual solids were heated in water at $90{ }^{\circ} \mathrm{C}$ for two days. The solvent was removed and a Raman spectrum of the residual solids showed no carbonyl bands. Bands associated with perrhenate were observed.

${ }^{1}$ Bryan SA, AD Crawford, WR Heineman, BM Rapko, and SD Branch. 2014. Non-Pertechnetate Technetium Sensor Research and Development. EMSP-RPT-025, Pacific Northwest National Laboratory (not yet published). 


\section{For Information Only}

\section{DISCUSSION}

Several attempts to generate Re-carbonyl compounds by high-pressure aqueous reaction were examined. Early on, it became clear that identifying the reaction products was a challenge; identifying the product semi-quantitatively or quantitatively even more so. The difficulty lies in the methods of analysis routinely available. Perrhenate possesses well-defined, characteristic vibrations in both the IR and Raman spectra. Metal carbonyl vibrations are also detectable with those methods but multiple compounds are possible that possess such signatures. Unlike Tc, Re-based NMR is of no utility and natural abundance C-13 NMR too insensitive for use here.

However, there exist multiple indications that a method could be worked out. Bipyridyl derivatives of the reaction product from perrhenate and $\mathrm{CO}$ showed the fluorescence typical of the presence of the Re-tricarbonyl moiety, and indications from vibrational spectroscopy were positive that some types of Re-carbonyl compounds were formed. However, the likely generation of multiple Re compounds, the presence of perrhenate in the reaction product mixture, and the inability to isolate a material that could be purified by crystallization suggested that this method would suffer from the same technical challenges characteristic of the FY 2013 studies of methods to prepare Tc-tricarbonyl compounds and so this approach was abandoned fairly quickly.

\section{$\underline{\text { REFERENCES }}$}

Calderazzo F, U Mazzi, G Panpaloni, R Poli, F Tisato, and PF Zanazzi. 1989. "Reduction of Ammonium Pertechnetate and Ammonium Perrhenate with CO. Synthesis of $\mathrm{M}_{2}(\mathrm{CO})_{10}(\mathrm{M}=\mathrm{Tc}, \mathrm{Re})$ and Crystal and Molecular Structure of the Trinuclear Cyano-Bridged Derivative $\mathrm{Re}_{3}(\mathrm{CN})_{3}(\mathrm{CO})_{12}{ }^{\prime \prime}$. Gazzetta Chimica Italiana, 119, 241-247.

Miroslavov AE, AA Lumpov, GV Sidorenko, EM Levitskaia, NI Gorshkov, DN Suglobov, R Alberto, H. Braband, VV Gurzhiy, SV Krivovichev, and IG Tananaev. 2008. "Complexes of technetium(I) $\left({ }^{99} \mathrm{Tc}\right.$, ${ }^{99 \mathrm{~m}} \mathrm{Tc}$ ) pentacarbonyl core p-acceptor ligands (tert-butyl isocyanide and triphenylphosphine): Crystal structures of $\left[\mathrm{Tc}(\mathrm{CO})_{5}\left(\mathrm{PPh}_{3}\right)\right] \mathrm{OTf}$ and $\left.\left[\mathrm{Tc}(\mathrm{CO})_{5}\right)\left(\mathrm{CNC}\left(\mathrm{CH}_{3}\right)_{3}\right)\right] \mathrm{ClO}_{4}$." J. Organometallic Chem., 693, pp. 4-10.

Miroslavov AE, GV Sidorenko, DN Suglobov, AA Lumpov, VV Gurzhiy, MS Grigor'ev, and VA Mikhalev. 2011. "Technetium(I) Carbonyl Dithiocarbamates and Xanthates." Inorg. Chem., 50, pp. 1098-1104.

Sidorenko GV, VV Gurzhii, AE Miroslavov, OV Sizova, SV Krivovichev, AA Lumpov, and DN Suglobov. 2009. "Crystal and Molecular Structure of $\left[\mathrm{TcCl}(\mathrm{CO})_{5}\right]$ and $\left[\mathrm{TcBr}(\mathrm{CO})_{5}\right]$. Correlations with the Reactivity and Electronic Structure.” Radiochemistry, 51, pp. 237-243.

Suglobov DN, AE Miroslavov, GV Sidorenko, NI Gorshkov, and AA Lumpov. 2005. "Complexation of $\mathrm{Tc}(\mathrm{CO})_{3}{ }^{+}$aq with Anions of Monobasic Carboxylic Acids in Aqueous Solutions: A ${ }^{99}$ Tc NMR Study." Radiochemistry, 47, pp. 49-52. 

PNNL-23654

EMSP-RPT-024, Rev. 0

\section{Distribution*}

U.S. Department of Energy

Office of Environmental Management

NP Machara

JA Poppiti

SP Schneider

DOE Office of River Protection

JA Diediker

TW Fletcher

BJ Harp

BM Mauss

SH Pfaff

Washington River Protection Solutions

PA Cavanah

DJ Swanberg

LE Thompson

Savannah River National Laboratory

SL Marra

DJ McCabe

WR Wilmarth
Pacific Northwest National Laboratory

PR Bredt

CF Brown

SA Bryan

D Chatterjee

JY Houchin

TG Levitskaia

JM Peterson

RA Peterson

NP Qafoku

BM Rapko

S Schlahta

RJ Serne

GL Smith

DM Wellman

JH Westsik Jr.

*All distribution will be made electronically. 


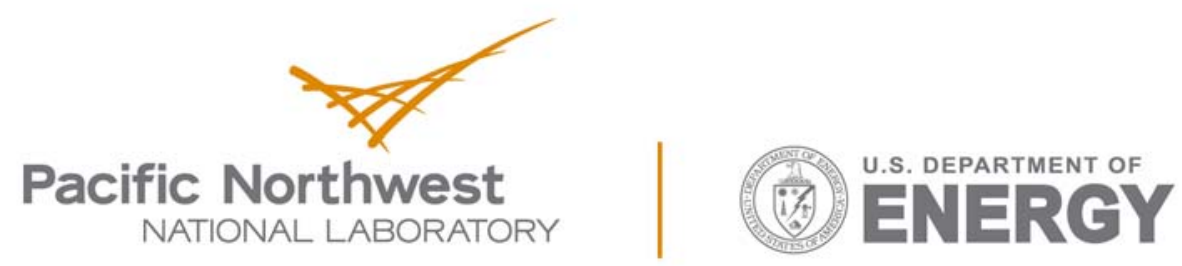

Proudly Operated by Battelle Since 1965

902 Battelle Boulevard

P.O. Box 999

Richland, WA 99352

1-888-375-PNNL (7665)

www.pnnl.gov 